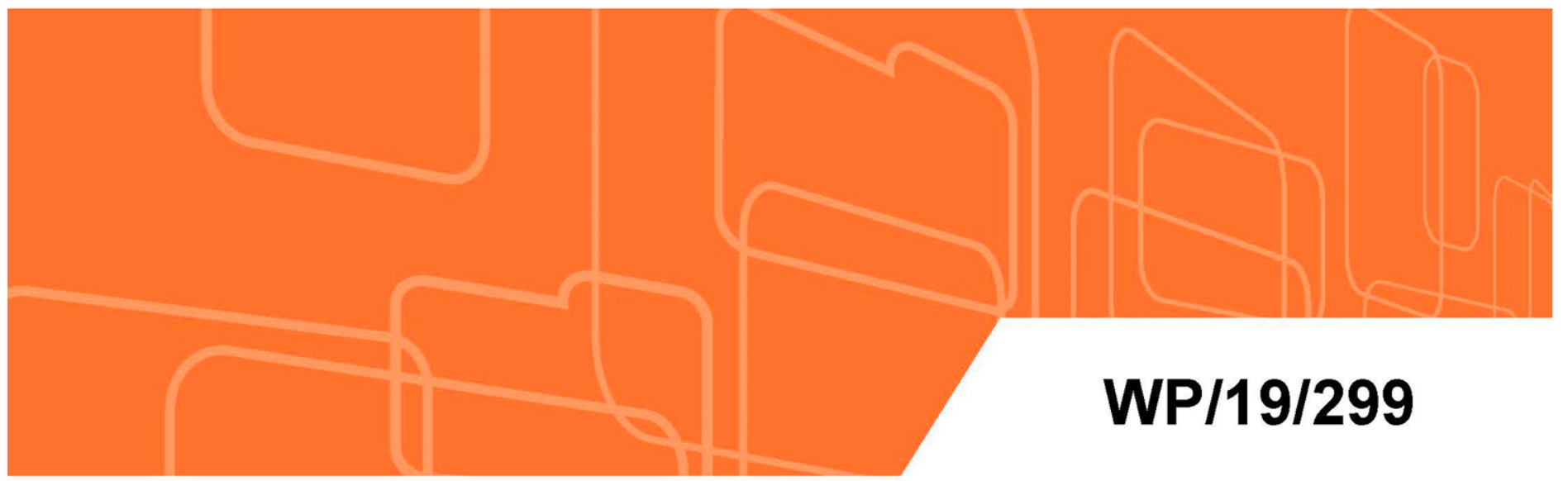

IMF Working Paper

\title{
Cross-Border Currency Exposures. New evidence based on an enhanced and updated dataset
}

by Luciana Juvenal, Deepali Gautam, Agustín Bénétrix and Martin Schmitz

IMF Working Papers describe research in progress by the author(s) and are published to elicit comments and to encourage debate. The views expressed in IMF Working Papers are those of the author(s) and do not necessarily represent the views of the IMF, its Executive Board, or IMF management. 


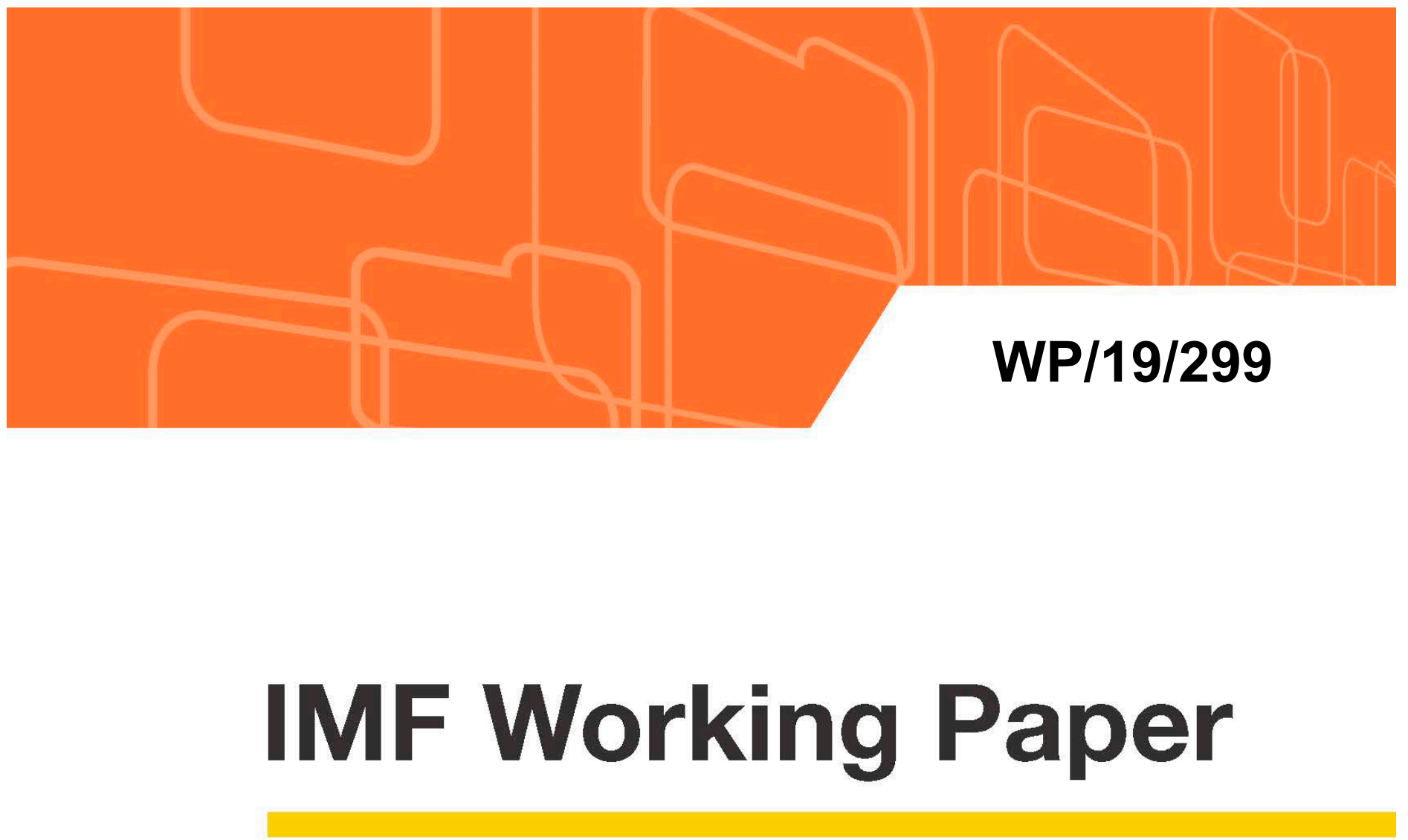

\section{Cross-Border Currency Exposures. New evidence based on an enhanced and updated dataset}

by Luciana Juvenal, Deepali Gautam, Agustín Bénétrix and Martin Schmitz

IMF Working Papers describe research in progress by the author(s) and are published to elicit comments and to encourage debate. The views expressed in IMF Working Papers are those of the author(s) and do not necessarily represent the views of the IMF, its Executive Board, or IMF management.

$$
\text { I N T E R N A T I O N A L M O N E T A R Y F U N D }
$$




\title{
IMF Working Paper
}

\author{
Research Department
}

\section{Cross-Border Currency Exposures. New evidence based on an enhanced and updated dataset*}

\section{Prepared by Luciana Juvenal, Deepali Gautam, Agustín Bénétrix and Martin Schmitz}

Authorized for distribution by Daniel Leigh

December 2019

IMF Working Papers describe research in progress by the author(s) and are published to elicit comments and to encourage debate. The views expressed in IMF Working Papers are those of the author(s) and do not necessarily represent the views of the IMF, its Executive Board, or IMF management.

\begin{abstract}
This paper provides a dataset on the currency composition of the international investment position for a group of 50 countries for the period 1990-2017. It improves available data based on estimates by incorporating actual data reported by statistical authorities and refining estimation methods. The paper illustrates current and new uses of these data, with particular focus on the evolution of currency exposures of cross-border positions.

JEL Classification Numbers: F20, F31, F41.

Keywords: Currency composition, foreign currency exposures.

Author's E-Mail Address: ljuvenal@imf.org (corresponding author), dgautam@imf.org, benetria@tcd.ie, martin.schmitz@ecb.int

*We thank Nataliya Ivanyk, Carlos-Sánchez Muñoz and Venkateswarlu Josyula from the Statistics Department of the IMF for their help with the survey sent to country authorities. For useful suggestions we thank Gustavo Adler, Luis Cubbedu, Philip Lane, Gian Maria Milesi-Ferretti and Livio Stracca. Sara De Peri, Moritz Kellers, Tadhg Nealon and Tamara Giltrap provided excellent research assistance at different stages of the project.
\end{abstract}




\section{Introduction}

The analysis of the role played by different currencies in trade and finance has lately been at the center of the agenda in international economics (Gopinath and Stein, 2018). This paper contributes to this literature by focusing on the currency composition of countries' external assets and liabilities. To this aim, we construct a new dataset on the currency composition of the international investment position (IIP) building on earlier estimates by Lane and Shambaugh (2010a) and Bénétrix, Lane and Shambaugh (2015).

A key refinement in our new dataset covering 50 countries over the period 1990-2017, centers on the expansion of available actual data, made possible thanks to a recent IMF survey on the currency composition of the main IIP components. Currencies of denomination were broken down into the five Special Drawing Rights (SDR) currencies (i.e. US dollar, euro, Japanese yen, Pound sterling and renminbi), domestic currency (if different from the five SDRs), and "other currencies" which bundle up all other foreign currencies not included in the previous two categories. This valuable new data obtained via the IMF survey are complemented with other sources of actual data: (i) data on the currency composition of portfolio equity and debt assets from the IMF's Coordinated Portfolio Investment Survey (CPIS), (ii) portfolio debt data reported to the European Central Bank (ECB) and (iii) banks cross-border positions reported to the Bank of International Settlements (BIS) available through its Locational Banking Statistics (LBS). In addition, where actual data are missing, estimates for currency denomination based on well-known methodologies are used. ${ }^{1}$ In some cases, these estimates have been refined, for example, to allow for a different treatment of equity and debt in foreign direct investment (FDI). ${ }^{2}$

A comparison between actual and estimated data which can naturally only be done for the years for which both are available reveals that by and large the main patterns of actual data are captured by the estimates. However, some contrasts are present. For example, on the asset side, we observe that US dollar weights tend to be underestimated, in particular for portfolio equity and FDI equity. This likely reflects the fact that our estimates rely on the geography of cross-border positions as the closest predictor of currency of denomination. However, certain cross-border asset positions which do not involve the issuers resident in the US are denominated in US dollars, due to its widespread international usage. ${ }^{3}$

On the liability side, domestic currency weights for portfolio debt liabilities are underestimated in particular for emerging countries. The estimation of this item relies largely on the BIS international debt issuance statistics. One source of discrepancy between actual and estimated data could be driven by the lack of information on domestically issued debt securities held by non-residents which may be denominated in domestic currency. ${ }^{4}$ These issues highlight that better availability of actual data is key for further improving the accuracy of the dataset.

We use the dataset to construct a number of indicators to guide our study. The core of our analysis focuses on an indicator of aggregate foreign currency exposure, defined as the net foreign assets denominated in foreign currency as a share of total assets and liabilities (Lane and Shambaugh, 2010a). It measures the overall sensitivity of a country's external balance sheet to a uniform movement of its domestic currency against all foreign currencies.

\footnotetext{
${ }^{1}$ The Appendix to this paper explains the methods used to estimate each component and describes the years for which actual and estimated data were used for each item of the IIP.

${ }^{2}$ Access to actual data revealed that the FDI equity and debt components have different currency distributions. In addition, IIP data show that FDI debt represents a sizable share of FDI for some countries. For all these reasons the separate estimation of these two components is important.

${ }^{3}$ The currency denomination of positions vis-à-vis Special Purpose Entities (SPEs) may also not be precisely captured by geography.

${ }^{4}$ Unfortunately, the BIS does not report the currency composition of domestically issued debt securities and there is no information on the proportion of domestically issued securities which is held by non-resident investors.
} 
Our key findings are described as follows. First, the analysis of the long-term dynamics shows that the cross-country distribution of foreign currency exposures has shifted significantly towards long positions (i.e. larger gross foreign assets in foreign currency than liabilities in foreign currency) between 1990 and 2017. This pattern was driven by both improving net international investment positions (excluding reserves) and larger net liability positions in domestic currency (resulting from larger gross equity liabilities). Second, with respect to 2012, the last year reported in Bénétrix et al. (2015), the distribution of foreign currency exposures has shifted slightly towards longer positions between 2012 and 2017. Third, most of the adjustment in net foreign currency exposure took place ahead of the global financial crisis period, as the post-crisis period has been characterized by relatively persistent net foreign currency exposures. In the pre-crisis period not only overall net international investment positions improved, but also the currency composition of external balance sheets moved towards larger shares of liabilities denominated in domestic, rather than foreign currency (particularly for equity, but also debt). The trend towards larger shares of equity liabilities being denominated in domestic currency continued after the global financial crisis, but overall changes were limited due to the persistence in net international investment positions over the post-crisis period. Fourth, net foreign currency exposures continue to differ substantially across country groups. Advanced economies have a large share of their debt liabilities denominated in domestic currency, while for emerging economies debt liabilities are predominantly denominated in foreign currency, despite the increase in local currency debt issuance. Net short positions in foreign currencies continue to be more prevalent in emerging economies, which have a history of borrowing heavily in foreign currency, a phenomenon referred to as "original sin" (Eichengreen, Hausman and Panizza, 2003), thereby leaving several emerging economies exposed to adverse valuation effects if the domestic currency weakens.

The dataset is also used to compute financial exchange rates, which are an input for the calculation of valuation effects, and a measure of international financial integration broken down by currency. Exchange rate movements can have significant effects on the economy through a valuation channel which reflects capital gains or losses on the international balance sheet. These valuation effects on foreign currency exposures have been found to be sizable and are moreover a key channel for the international transmission of monetary policy, as changes in the monetary policy stance also have wealth effects via exchange rate movements (Georgiadis and Mehl, 2016). The valuation effect depends on whether a country is long or short on foreign currency. For example, if a country has a negative net position in foreign currency, a depreciation can generate significant negative wealth effects. Our findings confirm the results of Lane and Shambaugh (2010a) that trade weighted exchange rates are not the adequate measure to evaluate wealth effects of currency movements and financial exchange rates should be used instead. One of the tools we provide with this dataset is an updated measure of financial exchange rates which can be used to compute valuation effects.

The scale of exchange-rate induced valuation effects is determined by the interaction of the financial exchange rate index and the size of a country's external balance sheet, which is given by the well-known measure of de-facto international financial integration (IFI) proposed by Lane and Milesi-Ferretti (2001). While this measure focuses on the size of the international balance sheet, little is known about its currency composition. Our data allow to look into the currency dimension of this IFI measure. A first glance at the aggregate measure confirms the main patterns documented in Lane and Milesi-Ferretti (2003, 2007 and 2018), who show that IFI increased from the 1990s until the global financial crisis and came to a halt afterward. On the currency dimension front, we find that: (i) euro-denominated cross-border holdings expanded rapidly between 1999 and 2007, but declined considerably after the global financial crisis; (ii) US dollar positions, after declining sharply in 2008, recovered quickly and have shown an upward trend since 2014, (iii) outside the US and euro area, there is an unambiguous 
dominance of cross-border holdings in US dollars throughout the whole sample period. ${ }^{5}$

The paper is organized as follows. Section 2 describes the data and its uses. Section 3 presents the building blocks to compute exchange rate valuation effects and the currency composition of the international financial integration measure. Section 4 focuses on the components and long-term dynamics of aggregate foreign currency exposures and shows our main results. Section 5 discusses the pre- and post- crisis adjustment of aggregate foreign currency exposures and Section 6 concludes. Details about data sources and estimation methods used are detailed in the Appendix.

\section{Data}

The dataset in this paper builds on the contributions by Lane and Shambaugh (2010a) and Bénétrix et al. (2015) who provide estimates of the currency composition of external assets and liabilities for a sample of 117 countries between 1990-2004 and 1990-2012, respectively.

Our dataset offers a number of improvements with respect to those efforts. Most notably, it makes use of actual data reported to the IMF by national statistical authorities. This, together with new access to more granular information, means a substantial reduction in the dependence on estimated currency weights. Previous vintages relied more heavily on dimensions such as geography, gravity models or bond issuance to obtain the currency composition of each component of the IIP. In some cases estimates have been refined, for example, to allow for a different treatment of equity and debt in foreign direct investment (FDI). This is a crucial improvement in the light of the increasing relevance of FDI debt positions since the global financial crisis (Blanchard and Acalin, 2016; Damgaard, Elkajer, and Johansen, 2019; and Lane, 2015).

Our approach consists of taking actual data whenever available and extend its coverage by using estimated data based on improved methodologies. More precisely, we complete the coverage of actual data with estimated currency weights for each component of the IIP. ${ }^{6}$ This allows for filling the gaps in actual data and expand its coverage over the period 1990-2017. ${ }^{7}$ Given the limited availability of actual data, we focus on a sample of 50 countries, which are part of the IMF External Balance Assessment and/or External Sector Report. ${ }^{8}$ Taken together, these countries account for over 90 percent of world's GDP.

The Appendix provides a detailed description of the methods and data sources used to estimate the currency composition of international balance sheets. In what follows we provide a summary which emphasizes the improvements with respect to earlier work.

\footnotetext{
${ }^{5}$ These patterns were partly driven by the fact that Euro Area banks develeraged from cross-border positions in the aftermath of the global financial crisis and by the uncertainty surrounding the Euro Area sovereign debt crisis which led investors to shift away from euro positions, in line with Maggiori, Neiman and Schreger (2019a). In addition, the US dollar appreciation and the high liquidity of dollar assets during the peak of the crisis has reinforced the dominant role of the US dollar, in particular as there is a lack of supply of safe euro-denominated assets (Ilzetzki, Reinghart and Rogoff, 2019) .

${ }^{6}$ We do not consider financial derivatives because the currency breakdown is generally unavailable due to methodological and data collection issues.

${ }^{7}$ Data for Russia start in 1993 due to lack of information. We report data for the Czech Republic since 1993 because that is the year in which the country was formed following the split of Czechoslovakia.

${ }^{8}$ The countries are: Argentina, Australia, Austria, Belgium, Brazil, Canada, Chile, China, Colombia, Czech Republic, Denmark, Egypt, Finland, France, Germany, Greece, Guatemala, Hong Kong SAR, Hungary, India, Indonesia, Ireland, Israel, Italy, Japan, Korea, Malaysia, Mexico, Morocco, Netherlands, New Zealand, Norway, Pakistan, Peru, Philippines, Poland, Portugal, Russia, Singapore, South Africa, Spain, Sri Lanka, Sweden, Switzerland, Thailand, Tunisia, Turkey, United Kingdom, United States and Uruguay.
} 


\subsection{Actual Data}

One of the main contributions of this dataset, which distinguishes it from earlier work, consists on the incorporation of actual data on the currency composition of the IIP. These are obtained from a variety of sources: (i) a survey sent by the IMF to country authorities; (ii) the Coordinated Portfolio Investment Survey (CPIS) (Table 2) dataset; (iii) European Union (EU) countries' data reports to the ECB and; (iv) the Locational Banking Statistics (LBS) from the Bank of International Settlements (BIS).

The main source of actual data is a survey sent to authorities by the IMF Research Department in collaboration with the Statistics Department. The survey requested data from 1990 on the main components of the IIP broken down into the five SDR currencies (i.e. US dollar, euro, Japanese yen, Pound sterling and renminbi), domestic currency (when different from the five SDRs), and "other currencies" which bundle up all the other foreign currencies not included in the previous two categories. Country authorities responded to the survey on a voluntary basis. For recent years, around 52 percent of countries reported some data but as we go back in time the coverage is more limited. Section A.1.1 in the Appendix provides more details about the survey.

We complemented the survey data with Table 2 from the CPIS, which includes the currency composition of portfolio equity and portfolio debt assets, and ECB data on the currency of denomination of portfolio debt assets and liabilities which Euro Area countries are required to submit. In addition, we use the currency of denomination of cross-border positions of banks sourced from the BIS LBS. Tables A.3 and A.4 in the Appendix describe the coverage of actual data for each country.

Our final dataset extends the coverage of actual data with estimated currency positions. A summary of the estimation methods is summarized below, while the Appendix explains in detail the methods used to estimate each item.

\section{$2.2 \quad$ Foreign Assets}

The asset side of a country's international investment position contains five main items: portfolio equity, foreign direct investment (equity and debt), portfolio debt, other investment (mainly bank-related), and reserves.

The sources of actual data for portfolio equity assets are the IMF survey and CPIS Table 2. In order to fill the data gaps going backwards we use the method based on geography as in Lane and Shambaugh (2010a) and Bénétrix et al. (2015). The CPIS dataset provides the geographical location of portfolio equity asset holdings for 82 reporting countries and 220 host countries since 2001. The use of geographical data to calculate currency weights relies on the assumption that equity issued by a country is denominated in the currency of that country. ${ }^{9}$

Actual data from the survey revealed that the debt component of FDI has a very different currency composition with respect to equity. Therefore, we estimate their currency of denomination separately. This is an improvement with respect to Bénétrix et al. (2015) which treat FDI as equity only. We obtain the share of equity in FDI from the IMF International Financial Statistics (IFS). For the cases in which actual data are missing we use estimated data on FDI equity as follows. Between 1990 and 2008 we use the data from Bénétrix et al. (2015). For the years between 2009 and 2017 we use data from CDIS which include outward and inward stocks of direct investment for 108 reporting countries. As in the case for portfolio equity assets, we assume that direct investment is denominated in the currency of the host country. For FDI debt, whenever available, we used actual data from the IMF survey. Our synthetic data were

\footnotetext{
${ }^{9}$ In order to estimate positions for the country pairs which are missing from the CPIS dataset we used a gravity-type model of equity holdings similar to the one developed by Lane and Milesi-Ferretti (2008). See Appendix for details about the methodology used pre-2001.
} 
obtained using the currency weights of portfolio debt assets.

The sources of actual data for portfolio debt are the IMF Survey, CPIS Table 2 and ECB data. We expand the coverage using the estimation method by Lane and Shambaugh (2010a) which is based on combining the geography of portfolio debt assets positions from CPIS with the currency of denomination of host countries' bonds issued in international markets.

Actual data for Other Investment is sourced from the IMF survey and extended backwards based on the BIS LBS since banking assets are the largest component of this item.

Data on the currency composition of reserves from 1990 to 2012 are sourced from Bénétrix et al. (2015). In order to update the data up to 2017 we construct a second dataset, which covers the period 2010-2017, by obtaining or estimating reserve weights from non-confidential sources such as Central Banks or Ministry of Finance Publications and publicly available IMF Currency Composition of Official Foreign Exchange Reserves (COFER) data (details on data sources are detailed in the Appendix). We merge the series from 1990-2012 with the ones from 2010-2017 using an interpolation method.

\section{$2.3 \quad$ Foreign Liabilities}

The liabilities side of a country's international investment position contains four main items: portfolio equity, foreign direct investment (equity and debt), portfolio debt and other investment (mainly bank-related).

Consistent with the treatment on the asset side, portfolio equity and FDI equity liabilities are assumed to be in the currency of the host country, which implies exposure in domestic currency. ${ }^{10}$ Whenever available, we used actual data on FDI debt from the IMF survey and extend its coverage backwards using as synthetic weights the currency breakdown of portfolio debt liabilities.

Actual data on portfolio debt are obtained from the IMF Survey and ECB data. For most countries, synthetic data for the currency breakdown are obtained from the BIS international debt issuance statistics. The dataset covers all debt securities issued by non-residents and includes a comprehensive breakdown by currency. However, for emerging markets this dataset tends to underestimate the share of domestic currency issuance, as the BIS does not report the currency composition of domestically issued debt securities and there is no information of the proportion of domestically issued securities which is held by non-resident investors. Due to the importance to correct for this, for a sample of 19 countries we use the share of central government securities held by foreigners and denominated in domestic currency from Arslanalp and Tsuda (2014). ${ }^{11}$ As in the case of other series, we used actual data whenever available and extend the series using synthetic data. Finally, the assembly of other investment liabilities proceeds analogously with the one for other investment assets.

\subsection{Comparison: Actual and Estimated Data}

The estimation of the currency composition of the different components of the IIP requires making a number of assumptions and in some cases data availability is limited. Section A.4 of the Appendix provides a comparison between actual and estimated currency weights. This can naturally only be done for the years for which actual data are available. In that case, estimated data are used for comparison purposes but are not part of the final dataset since the hierarchy of sources gives priority to actual data.

Overall, the main patterns of actual data are captured by the estimates. However, some contrasts are present. On the asset side, we observe that US dollar weights are underestimated,

\footnotetext{
${ }^{10}$ Access to actual data confirms the validity of this assumption.

${ }^{11}$ The 19 countries are: Argentina, Brazil, Chile, China, Colombia, Egypt, Hungary, India, Indonesia, Malaysia, Mexico, Peru, Philippines, Poland, Russia, South Africa, Thailand, Turkey and Uruguay.
} 
in particular for portfolio equity and FDI equity for which synthetic data rely on the geography of cross-border positions as the closest predictor of currency denomination. However, given the dominance of the US dollar, it is likely that certain cross-border positions which do not involve the issuers resident in the US are denominated in US dollars and these would not be captured by geography. Another source of discrepancy could be driven by the currency of denomination of positions vis-à-vis Special Purpose Entities (SPEs) which may not be captured by geography.

On the liability side, domestic currency weights of portfolio debt liabilities in domestic currency are underestimated in particular for emerging countries. This happens because the BIS does not report the currency composition of domestically issued debt securities and there is moreover no information of the proportion of domestically issued securities which is held by non-resident investors. Other investment liabilities exhibit substantial dispersion with US dollar weights revealing a slight underestimation in the early to mid-2000s. As in the case of the asset side, this item is proxied using banking data only while other components are not estimated. This could partly explain the differences between actual and estimated data.

Given that there are some differences between actual and estimated data, it is very important to incorporate as much actual data as possible.

\subsection{Data Uses}

The dataset we construct and make publicly available contains asset, debt asset, liability, and debt liability weights. These are obtained combining the shares of each component of the IIP from the External Wealth of Nations dataset by Lane and Milesi-Ferretti (2007) with the corresponding currency weights which we calculate using the methods described in this section as well as in the Appendix. Debt assets include portfolio debt, FDI debt, other investment and reserve assets, while debt liabilities include portfolio debt, FDI debt and other investment.

The dataset can be used to compute a number of indicators which will guide our analysis. In particular, we calculate a measure of valuation effects in response to exchange rate movements which contains two main ingredients: financial exchange rates and a measure international financial integration. After introducing this indicator we zoom into the currency composition of the stock of external assets and liabilities and compute US dollar and euro measures of international financial integration. The core of our paper centers around a measure of aggregate foreign currency exposure.

\section{Exchange Rate Valuation Effects: Building Blocks}

Exchange rate movements can potentially have significant effects on the economy through a financial and a trade channel. The financial channel refers to capital flows and capital gains or losses related to external balance sheets. The trade channel operates through the effects on exports and imports.

In order to assess the impact of currency movements on gross stocks, Lane and Shambaugh (2010a) propose the following measure of valuation effects:

$$
V A L_{i, t+1}^{X R}=\% \Delta I_{i, t+1}^{F} I F I_{i, t},
$$

where $V A L_{i, t+1}^{X R}$ indicates the currency-induced valuation change related to currency movements for country $i . \% \Delta I_{i, t+1}^{F}$ is the percentage change in the net financial exchange rate index during the period $t+1$ and $I F I_{i, t}$ denotes the size of the external balance sheet, measured by the international financial integration index proposed by Lane and Milesi-Ferretti (2007). This is calculated as $I F I_{i, t}=\left(A_{i, t}+L_{i, t}\right) / G D P_{i, t}$, where $A_{i, t}$ and $L_{i, t}$ are the end-of-period $t$ gross stock of external assets and liabilities expressed in current US dollars. 


\subsection{Financial Exchange Rate Indices}

One of the building blocks for the calculation of valuation effects is the financially weighted exchange rate index based on net foreign currency exposures. This provides a measure of the sensitivity of country's external balance sheets to currency movements and is given by

$$
I_{i, t+1}^{F}=I_{i, t}^{F}\left(1+\sum \omega_{i j, t}^{F} \% \Delta E_{i j, t}\right)
$$

$\% \Delta E_{i j, t}$ is the percentage change in the bilateral end-of-period nominal exchange rate between the currency of country $i$ and the foreign currency $j$ between $t$ and $t+1 . \omega_{i j, t}^{F}$ is the net financial weight of country $i$ to currency $j$ in period $t$. This is calculated as

$$
\omega_{i j, t}^{F}=\omega_{i j, t}^{A} s_{i, t}^{A}-\omega_{i j, t}^{L} s_{i, t}^{L},
$$

where $\omega_{i j, t}^{A}\left(\omega_{i j, t}^{L}\right)$ is the proportion of assets (liabilities) denominated in currency $j, s_{i, t}^{A}=$ $\frac{A_{i, t}}{A_{i, t}+L_{i, t}}$ is the share of assets in the country external balance sheet and $s_{i, t}^{L}=\frac{L_{i, t}}{A_{i, t}+L_{i, t}}$ is the corresponding share for its liabilities. By construction $s_{i, t}^{A}+s_{i, t}^{L}=1$.

While a depreciation of the domestic currency tends to be associated with a net financial outflow (via interest parity conditions) and thus an improvement in the net IIP, that same exchange rate movement could amplify or mitigate that flow effect via valuation changes in gross external positions. The direction of the latter depends on whether the country has a long or a short position in foreign currencies. The magnitude, depends on the size of the external balance sheet.

Traditionally, the effect of exchange rates on external positions and its sustainability has been studied by using trade-based exchange rate indices (originally designed to study trade flows as the outcome variable) and their effect on the balance of payments counterpart of the financial account, i.e. the current account or its main component, the trade balance. Although this approach could be a fair approximation of the effects of a uniform change in a currency value on financial flows and external positions, it has its limits. First, it is based on a "proxy" for the financial account: the current account. While conceptually, one should be a close reflection of the other, a more precise assessment should focus on the financial account itself. $^{12}$ Second, it is based on the geography of trade, which does not necessarily match the counterparts of international investment positions and the currencies in which these are denominated. Third, it does not provide a one-to-one link between the change in value of the external positions - a dimension increasingly relevant in the light large scale of international balance sheets, as documented by Lane and Milesi-Ferretti (2001, 2007) - and exchange rate movements. Given these fundamental differences, it is reasonable to expect that financial and trade-based exchange rate indices exhibit heterogeneous dynamics.

In fact, the trade-weighted and financial exchange rates can move in opposite directions, making the latter a crucial tool for the assessment of the sustainability of external imbalances and for surveillance purposes. Therefore, as a byproduct of this dataset we provide an updated measure of financial exchange rates to calculate valuation effects. ${ }^{13}$

The findings in Lane and Shambaugh (2010a) reveal that there is considerable heterogeneity in the comovement between the trade-weighted and financial exchange rates and conclude that trade-weighted exchange rates are not the adequate measure to evaluate the wealth effects of currency movements. When we compute financial exchange rates for our sample of 50 countries between 1990 and 2017 and compare them with trade-weighted indices we confirm their results. ${ }^{14}$

\footnotetext{
${ }^{12}$ See Lane and Milesi-Ferretti (2009) on the relevance of error and omissions on US external positions.

${ }^{13}$ The dataset on financial exchange rates is available upon request.

${ }^{14}$ Note that the financial exchange rates are calculated based on four foreign currencies only (the US dollar,
} 
Figure 1 shows examples of financial exchange rates vis-à-vis trade weighted exchange rates for a subsample of countries. The case of the US is interesting since the financial exchange rate index shows much less volatility than the trade-weighted index. As documented in Lane and Shambaugh (2010a) this is due to the fact that the foreign currency component of US external liabilities is low and that the trade index gives more weight to trading partners which are not necessarily major destinations of US investment (see also Tille, 2003).

Figure 1 also shows the financial and trade weighted exchange rate indices for Colombia. It is interesting to see that both indices show a high degree of comovement but the financial index exhibits substantially lower volatility since the 2000s, reflecting the increasing importance of domestic currency in total liabilities.

Finally, the Figure displays the comparison for Germany. In line with a typical case for an advanced economy, we observe that the financial exchange rate index exhibits lower volatility than the trade-weighted index, which indicates the presence of domestic currency liabilities and the fact that Germany's investment partners (and the investment currencies) may not necessarily be aligned with its trading partners.

Table 1 shows the mean and median within-country correlations of the different indices. The asset and liability indices exhibit a high correlation but it is smaller for emerging and developing economies. We then calculate the correlation between each of these two individual indices and the trade-weighted index and observe that the correlations are weak. Finally, we compute the pairwise correlation between the financial and trade-weighted indices and show that the correlations are small, but slightly larger for the group of advanced economies. The volatility of the financial exchange rate is significantly lower than that of the trade-weighted index. However, the financial index for emerging and developing economies is more volatile than that of advanced economies. ${ }^{15}$

After computing the financial exchange rates we can calculate the valuation effects. As an example, in Figure 2 we plot our measure of valuation effects for Germany and compare it with a measure of revaluations of external net financial assets and liabilities due to exchange rate changes sourced from the Deutsche Bundesbank. ${ }^{16}$ Our measure tracks the valuation changes extremely well. The calculation of $V A L^{X R}$ allows us to see the valuation loss experienced in the aftermath of the global financial crisis and the subsequent recovery.

The calculation of financial exchange rates and valuation effects are a useful tool to quantify the effects of exchange rate movements on the external balance sheet. For countries that have a negative net position in foreign currency, a depreciation of the domestic currency can generate significant negative wealth effects. This is the prototype example of a developing country. However, many developing countries have increased the share of foreign liabilities in domestic currencies mainly through an increase in equity and in some cases also through an increase in debt denominated in domestic currency (see IMF External Sector Report, 2019). These shifts can have substantial implications in the wealth effects from currency movements. The formula for valuation effects in Equation 1 can be applied to any country of our sample in a straightforward way.

the euro, the Japanese yen and the Pound sterling). However, these currencies represent the bulk of external assets and liabilities.

${ }^{15}$ These results are not shown here to preserve space but are available upon request.

${ }^{16}$ The series code is BBFI1.Q.N.DE.W1.S1.S1.K7A.N.FA._T.F._Z._T. X.N and it is available at https://www. bundesbank. de/dynamic/action/en/statistics/time-series-databases/time-seriesdatabases/745582/745582?tsTab=0\&listId=wWw_s201_veraenderungs\&id=0\&tsId=BBFI1.Q.N.DE.W1.S1.S1. K7A.N.FA._T.F._Z._T._X.N.. 


\subsection{International Financial Integration}

Another building block to compute valuation effects is the IFI measure, which does not contain a currency dimension, but once multiplied by the change in the financial exchange rate index we obtain the valuation effect. However, our dataset allows us to break down the IFI measure by currency and analyze the main trends.

The literature pioneered by Lane and Milesi-Ferretti (2003) and Lane and Milesi-Ferretti (2007) has analyzed the evolution of de-facto IFI based on cross-border assets and liabilities positions relative to GDP. The authors have documented the large increase in international financial integration from the 1990s to the global financial crisis and noted that since the 1990s the pace of integration has been more gradual for emerging markets than for advanced economies. More recently, Lane and Milesi-Ferretti (2018) highlight that the growth in international financial integration came to a halt in the aftermath of the global financial crisis. This trend is mainly attributed to the decline in cross-border activity by banks in advanced economies (McQuade and Schmitz, 2017). While the IFI measure focuses on the size of the international balance sheet and its decomposition into financial instruments, little is known about the currency composition of the stocks of external assets and liabilities.

Our dataset allows us to look into this dimension and analyze how the trends in international financial integration are reflected in the currency breakdown. Of particular interest is to assess the role of the US dollar relative to the euro since these are the two dominant currencies in international finance and trade.

Figure 3 reports the measure of IFI denominated in US dollars (in blue) and in euros (in red) for all the countries in our sample. In addition, we include a measure of $I F I$ in US dollars (dotted blue) and euros (dotted red) for a sample of all countries excluding the US and the Euro Area. Figures 4 and 5 show the same information for advanced and emerging economies, respectively. In all cases we include the sum of external assets and external liabilities scaled by the weighted average of each country's GDP. ${ }^{17}$

From the figures we observe some interesting patterns. The overall trends described in Lane and Milesi-Ferretti (2003), Lane and Milesi-Ferretti (2007) and Lane and Milesi-Ferretti (2018) are clearly visible in our dataset, demonstrating the large role the countries in our sample play in global finance. In particular, the IFI measure shown in Figure 3 has increased two-folds from the early 1990s levels to 360 percent of GDP by 2017 and exhibits a decline in the aftermath of the global financial crisis. For reference, as of 2017, around seventy percent of the cross-border holdings are denominated in US dollars or euros.

In the sample including all countries we observe that euro-denominated cross-border holdings expanded rapidly between 1999 and 2007, but declined considerably after the global financial crisis. US dollar positions on the other hand dropped in 2008, but quickly recovered showing an upward trend and gaining a clear predominance over the euro since 2014. Note that this pattern is not only evident for the US or Euro Area countries. In fact, when we exclude the US and the Euro Area countries (dotted lines) the shift away from the euro and into the dollar is still present. ${ }^{18}$ However, in this case we observe an unambiguous dominance of cross-border holdings in US dollars throughout the whole sample period. The difference between the IFI measure (dotted lines) in dollars (in blue) and in euros (in red) has widened since 2007 and US dollar cross-border positions were three times larger in 2017.

Several factors played a role in driving this pattern. On the one hand, Euro Area banks

\footnotetext{
${ }^{17}$ The use of weighted averages provides a global perspective on the IFI measures.

${ }^{18}$ Excluding Euro Area countries takes into account that intra-Euro Area positions do not really reflect an international dimension, but "quasi-domestic" integration. The fact that intra-Euro Area positions are to a large extent denominated in euros is linked to the results described in Coeurdacier and Martin (2009). They find that the reduction in transaction costs due to the introduction of the euro has stimulated trade in financial assets (denominated in euros) among Euro Area countries.
} 
have persistently deleveraged from cross-border positions since the crisis. ${ }^{19}$ Moreover, as documented in Maggiori, Neiman and Schreger (2019b), the uncertainty triggered by the Euro Area sovereign debt crisis led investors to shift away from euro positions. In addition, the US dollar appreciation and the high liquidity of dollar assets during the peak of the crisis has reinforced the dominant role of the US dollar, in particular as there is a lack of supply of safe euro-denominated assets, relative to the US dollar (Ilzetzki et al., 2019).

Figure 4 shows that the IFI measure in US dollars for the sample of advanced economies (solid blue line) is very similar to the one of advanced economies excluding the US and the Euro Area (dotted blue line). The overall trend of increased financial integration and subsequent decline in the aftermath of the global financial crisis described in Lane and Milesi-Ferretti (2018) is also very clear from this graph. As in the sample which includes all countries, Figure 4 shows that this pattern is accompanied by a substantial decline in positions in euros, especially in the sample which excludes the US and Euro Area, in line with Maggiori et al. (2019a) and Maggiori et al. (2019b).

Further analysis, focusing on the sample of all advanced and emerging economies excluding the US and the Euro Area, reveals that both external assets and liabilities denominated in euros declined over the past decade, although the reduction in assets contributed slightly more to the decline. For the full sample, US dollar denominated liabilities are still slightly below their peak, but in the sample of advanced economies both assets and liabilities exceed previous peaks. In addition, the decline in euro denominated IFI is largely driven by the debt component with equity showing an upward trend for advanced economies. By contrast, we observe an increase in both equity and debt cross-border holdings denominated in US dollars in the aftermath of the global financial crisis. $^{20}$

Emerging markets certainly account for a small but growing share of cross-border holdings (Figure 5). For this group of countries, the euro plays a muted role since the majority of cross-border holdings of assets and liabilities are denominated in US dollars. Figure 5 shows the disproportionate role of the dollar in cross-border holdings for emerging economies.

The finding that the dollar dominates the holdings of cross-border positions is linked to the role of the dollar in trade invoicing as documented in Goldberg and Tille (2008), and in trade and finance as described in Gopinath and Stein (2018).

\subsection{Foreign Currency Exposures}

The core of the analysis in the rest of the paper is centered around a measure of foreign currency exposure as a crucial building block. As common in the literature on foreign-currency exposures, we use an indicator which is intuitively defined as the net foreign assets denominated in foreign currency as a share of total assets and liabilities. Following Lane and Shambaugh (2010a) we calculate the aggregate foreign currency exposure indicator as

$$
F X_{i, t}^{A G G}=\omega_{A i, t}^{F} s_{i, t}^{A}-\omega_{L i, t}^{F} s_{i, t}^{L},
$$

where $s_{i, t}^{A}$ and $s_{i, t}^{L}$ are defined in equation (3) and their relative size captures whether the country exhibits a creditor or debtor external position. ${ }^{21} \omega_{A i, t}^{F}$ and $\omega_{L i, t}^{F}$ are the proportions of asset and liabilities denominated in foreign currency, respectively.

This indicator ranges between -1 (case where all liabilities are denominated in foreign currency and all assets are in domestic currency) and 1 (case where all assets are denominated

\footnotetext{
${ }^{19}$ As shown in McCauley et al. (2019) and Emter et al. (2019) this was driven by European banks responding to credit losses by retrenching from assets abroad.

${ }^{20}$ This decomposition is not shown to preserve space but it is available upon request.

${ }^{21}$ Note that $F X_{i, t}^{A G G}=\sum_{j \in F C} \omega_{i j, t}^{F}$ from equation (3), where $F C$ is the set of foreign currencies.
} 
in foreign currency and all liabilities in domestic currency). A country is "long on foreign currency" if $F X^{A G G}$ is positive and "short on foreign currency" if it is negative. More generally, this indicator captures the sensitivity of a country's external position to a uniform appreciation or depreciation of its currency vis-à-vis all other currencies. ${ }^{22}$ Note that if we were interested in calculating the impact of a uniform change in the value of the domestic currency against all foreign currencies, the uniform valuation effect $\left(V A L^{X R, U}\right)$ would be given by

$$
V A L_{i, t+1}^{X R, U}=F X_{i, t}^{A G G} I F I_{i, t} \% \Delta E_{i, t+1}^{U},
$$

where $\% \Delta E^{U}$ denotes a uniform shift in the value of the domestic currency against all foreign currencies. Our interest in $F X^{A G G}$ extends beyond its use for the calculation of valuation effects. In the remainder of the paper we build our analysis around this indicator and its main subcomponents. Due to international data limitations our dataset does neither capture the currency denomination of cross-border financial derivatives nor the extent to which various types of financial derivatives are used to hedge cross-border currency mismatches. However, Bénétrix et al. (2015) point out that this is not a major drawback to estimates of foreign currency exposures due to several factors. First, hedging activities tend to be mainly concentrated in advanced economies and on the liability side. As advanced economies tend to show long foreign currency exposures, this implies that with the inclusion of hedging activities, these positions would even be longer in foreign currency (i.e. not hedged away). Moreover, for most countries net financial derivatives positions tend to be a minor component of the external balance sheet (less than 1 percent of GDP), which mechanically limits their potential to provide large valuation gains or losses.

While the focus of our approach is on cross-border positions, one implication of financial globalization is that foreign currencies may also be used in "local" positions (i.e. between residents of the same economy). Data on the currency denomination of these positions is very sparse, but available for the banking sector of a number of countries in the BIS Locational Banking Statistics. For euro-US dollar positions, Bénétrix and Schmitz (2019) find suggestive evidence that cross-border currency exposures and local currency exposures may partly serve as hedges for each other. However, as this type of hedging is only partial in nature and confined to the banking sectors of a few advanced economies, it has only a very limited impact on the country-level exposures reported in our dataset.

\section{Components and Long-Term Dynamics of $F X^{A G G}$}

This section describes the different components of aggregate foreign currency exposures, presents some descriptive statistics, a snapshot of the long-term dynamics and a regression analysis to identify the extent to which these are associated with relevant macroeconomic variables.

\subsection{Components}

Given that $F X^{A G G}$ accounts for the currency exposure on the net aggregate IIP, all asset classes are incorporated in this measure on both sides of the balance sheet. This implies that long and short foreign currency positions are affected by the currency composition of the different assets classes as well as the overall size and sign of the net international investment position, regardless of its underlying currency of denomination. More precisely, if a country has $60 \%$ of both its assets and liabilities denominated in foreign currency $\left(\omega_{A i, t}^{F}=\omega_{L i, t}^{F}=0.6\right)$,

\footnotetext{
${ }^{22}$ Given the currency breakdown in our data set into US dollar, euro, Pound sterling, Japanese yen, and renminmbi, it is also possible to study the impact of fluctuations in the value of these currencies on countries gross positions.
} 
the value of $F X^{A G G}$ will depend on the net IIP only. If the country is a net debtor, say $(A-L) /(A+L)=-0.6, F X^{A G G}$ will be negative and equal to -0.36 . The only case where the currency of denomination will be the sole determinant of $F X^{A G G}$ is when a country's IIP is zero (i.e. balanced), a very unlikely scenario.

In order to understand the relative role of its different components, we break $F X^{A G G}$ down into two components:

$$
F X^{A G G}=\frac{(A-L)}{(A+L)}+F X_{o}^{A G G}
$$

where the first component the net foreign asset position $(A-L)$ scaled by the size of the external balance sheet $(A+L)$, and $F X_{o}^{A G G}$ measures the net liability position in domestic currency $(D C)\left(L^{D C}-A^{D C}\right)$ as a proportion of the external balance sheet. A positive value of this indicator implies that the proportion of liabilities denominated in domestic currency is greater than the proportion of assets denominated in domestic currency in relation to $(A+L)$. $F X_{O}^{A G G}$ can be interpreted as the aggregate foreign currency exposure evaluated at a zero net foreign asset position. If $A-L=0$, a positive value of $F X_{O}^{A G G}$ would imply that the proportion of assets denominated in foreign currency is larger than the proportion of liabilities denominated in foreign currency in relation to $(A+L)$. From here onward, we refer to $F X^{A G G}$ as the foreign currency exposure and to $F X_{o}^{A G G}$ as the foreign currency mix.

Table 2 reports the summary statistics of this decomposition and its subcomponents for the full sample of 50 countries as well as for the advanced and emerging economy groups in 2017 (the final year of the dataset).

The mean and median in all country groupings show a long foreign currency position, $F X^{A G G}>0$, ranging from 0.11 to 0.18 . This is also observed in the interquartile range of the full sample and in the advanced group. However, some countries show a short position in the emerging economies group. Note that a negative value of $F X^{A G G}$ implies balance sheet losses in case of a depreciation and gains in case of an appreciation.

Considering the two main components of the exposures, Table 2 reveals that there are two counterbalancing forces in most of the cases. On the one hand, many countries exhibit a debtor position with $(A-L) /(A+L)$ ranging from -0.13 to -0.2 across mean and median countries. On the other hand, all statistics show a long position for the foreign currency mix, $F X_{o}^{A G G}>0$. More precisely, long foreign currency exposures in 2017 were mostly the result of the currency mix of assets and liabilities rather than net creditor positions. In terms of the dispersion, the interquartile range shows more cross-country variation in $(A-L) /(A+L)$ than in $F X_{o}^{A G G}$.

In order to have a deeper understanding of these two items, we break them down into their relevant subcomponents. First, we decompose $(A-L) /(A+L)$ into the net foreign asset position excluding foreign exchange reserves and the reserves component as follows:

$$
\frac{(A-L)}{(A+L)}=\frac{\left(A_{N R}-L\right)}{(A+L)}+\frac{F X R}{(A+L)} .
$$

$A_{N R}$ are foreign assets excluding reserves and $F X R$ denotes the foreign exchange reserves. As expected, the net position is dominated by the non-reserve component. In addition, Table 2 indicates that it is negative for most countries, in particular for emerging economies. While advanced economies mean value of $\frac{\left(A_{N R}-L\right)}{(A+L)}$ is -0.04 , it is -0.33 for emerging countries. By definition, foreign currency reserves are always positive, but we observe that they represent a larger share of external assets in emerging countries. In fact, foreign reserves in these countries have been assessed to exceed the IMF's reserve adequacy guidelines (Alfaro and Kanczuk, 2019). 
Second, we decompose $F X_{o}^{A G G}$ into the following terms:

$$
F X_{o}^{A G G}=\frac{P E Q L^{D C}+F D I L^{D C}}{(A+L)}+\frac{D E B T L^{D C}}{(A+L)}-\frac{A_{N R}^{D C}}{(A+L)},
$$

where $P E Q L^{D C}$ denotes portfolio equity liabilities, which are denominated in domestic currency, and $F D I L^{D C}$ is the equity component of direct investment liabilities denominated in domestic currency. $D E B T L^{D C}$ are debt liabilities denominated in domestic currency and $A_{N R}^{D C}$ are non-reserve assets denominated in domestic currency.

Note that for advanced economies $F X_{o}^{A G G}$ is mainly driven by debt liabilities in domestic currency followed by equity liabilities in domestic currency, including both FDI equity and portfolio equity. By contrast, the key driver of $F X_{o}^{A G G}$ for emerging economies is the equity component of liabilities. Compared to advanced countries, the debt component in domestic currency is small but still positive. It has been documented that during the last decade there has been a remarkable change in emerging market government finance as governments in these economies have increasingly borrowed in their own currency (Alfaro and Kanczuk, 2019). While our analysis does not break debt down between public and private sectors, we confirm this trend when we analyze the evolution of portfolio debt liabilities. However, as external debt liabilities also include FDI debt and other investment, which in emerging markets continue to be dominated by foreign currencies, the domestic currency component in debt instruments remains relatively small.

Table 3 reports the mean, median and interquartile range of the correlation coefficient across all these items for the period 1990-2017. For $F X^{A G G}$, the decomposition shows that $(A-L) /(A+L)$ and $F X_{o}^{A G G}$ are positively correlated with $F X^{A G G}$. The correlations suggest that $F X^{A G G}$ is more responsive to changes in $(A-L) /(A+L)$ than in $F X_{O}^{A G G}$. The relation between these differs depending on the summary statistic of the correlation distribution that we analyze. On the one hand, the mean and median correlations are very small with negative and positive signs, respectively. On the other hand, the interquartile range is wide and includes large negative and positive correlations.

As expected, there is a strong positive correlation between $(A-L) /(A+L)$ and $\left(A_{N R}-\right.$ $L) /(A+L)$. By contrast, the correlation between $(A-L) /(A+L)$ and $F X R /(A+L)$ is positive at the mean and median but negative correlations emerge in the interquartile range indicating that $(A-L) /(A+L)$ and $F X R /(A+L)$ move in opposite directions for some countries.

When the focus is on the foreign currency mix, $F X_{o}^{A G G}$, Table 3 shows that the equity liability components, $(P E Q L+F D I L) /(A+L)$, are highly correlated with $F X_{o}^{A G G}$. High mean (0.76) and median (0.97) correlations highlight the relevance of changes in equity liabilities for overall exposures. Conceptually, a positive relation is also expected for debt liabilities in domestic currency, $D E B T L^{D C} /(A+L)$, and $F X_{o}^{A G G}$. Although it is positive, this relation is not strong at the mean or median of the correlation distribution. The interquartile range is wide with correlations from -0.25 at the $25^{\text {th }}$ percentile to 0.74 at the $75^{\text {th }}$ percentile. By construction, the correlation between non-reserve assets denominated in domestic currency, $A_{N R}^{D C} /(A+L)$, and the foreign currency mix, $F X_{o}^{A G G}$, should be negative. For the mean and median correlations we find that this is the case, although the correlations are small in absolute value.

For completeness, we also present correlation matrices for the advanced and the emerging country groups. As in the full sample, $(A-L) /(A+L)$ and $F X_{o}^{A G G}$ are positively correlated with $F X^{A G G}$ in both groups. Interestingly, advanced countries show a negative link between $(A-L) /(A+L)$ and $F X_{o}^{A G G}$ indicating that debtor countries are able to "hedge" their overall negative net positions with a long foreign currency mix. In these cases, exchange rate movements will improve the net external position of the country. However, this is not the case for 
emerging countries as they show a positive correlation between these items for at least half of the countries in the group. For them, the exposure associated with a net debtor position is exacerbated by a short foreign currency mix. This means that a depreciation of the exchange rate would act as a destabilizing force increasing a net debtor position further. A reason for this result could be that emerging countries with negative net external positions are deemed as inherently more risky, which in turn reduces their ability to issue liabilities in domestic currency. Other differences between these country groups include the role of foreign exchange reserves which, as expected, are more strongly associated with $(A-L) /(A+L)$ and $F X_{O}^{A G G}$ in emerging countries.

In sum, the mean and median countries show long foreign currency positions in 2017, driven by a positive foreign currency mix $F X_{o}^{A G G}$. In advanced economies this is mainly due to debt liabilities, while for emerging economies the key driver is the equity liabilities component. Moreover, we uncover a very interesting stylised fact. While net international investment positions and long foreign currency mix exhibit a negative correlation in advanced economies, indicating currency hedging of the liability positions, emerging economies show a positive correlation. Even if there has been a movement toward a long foreign currency exposure via long foreign currency mixes, the way in which these two subcomponents interact suggests that exchange rate movements are more likely to worsen than to improve external positions via valuation effects in emerging countries.

\subsection{Long-term dynamics}

Figure 6 presents the cumulative cross-country distribution of $F X^{A G G}$ positions at the start and end of our sample period for advanced (in red) and emerging economies (in blue). Consistent with the evidence provided in Lane and Shambaugh (2010a) and Bénétrix et al. (2015), the curve has shifted significantly towards long positions in foreign currency since 1990 in the context of a surge in global financial flows. While 60 percent of countries in our sample exhibited net negative positions in foreign currencies in 1990, this proportion declined to 20 percent in $2017 .{ }^{23}$

Net negative positions in foreign currencies continue to be dominated by emerging market economies, which have a history of borrowing heavily in foreign currency, a phenomenon referred to as "original sin" (Eichengreen, Hausman and Panizza, 2003), raising questions about their vulnerability to external shocks, particularly those associated with large currency movements. Our analysis reveals that there has been an improvement in their net position, partly driven by a change in the currency composition of foreign liabilities away from foreign currency and toward local currency instruments as well as a sustained accumulation of foreign currency assets. While emerging economies accounted for 22 out of the 29 countries with short foreign currency positions in 1990, they represent 9 of the 10 countries short in foreign currency in 2017. In 2017 the only advanced economy with negative positions is Greece.

In what follows we will decompose the different elements of $F X^{A G G}$ which will help us understand the role played by the different subcomponents in driving the movement in the curve.

\subsubsection{Decomposition}

Figure 7 displays the cumulative distribution of the components of $F X^{A G G}$ as described in Equation 6. It shows that the remarkable shift towards long foreign currency positions in the distribution of $F X^{A G G}$ between 1990 and 2017 was mainly driven by the improvement in the

\footnotetext{
${ }^{23}$ Compared to 2012, the latest available data point available in Bénétrix et al. (2015) where the proportion of countries with negative $F X^{A G G}$ positions stood at 24 percent, we report a further rightward shift in the distribution of $F X^{A G G}$.
} 
net international investment positions, $(A-L) /(A+L)$. In fact, 35 percent of the countries in the sample were net creditors in 2017, compared to 20 percent in 1990. Moreover, the size of net debtor positions (scaled by total external assets and liabilities) shrank substantially as visible in the downward shift of the distribution in the chart on the bottom left. In addition, the foreign currency mix, $F X_{o}^{A G G}$, moved towards longer positions since 1990, thereby also contributing to the rightward shift in $F X^{A G G}$.

Figure 8 shows the cumulative distribution of the components of $(A-L) /(A+L)$ following Equation 7, which breaks down the net international investment position into a term that includes foreign assets without reserves, $\left(A_{N R}-L\right) /(A+L)$, and foreign exchange reserves component, $F X R /(A+L)$. The Figure reveals that the improvement in net foreign assets (scaled by $A+L$ ) since 1990 was overwhelmingly driven by the non-reserve components of the IIP. Note that emerging economies experienced an expansion in foreign reserves since the mid-1990s, partly driven by an increase in financial development, as described in Obstfeld, Shambaugh and Taylor (2010). Interestingly, the accumulation of reserves by these countries has been so large that it is hard to reconcile from the lens of theoretical models which feature insurance against a "sudden stop" (Jeanne, 2007). However, Figure 8 shows that this item played a limited role in the overall improvement of the net IIP.

Finally, Figure 9, displays the cumulative distribution of the components of $F X_{o}^{A G G}$, described in equation 8. In this Figure, $F X_{o}^{A G G}$ is broken down into domestic currency (portfolio and FDI) equity liabilities, domestic currency debt liabilities and external assets denominated in domestic currency (all scaled by $A+L$ ). While the distribution of the asset component in domestic currency has not changed much for most of the sample since 1990, it increased quite substantially for the Euro Area countries. The adoption of the euro meant for these countries that a big part of their cross-border assets were "redenominated" from foreign to domestic currency. Therefore, the overall right-ward shift (i.e. increase) was mainly driven, in a rather uniform way, by larger equity liabilities denominated in domestic currency. The importance of this item is even more marked for emerging economies. This is in stark contrast with the distribution of debt liabilities in domestic currency which looks very similar in 1990 and 2017 for around 80 percent of the countries in the sample.

We find that the improvement in the foreign currency exposure in emerging economies is dominated by an increase in equity liabilities in domestic currency and to a lesser extent an increase in portfolio debt liabilities in domestic currency. This result is related to the findings in Haussman and Panizza (2011), who suggest that the reduction in "original sin" for emerging economies is small and very specific to a limited number of countries. When we look at overall debt, the predominance of domestic currency borrowing is more tenuous given that external debt is defined as the sum of FDI debt, other investment and portfolio debt with the first two being predominantly in dominant currencies. By contrast, some advanced economies, notably the Euro Area countries, experienced a strong expansion in debt liabilities denominated in domestic currency. The adoption of the euro allowed Euro Area countries to issue more debt instruments in domestic currency.

Overall, the decomposition analysis reveals that the shift towards foreign currency positions since 1990 was mainly driven by improving net international investment positions (excluding reserves) and to a lesser extent also due to larger net liability positions in domestic currency (driven by larger equity liabilities).

\subsection{Regression Analysis}

In this section we assess the extent to which foreign currency exposures are associated with a set of relevant macroeconomic variables. To this end, we present a series of parsimonious regressions models following the approach in Lane and Shambaugh (2010b). Our goal is to study the importance of trade and financial openness, macroeconomic risk, exchange rate regimes, 
country size and development on aggregate foreign currency exposure and its subcomponents.

Table 4 shows pooled regression models including three years of data: 1997, 2007 and 2017. The set of core covariates includes trade openness (calculated as the sum of exports and imports scaled by GDP and denoted by Trade), macroeconomic risk indicators captured by the volatility of GDP $(\operatorname{vol}(G D P))$, volatility of inflation $(\operatorname{vol}(\pi))$ and financial exchange rates (computed as shown in equation (2) and denoted by $I) .{ }^{24}$

Foreign currency exposures can have stabilizing or destabilizing effects as a result of exchange rate movements. Countries long in foreign currency will exhibit a net capital gain on their external financial position as a result of a uniform depreciation of their currency. If this takes place in a recession context, that capital gain will act as a buffer or a stabilizing force. On the contrary, if the country is short foreign currency, the effects of a uniform depreciation in recessions will be exacerbated by a capital loss in the external position. The latter was a common feature in emerging market economies unable to issue debt in domestic currency. To proxy these stabilizing/destabilizing effects, we include the correlation coefficient between GDP and the financial exchange rate index. When this correlation is positive, recessions are associated with an exchange rate depreciation and vice-versa. Thus, a positive coefficient for $\operatorname{corr}(G D P, I)$ in the $F X^{A G G}$ regression model can be interpreted as evidence that the currency exposure in the external position is acting as a stabilizing force. ${ }^{25}$

In addition to the above explanatory variables, we include indicators for the degree of financial account openness, exchange rate regime classification, EMU membership, as well as country size and development. We use the updated Chinn and Ito (2006) de jure measure of financial openness (KA open) while the exchange rate regime classification is obtained from Shambaugh (2004) (the variable Peg takes value of one if the country is classified as having a fixed exchange rate). EMU membership is a dummy variable for the sample of countries in our data that belong to the European Monetary Union: it takes a value of zero for all countries in 1997 and one for member countries in 2007 and 2017. Country size and level of development are proxied by the logarithm of population (denoted by Size) and GDP per capita (GDPpc), respectively. Finally, we control for long-term movements in currency exposure distributions by including two dummy variables for the years 2007 and $2017 .{ }^{26}$

As in the previous section, we break $F X^{A G G}$ down into its subcomponents to study how the above variables affect each of them. This is important to uncover counterbalancing relations at the subcomponent level. We report the regression estimates for $(A-L) /(A+L)$ and $F X_{o}^{A G G}$ in columns (2) and (3), respectively. Then, we break the former down into $\left(A_{N R}-L\right) /(A+L)$ and $F X R /(A+L)$. Regression results for this split are reported in columns (4) and (5), respectively. $F X_{o}^{A G G}$ is divided into $\left(P E Q L^{D C}+F D I L^{D C}\right) /(A+L), D E B T L^{D C} /(A+L)$ and $A_{N R}^{D C} /(A+L)$ with regression outputs shown in columns (6), (7) and (8), respectively.

Table 4 shows that our model is able to explain more than 50 percent of the cross-country variation in aggregate foreign-currency exposures. However, its explanatory power varies considerably across subcomponents, with $R^{2}$ 's ranging from 0.40 to 0.90 .

In line with the work of Lane and Shambaugh (2010b), we find that trade openness is positively associated with long positions in foreign currency. ${ }^{27}$ This is driven by a positive

\footnotetext{
${ }^{24}$ To ensure cross-country comparability, we include volatility as measured by the coefficient of variation. These variables are computed retrospectively taking a ten-year non-overlapping window ending in the considered year. For instance, the volatility values for 1997 are computed using annual data for the 1988-1997 period.

${ }^{25}$ Since our data on currency exposures are solely based on cross-border positions, this variable would not account for additional stabilizing/destabilizing effects due to local financial exposures.

${ }^{26}$ The remaining data are obtained from standard sources: exchange rate and inflation data are from the International Monetary Fund's International Financial Statistics database, while GDP and trade data are from the World Bank's World Development Indicators database. The use of alternative measures of financial openness such as the one in di Giovanni and Shambaugh (2008) makes nearly no difference in the results.

${ }^{27}$ The results in Lane and Shambaugh (2010b) are based on a shorter time period, ending in 2004, but a larger country sample.
} 
effect in the net external positions, $(A-L) /(A+L)$, instead of the foreign currency mix, $F X_{O}^{A G G}$. The former is, in turn, unrelated to trade openness through foreign exchange reserves, as shown in column (5). The absence of a significant link between trade and $F X_{o}^{A G G}$ relates to its balancing effect on debt liabilities and non-reserve assets denominated in domestic currency, shown in columns (7) and (8). The link with debt liabilities in domestic currency is negative, meaning that countries which are more open are less likely to issue debt in domestic currency, possibly to hedge trade positions. On the other hand, countries that trade more have larger non-reserve assets in foreign currency. This positive association can be reconciled with the idea that the home bias in equity portfolio assets is smaller (that is, agents hold more foreign denominated portfolio assets) the higher the share of imports in domestic consumption is (Obstfeld and Rogoff, 2011). The empirical specification does not uncover a relation between trade openness and equity liabilities in column (6).

In relation to the country risk proxies, GDP volatility is positively associated with a long position in foreign currency as shown in column (1). This relation presumably indicates that a higher volatility in domestic wealth leads to the use of the balance sheet to hedge against risk. We find that this relation is driven by longer foreign currency positions in non-reserve assets (column (8)). The second proxy of country risk, given by inflation volatility, does not have a significant effect on aggregate exposure and the main subcomponents. Our model suggests that there is a small positive link between inflation volatility and the size of foreign exchange reserves, implying that countries that face higher inflation volatility tend to accumulate larger foreign exchange reserve assets. By contrast, exchange rate volatility has a significant effect on the aggregate foreign currency exposure in our sample. Higher exchange rate volatility is associated with short aggregate positions in foreign currency. Unfortunately, our model is not able to show clearly whether the net position, $(A-L) /(A+L)$, or the foreign currency mix, $F X_{o}^{A G G}$, dominate this relation. However, the model uncovers a negative link between exchange rate volatility and both domestic currency denominated debt liabilities and nonreserve assets, in columns (7) and (8).

In terms of the potential buffer/amplifier effects of currency exposures via valuation effects, our model shows that the correlation between GDP and the financial exchange rate is positively associated with a long aggregate position in foreign currency. This means that countries in recession with depreciating currencies would also exhibit a capital gain on the net external position that would act as a buffer. This effect is driven by the response of the net position $(A-L) /(A+L)$ instead of the foreign currency mix $F X_{o}^{A G G}$. The former channel is mostly explained by the effect on the net position excluding reserves (column (4)).

When we focus on the additional controls, our model suggests that the de jure measure of financial openness is not associated with the aggregate foreign currency exposure due to potentially counterbalancing effects on $(A-L) /(A+L)$ and $F X_{o}^{A G G}$. The KA open indicator is negatively and statistically related with the latter only. In terms of the additional subcomponents, our model yields mixed results. Financial openness is negatively associated with reserve assets and equity liabilities (columns (5) and (6)). By contrast, the link with debt liabilities and non-reserve assets in domestic currency is positive (columns (7) and (8)). In turn, the exchange rate regime is not statistically significant in the $F X^{A G G}$ and main subcomponents regressions (columns (1)-(3)). However, our model shows a positive link between Peg and reserves, and a negative link between Peg and equity liabilities in domestic currency. Interestingly, EMU membership plays a strong role for aggregate currency exposures (column (1)). Our model shows that it is associated with short aggregate foreign-currency positions,

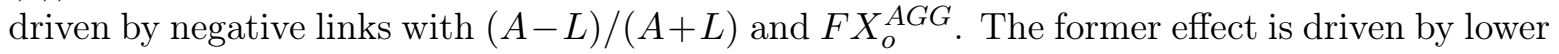
reserve assets of Euro Area countries (column (5)). For the latter, the model shows statistically significant links with all subcomponents (columns (6)-(8)). The effect on equity liabilities in domestic currency is smaller than for debt liabilities. Importantly, the overall impact is driven 
by larger external assets denominated in domestic currency (i.e. the euro), thereby leading to lower net liabilities in domestic currency, which highlights the relevance of EMU membership on the currency of cross-border positions.

In relation to the country size and development controls, we find that these are positively associated with long aggregate foreign currency exposures through their link with net positions $(A-L) /(A+L)$ and not with the foreign currency mix. These variables are also positively associated with the non-reserve net position. Only GDP per capita is negatively related with the stock of foreign exchange reserves. Larger and richer countries hold more debt liabilities and non-reserve assets denominated in domestic currency.

Finally, our year dummies shed light on the impact of time conditioning on the factors described before. In line with previous evidence in Lane and Shambaugh (2010a), Lane and Shambaugh (2010b) and Bénétrix et al. (2015) these show a rightward shift in the aggregate foreign currency exposures distribution. Here, we confirm this movement toward a longer foreign currency position unconditionally, as in the previous studies, and conditional on our set of covariates. Interestingly, the conditional movement in aggregate currency exposures is explained by a foreign currency mix effect and not by the net foreign asset position for the full sample including advanced and emerging countries. This is shown in column (3). Moreover, 2007 is associated with a reduction in the non-reserve net position while 2017 with an increase in foreign exchange reserves. Our model also uncovers a positive association between the year dummies and equity liabilities in domestic currency, and a negative link between the year dummies and external assets denominated in domestic currency.

\subsubsection{Country Group Comparison: Advanced vs. Emerging Economies}

While looking at the full country sample is a reasonable first step to study the relationship between a number of key variables and currency exposures, it is also relevant to study how these links may change when we focus on advanced and emerging countries separately. One natural reason to do so is that the former includes the issuers of the dominant foreign currencies in which the majority of external positions are denominated. More generally, there may be more fundamental differences between these groups such as those related to institutions, legal systems, economic policy, history, not captured by our previous approach.

With this in mind, we report the regressions for the two country groups in Tables 5 and 6. The results show that the positive effect between trade openness and long foreign currency exposures reported before is dominated by advanced economies since it is not significant for emerging markets (column (1)).

Unfortunately, the country group strategy does not reveal which one dominates the relation between GDP volatility and foreign currency exposures. The point estimates in column (1) of Tables 5 and 6 are both statistically insignificant. The sign is negative in advanced and positive in emerging economies, as in the full sample. When we look at the subcomponents for the advanced economies group, GDP volatility yields a negative and statistically significant coefficient for $(A-L) /(A+L)$ and a positive one for $F X_{o}^{A G G}$. In turn, higher GDP volatility is associated with smaller net creditor positions (column (4)) and it yields no significant relation with reserves (column (5)). By contrast, GDP volatility is associated with more positive external positions in the emerging countries group (column (2)). Interestingly, GDP volatility yields a positive and statistically significant effect on non-reserve domestic assets denominated in domestic currency (column (8)).

Inflation volatility is associated with a long foreign currency mix, higher reserves and larger equity liabilities in the advanced economies group (columns (3), (5), and (6)). In the emerging economies group there is also a positive association between inflation volatility and reserves (column (5)).

When the focus is on exchange rate volatility the country split shows that this variable is 
only significant for the emerging markets group, suggesting that the effects for the full sample may be driven by this group. Our model indicates that the relation comes from the link between exchange rates and reserve assets (column (5)). In relation to the stabilizing role of foreign currency exposures, the split reveals a strong effect in emerging countries that is driven by the effect on the net position (column (2)). For advanced countries, this variable does not show a statistically significant relation.

The link between aggregate foreign currency exposures and country characteristics (Size and GDP per capita) is present in both country groups. GDP per capita is associated with a long foreign currency position in advanced economies driven by the effect on net positions (column (2)), which is dominated by the impact on $\left(A_{N R}-L\right) /(A+L)$ (column (4)). The effect on the foreign currency mix is explained by the negative association between GDP per capita and debt liabilities in domestic currency (column (7)). In the emerging countries group, the positive relation uncovered with $F X^{A G G}$ is driven by the net position and is also unrelated to reserve assets.

The conditional dynamics, captured by the 2007 and 2017 dummy variables yields no statistically significant relation for the aggregate and net positions in the advanced economies group. However, a movement toward a long foreign currency mix $F X_{o}^{A G G}>0$ is present for both groups in 2017 and only for emerging economies in 2007. For advanced economies, we find a negative link between the 2017 dummy and non-reserve net positions (column (4)). For emerging economies, the 2007 and 2017 dummy variables are positively associated with equity liabilities in domestic currency (column (6)).

We checked the sensitivity of our results to alternative models which encompassed the inclusion of country fixed effects, a different proxy for financial integration given by the IFI indicator, proxies for financial deepening such as stock market capitalization, credit and deposits, the inclusion of a financial center dummy following the classification of Lane and MilesiFerretti (2018), alternative measures of volatility based on growth rates and appreciation rates. Overall, the results remain robust to different specifications. ${ }^{28}$

Our regression analysis shows that trade openness (driven by advanced economies) and output volatility are associated with longer positions in foreign currency, while exchange rate volatility (due to emerging economies) and EMU membership are associated with shorter aggregate positions in foreign currency. We also find among emerging economies that countries in recessions with depreciating currencies tend to exhibit capital gains on the net external position, thereby providing a hedge against domestic output fluctuations.

\section{Pre- and post-crisis adjustment of $F X^{A G G}$}

The goal of this section is to document the heterogeneity in the long-term adjustment of currency exposures before and after the global financial crisis. As the post-crisis period was marked by a broad-based and persistent fall in international capital flows (Milesi-Ferretti and Tille, 2011; McQuade and Schmitz, 2017), it is of high interest to analyze how currency exposures adjusted in such an environment. To this aim, we describe the main patterns of the data and a regression analysis.

\subsection{Descriptive Evidence}

We build on the stylized fact of a rightward shift in the distribution of $F X^{A G G}$ documented in the previous section. While Bénétrix et al. (2015) show that this shift was associated with a reduction of large initial short foreign-currency exposures in the run-up to the crisis, we analyze the adjustment in the post-crisis period in which a sharp deceleration was observed

\footnotetext{
${ }^{28}$ Not included here to preserve space but available upon request.
} 
(Figure 10). While 48 percent of countries had negative $F X^{A G G}$ in 1997, only 14 percent showed negative values in 2007. The curve changed direction in a minor way in 2012 (last year of Bénétrix et al., 2015) and 2017 (last year in the current dataset). In fact, 24 percent of countries displayed negative values in 2012 and 20 percent in 2017. Therefore, with respect to 2012 the curve moved slightly to the right.

This change in dynamics is also evident from the scatter plots presented in Figure 11. In the pre-crisis period, the relation between initial foreign-currency exposures and the subsequent change in the run-up to the crisis is negative for the full sample as well as for the advanced and emerging country groups individually. All countries with short positions in foreign currency in 1997 exhibited improvements in $F X^{A G G}$ between 1997 and 2007, with the exception of Sri Lanka. This pattern holds in particular for emerging market economies which generally started with substantially larger short positions, but also for advanced economies.

For countries that exhibited long positions in 1997, the ensuing changes are rather heterogeneous. All emerging economies move towards longer positions, while advanced economies movements go in both directions. Importantly, all advanced economies with long positions in 1997 still exhibited long positions in 2007.

The second panel of Figure 11 provides novel evidence of a marked change in the relation between the initial currency exposure (i.e. at the eve of the crisis in 2007) and the subsequent adjustment until 2017. Among the advanced group, most economies move towards larger long positions, with only Greece ending up in a slightly negative position in 2017. However, as indicated by the flat trend line, there is no significant relation between the initial level and the subsequent change. Among emerging countries the relation between the initial exposure and the change in the following ten years turns slightly positive. This reflects two developments. First, most emerging economies that achieved a positive $F X^{A G G}$ position in 2007 moved further towards longer foreign currency exposures, with a notably large change recorded for the Philippines. Second, those countries with negative $F X^{A G G}$ in 2007 moved further into shorter positions. The latter group of countries, which includes Turkey, Sri Lanka, Pakistan and Tunisia, worsened their foreign currency exposures since the crisis. Notably also Egypt and Morocco recorded short foreign currency positions in 2017, despite starting with long exposures in 2007. ${ }^{29}$ The pre-crisis period was marked by strong adjustments in the direction of longer $F X^{A G G}$ positions, while the post-crisis period is characterized by persistence in currency exposures.

\subsection{Regression Analysis}

Building on this evidence, we further study the structure of these dynamics by looking into the various components in a regression framework. We use a variety of specifications that allow us to study these bi-variate relations, while controlling also for several conditioning factors.

Table 7 shows the coefficients for the initial value of $F X^{A G G}$ and subcomponents as explanatory variables in the regression models, with the dependent variable being the change of $F X^{A G G}$ (or the respective subcomponents) between 1997 and 2007 or between 2007 and 2017. For each of these items we follow three approaches.

First, we report the coefficient for the initial values from simple bivariate regression models. For instance, in column (1) of Table 7 (Panel A) we find that the coefficient of a regression including all countries in our sample for the change in $F X^{A G G}$ between 1997 and 2007 and the initial level of $F X^{A G G}$ in 1997 is equal to -0.53 and statistically significant at the $1 \%$ level. The coefficient for the same specification for $(A-L) /(A+L)$ is -0.32 . Second, we report the same

\footnotetext{
${ }^{29}$ Overall the scale of changes in $F X^{A G G}$ in the post-crisis period is compressed compared with the changes observed before the crisis: for 2007-2017 the scale of the $F X^{A G G}$ adjustment ranges between -0.2 and +0.2 , while for the 1997-2007 it ranges from -0.2 to +0.6 .
} 
set of coefficients but including additional controls in the estimations to account for different dimensions of macroeconomic risk. These controls are those used in the previous section. ${ }^{30}$ For the change of $F X^{A G G}$ between 1997 and 2007 their inclusion does not affect the sign or the statistical significance of its initial value. Third, we add further controls to the regression models following the specifications discussed in the previous sections. ${ }^{31}$ Again, Table 7 shows no qualitative change in our coefficient of interest. The relation between $F X^{A G G}$ in 1997 and its change between 1997 and 2007 is strongly significant and negative. This is in line with the scatter plot evidence discussed above. Negative foreign currency positions in 1997 were reduced or turned positive by 2007, while larger positive foreign currency positions tended to become less positive.

Columns (2) through (8) report the coefficients for each of the $F X^{A G G}$ components, as outlined before. For the pre-crisis period there is strong evidence of net positions, $(A-$ $L) /(A+L)$, and the foreign currency mix, $F X_{o}^{A G G}$, both contributing to the adjustment. The non-reserve component of the net position dominates the adjustment for the former. On the other hand, the statistically insignificant effect for reserves in the bivariate model becomes large and statistically significant when the conditioning factors are included. For the $F X_{o}^{A G G}$ adjustment, we observe no role for assets in domestic currency, but some evidence for debt liabilities in domestic currency. Moreover, equity liabilities played a relevant role. Countries with initially low equity liability positions in domestic currency expanded these strongly before the crisis, thereby driving the adjustment in $F X^{A G G}$. This is in line with the shift from debtbased to equity-based liability funding documented by Lane and Shambaugh (2010b).

Table 7 also reports regression outputs for the post-crisis period, 2007 to 2017 . The bivariate coefficient in the model for $F X^{A G G}$ is positive but statistically insignificant, in line with the scatter evidence. This turns negative, without gaining statistical significance, when further controls are added.

Going through the subcomponents, we do not find significant coefficients for the overall net foreign asset positions. This is consistent with the observation that global imbalances as reflected in net international investment positions have remained persistent since the crisis (Lane and Milesi-Ferretti, 2014). On the other hand, there is still evidence of an adjustment in the foreign currency mix, $F X_{o}^{A G G}$, with a negative coefficient as in the pre-crisis period. This indicates that countries with initially low net liability positions in domestic currency expanded them after the crisis, while countries with larger net liability positions in domestic currency saw a decline over the same period.

Drilling deeper into the subcomponents reveals that reserve assets adjusted during this period. However, the magnitude was not enough to affect overall net foreign asset positions. In terms of $F X_{o}^{A G G}$, we find that the adjustment after 2007 continued to be driven by equity liabilities.

To get more insights from these decomposition, we repeat the exercise for the advanced (Panel B) and emerging country groups (Panel C). As in the full sample, Table 7 shows that both groups exhibited strong dynamics in the pre-crisis window, in line with the overall results. In the period 2007-2017 however, the general findings are driven by emerging market economies, while we do find any robustly significant coefficients for advanced countries.

For the former there is no evidence of an adjustment in $F X^{A G G}$ and underlying net foreign asset positions, but a continued negative link in the foreign currency mix $F X_{o}^{A G G}$. Thus, countries with lower net liability positions in domestic currency before the crisis experienced larger increases in these positions. This development seems to have been dominated by an

\footnotetext{
${ }^{30}$ We hence include the coefficient of variation of GDP, inflation and exchange rates as well as the correlation between GDP and exchange rate.

${ }^{31}$ More precisely we add trade openness, capital account openness, exchange rate regime, EMU membership, GDP per capita and country size.
} 
adjustment in equity liabilities in domestic currency, in line with relatively robust FDI inflows to emerging economies in the post-crisis period (McQuade and Schmitz, 2017).

Overall, this section shows that the pre-crisis period was marked by strong adjustments in foreign currency exposures towards longer $F X^{A G G}$ positions, while the post-crisis period is characterized by persistence in currency exposures. In both periods equity liabilities in domestic currency grew the most for emerging countries with low initial positions. A key difference between the two periods is that the pre-crisis period exhibited improving overall net international investment positions, while this is not the case after the global financial crisis, thereby limiting the adjustment in aggregate foreign currency exposures.

\section{Conclusion}

Our paper offers a number of contributions on the data front. Most notably, it incorporates actual information on the currency composition of external positions reported by national statistical authorities to the IMF and the ECB, as well as data from national sources. This, together with new access to more granular datasets, has reduced the general dependence on estimates and improved the precision of currency weights in cases where actual data are not available. In addition, our new approach refines the procedure for the currency of denomination of FDI by treating its equity and debt components separately. This is an important improvement in the light of the increasing relevance of FDI-related debt since the global financial crisis.

The focus of the paper is on the measurement of foreign currency exposures, the importance of its subcomponents, the variables that explain them and their long-term dynamics. In addition, we illustrate other applications of our data by discussing the construction of financial exchange rate indices and their use for computing valuation effects. Moreover, we also propose a new application of our data by reporting the currency profile and dynamics of a financial globalization indicator. We document three stylized facts based on the Lane and Milesi-Ferretti (2003) well-known IFI indicator. First, we show that euro-denominated holdings expanded rapidly between 1999 and 2007, but declined considerably after the global financial crisis. Second, we illustrate that US dollar positions declined briefly in 2008, but recovered afterwards and kept rising, resulting in a clear predominance over the euro. Third, we confirm the dominance of the US dollar is even more apparent when focusing on cross-border positions excluding the US and the Euro Area and even more so for emerging economies.

In terms of our study of foreign currency exposures, we report that its cross-country distribution has shifted significantly towards long positions between 1990 and 2017, which is in line with the evidence reported in Bénétrix et al. (2015) for the period ending in 2012. Our analysis shows that between 2012 to 2017 there was a slight shift towards longer positions.

Focusing on our latest data point, we find that the mean and median countries show long foreign currency positions in 2017. This is dominated by a long foreign currency mix, rather than overall net creditor positions. For advanced economies this is mainly driven by debt liabilities, while for emerging economies the key driver is equity liabilities.

By contrast, the documented shift towards foreign currency positions between the start and end of our sample was mainly driven by an improvement in net international investment positions and to a lesser extent due to the foreign currency mix itself. Larger net liability positions in domestic currency have been driven by larger equity liabilities, in particular for emerging economies.

Our analysis of pre- and post-crisis adjustments in currency exposures highlights that the former was marked by strong adjustments in foreign currency exposures towards longer $F X^{A G G}$ positions. However, the post-crisis period is characterized by persistence in currency exposures. In both periods equity liabilities in domestic currency grew the most for emerging countries 
with low initial positions. A key difference between the two periods is that the pre-crisis period exhibited an improvement in overall net international investment positions, while this is not the case after the global financial crisis, thereby limiting the adjustment in aggregate foreign currency exposures.

The empirical analysis on the determinants of currency exposures reveals that trade openness (driven by advanced economies) and output volatility are associated with longer positions in foreign currency, while exchange rate volatility (due to emerging economies) and EMU membership are associated with shorter aggregate positions in foreign currency. We also find among emerging economies that countries in recessions with depreciating currencies tend to exhibit capital gains on the net external position, thereby providing a hedge against domestic output fluctuations. 


\section{References}

Alfaro, L. And F. KAnCZuK (2019): "Debt redemption and reserve accumulation," IMF Economic Review, 67, 261-287.

Arslanalp, S. And T. Tsuda (2014): "Tracking global demand for emerging market sovereign debt," IMF Working Papers 14/39, International Monetary Fund.

Blanchard, O. And J. ACALin (2016): "What does measured FDI actually measure?" Policy brief 16-17, Peterson institute for International Economics.

Bénétrix, A. S., P. R. Lane, And J. C. Shambaugh (2015): "International currency exposures, valuation effects and the global financial crisis," Journal of International Economics, 96, 98-109.

Bénétrix, A. S. And M. Schmitz (2019): "Euro-US dollar exposures in cross-border banking,," The international role of the euro 2019, European Central Bank.

Chinn, M. D. And H. Iто (2006): "What matters for financial development? Capital controls, institutions, and interactions," Journal of Development Economics, 81, 163 - 192.

Coeurdacier, N. And P. Martin (2009): "The geography of asset trade and the euro: Insiders and outsiders," Journal of the Japanese and International Economies, 23, 90-113.

Damgaard, J., T. Elkjaer, and N. Johannesen (2019): "The rise of phantom investments," Finance and Development 12/13, International Monetary Fund.

Di Giovanni, J. and J. C. Shambaugh (2008): "The impact of foreign interest rates on the economy: The role of the exchange rate regime," Journal of International Economics, 74, $341-361$.

Eichengreen, B., R. Hausmann, And U. Panizza (2003): "The Pain of Original Sin," in Debt denomination and financial instability in emerging-market economies, ed. by B. Eichengreen, R. Hausmann, and U. Panizza, University of Chicago Press Economics Books.

Emter, L., M. Schmitz, And M. Tirpák (2019): "Cross-border banking in the EU since the crisis: What is driving the great retrenchment?" Review of World Economics (Weltwirtschaftliches Archiv), 155, 287-326.

Georgiadis, G. And A. Mehl (2016): "Financial globalisation and monetary policy effectiveness," Journal of International Economics, 103, 200-212.

Goldberg, L. S. And C. Tille (2008): "Vehicle currency use in international trade," Journal of International Economics, 76, 177-192.

Gopinath, G. And J. C. Stein (2018): "Banking, trade, and the making of a dominant currency," NBER Working Papers 24485, National Bureau of Economic Research, Inc.

Haussman, R. And U. Panizza (2011): "Redemption or abstinence? Original sin, currency mismatches and counter cyclical policies in the new millennium," Journal of Globalization and Development, 2, 1-35.

Ilzetzki, E., C. Reinhart, And K. Rogoff (2019): "Why is the euro punching below its weight?" mimeo.

International Monetary Fund (IMF) (2000): "The dynamics of external adjustment," Exernal sector report, Washington, DC. 
JEANne, O. (2007): "International reserves in emerging market countries: too much of a good thing?" Brookings Papers on Economic Activity, 38, 1-80.

LANE., P. R. (2015): "A financial perspective on the UK currenc account deficit," Tech. Rep. 234, National Institute Economic Review.

Lane, P. R. And G. M. Milesi-Ferretti (2001): "The external wealth of nations: measures of foreign assets and liabilities for industrial and developing countries," Journal of International Economics, 55, 263-294.

(2003): "International financial integration," IMF Staff Papers, 50, 82-113.

(2007): "The external wealth of nations mark II: Revised and extended estimates of foreign assets and liabilities, 1970-2004," Journal of International Economics, 73, 223-250.

(2008): "International investment patterns," The Review of Economics and Statistics, $90,538-549$.

(2009): "Where did all the borrowing go? A forensic analysis of the U.S. external position," Journal of the Japanese and International Economies, 23, 177-199.

(2014): "Global imbalances and external adjustment after the crisis," IMF Working Papers 14/151, International Monetary Fund.

(2018): "The External Wealth of Nations Revisited: International Financial Integration in the Aftermath of the Global Financial Crisis," IMF Economic Review, 66, 189-222.

Lane, P. R. And J. C. Shambaugh (2010a): "Financial exchange rates and international currency exposures," American Economic Review, 100, 518-540.

(2010b): "The long or short of it: determinants of foreign currency exposure in external balance sheets," Journal of International Economics, 80, 33 - 44, special Issue: JIE Special Issue on International Macro-Finance.

Maggiori, M., B. Neiman, And J. Schreger (2019a): "International currencies and capital allocation," Journal of Political Economy, forthcoming.

- (2019b): "The rise of the dollar and fall of the euro as international currencies," $A E A$ Papers and Proceedings, 109, 521-26.

McCauley, R. N., A. S. Bénétrix, P. M. McGuire, and G. von Peter (2019): "Financial deglobalisation in banking?" Journal of International Money and Finance, 94, 116-131.

McQuade, P. And M. Schmitz (2017): "The great moderation in international capital flows: A global phenomenon?" Journal of International Money and Finance, 73, 188-212.

Milesi-Ferretti, G. And C. Tille (2011): "The great retrenchment: international capital flows during the global financial crisis," Economic Policy, 26, 285-342.

Obstfeld, M. And K. Rogoff (2001): "The six major puzzles in international macroeconomics: is there a common cause?" in NBER Macroeconomics Annual 2000, Volume 15, National Bureau of Economic Research, Inc, NBER Chapters, 339-412.

Obstfeld, M., J. C. Shambaugh, and A. M. Taylor (2010): "Financial stability, the trilemma, and international reserves," American Economic Journal: Macroeconomics, 2, $57-94$. 
Shambaugh, J. C. (2004): "The effect of fixed exchange rates on monetary policy," The Quarterly Journal of Economics, 119, 301-352.

TILle, C. (2003): "The impact of exchange rate movements on U.S. foreign debt," Current Issues in Economics and Finance, 9. 
Figure 1: Financial and Trade weighted exchange rates


Notes: This figure shows a comparison between financial and trade weighted exchange rate indices for the USA, Colombia and Germany. The Financial Exchange Rate Index is calculated using weights of US dollar, euro, Pound sterling, Japanese yen and domestic currency as described in this working paper. These weights are then applied to changes in bilateral exchange rates in these currencies for each country, keeping 1990 as base year.

Figure 2: Valuation Effects: Comparison of VALXR for Germany

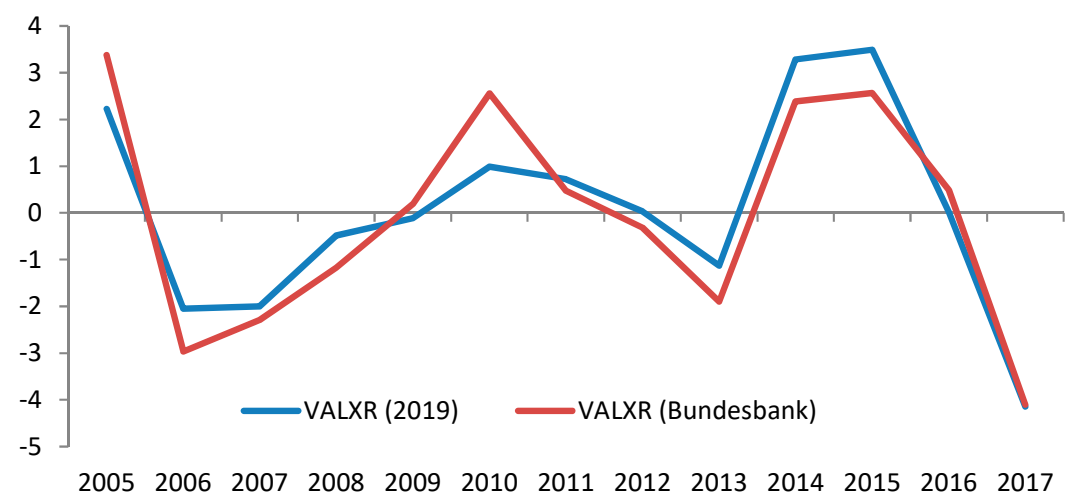

Notes: This figure compares our measure of valuation effects (VALXR) for Germany with the one sourced from the Deutsche Bundesbank. 
Figure 3: International Financial Integration: All Countries



Notes: This figure shows the measure of international financial integration for all countries.

Figure 4: International Financial Integration: Advanced Economies

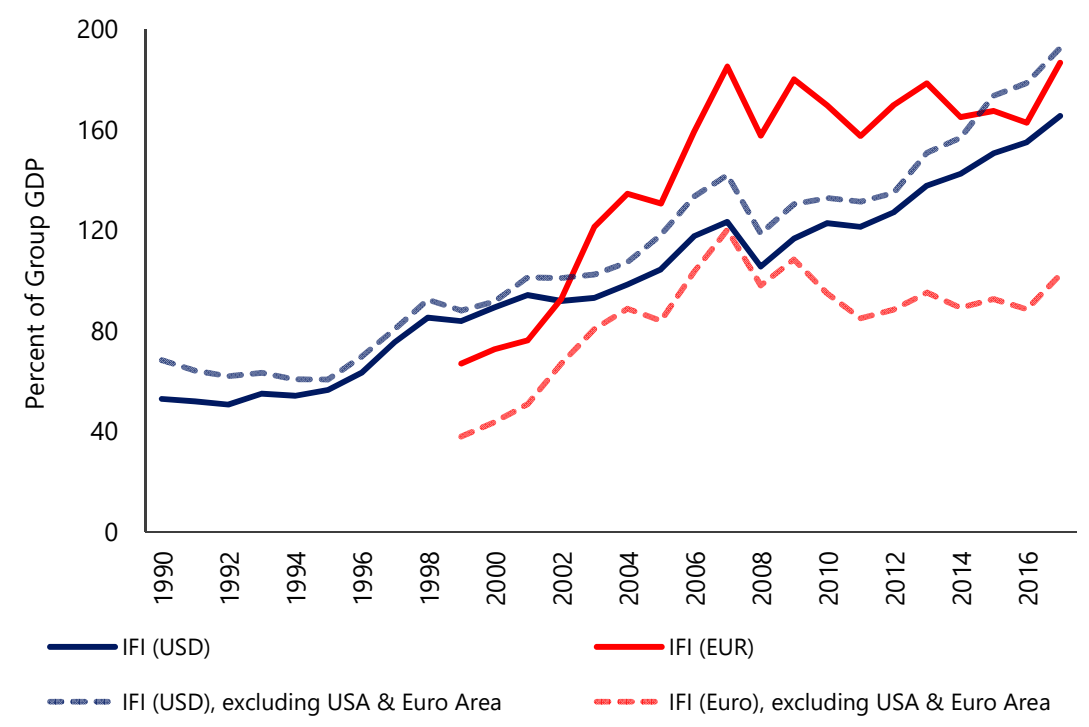

Notes: This figure shows the measure of international financial integration for advanced economies. 
Figure 5: International Financial Integration: Emerging and Developing Economies

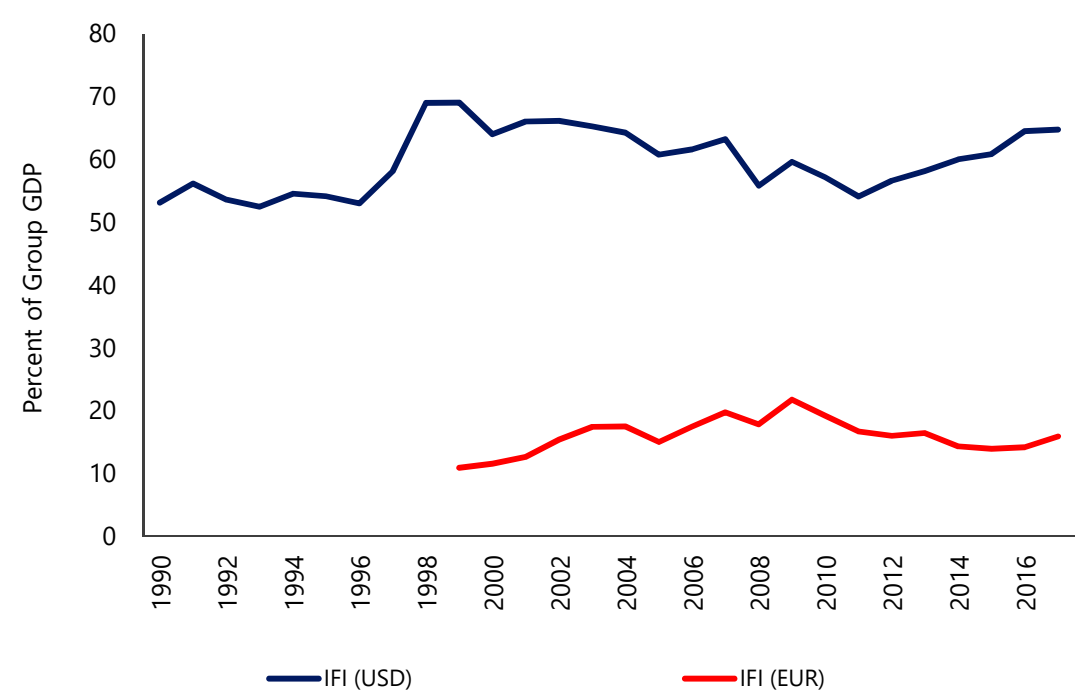

Notes: This figure shows the measure of international financial integration for emerging and developing economies. 
Figure 6: $F X^{A G G}$ long-term dynamics: 1990 vs 2017

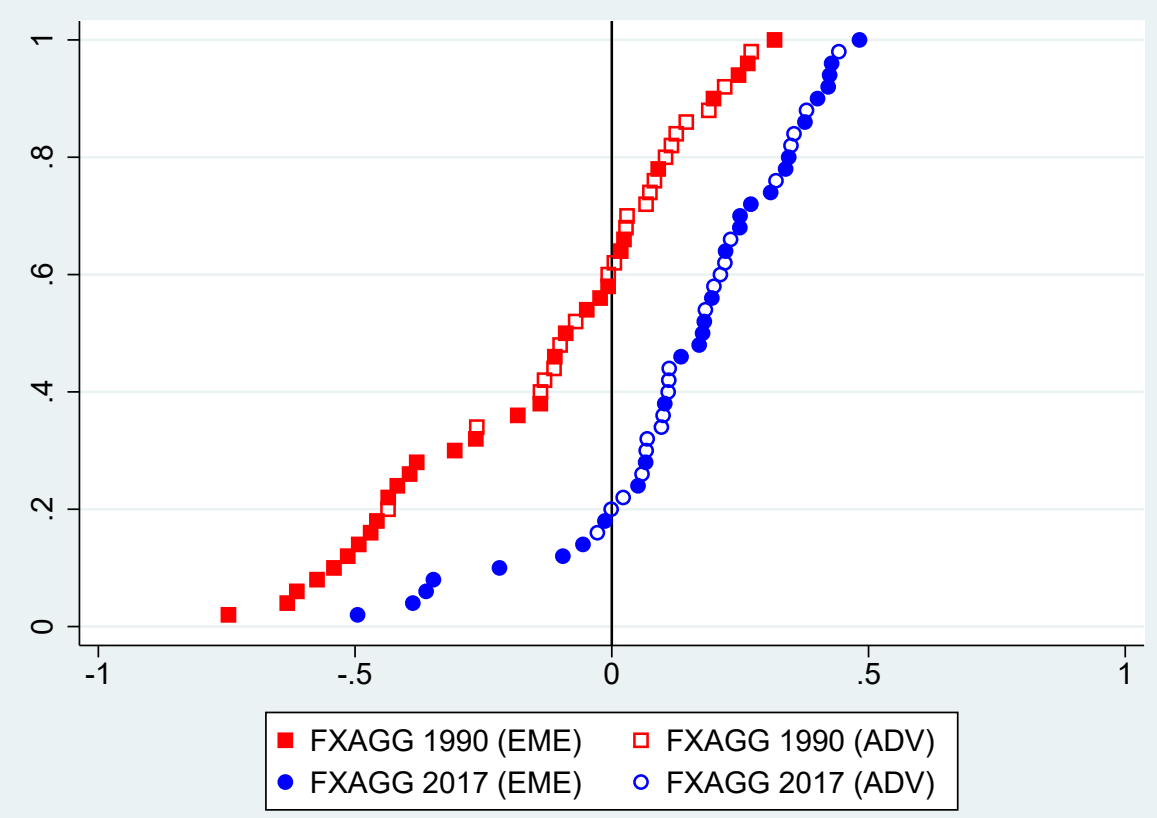

Notes: Cumulative distribution for net aggregate foreign-currency exposures defined as $F X_{i, t}^{A G G}=\omega_{A i, t}^{F} s_{i, t}^{A}-\omega_{L i, t}^{F} s_{i, t}^{L}$, where $s_{i, t}^{A}\left(s_{i, t}^{L}\right)$ is the share of total assets (liabilities) in the sum of total assets plus liabilities. $\omega_{A i, t}^{F}$ and $\omega_{L i, t}^{F}$ are the proportions of total assets and liabilities denominated in foreign currency, respectively. $F X_{i, t}^{A G G}$ is measured on the horizontal axis and ranges between -1 and 1 . The vertical axis measures the cumulative distribution, or the proportion of countries, below each $F X^{A G G}$ value in the horizontal axis. We include 50 countries. For Russia and Czech Republic, we use $F X_{i, t}^{A G G}$ for 1993. 
Figure 7: Long-term dynamics: $F X^{A G G}$ decomposition

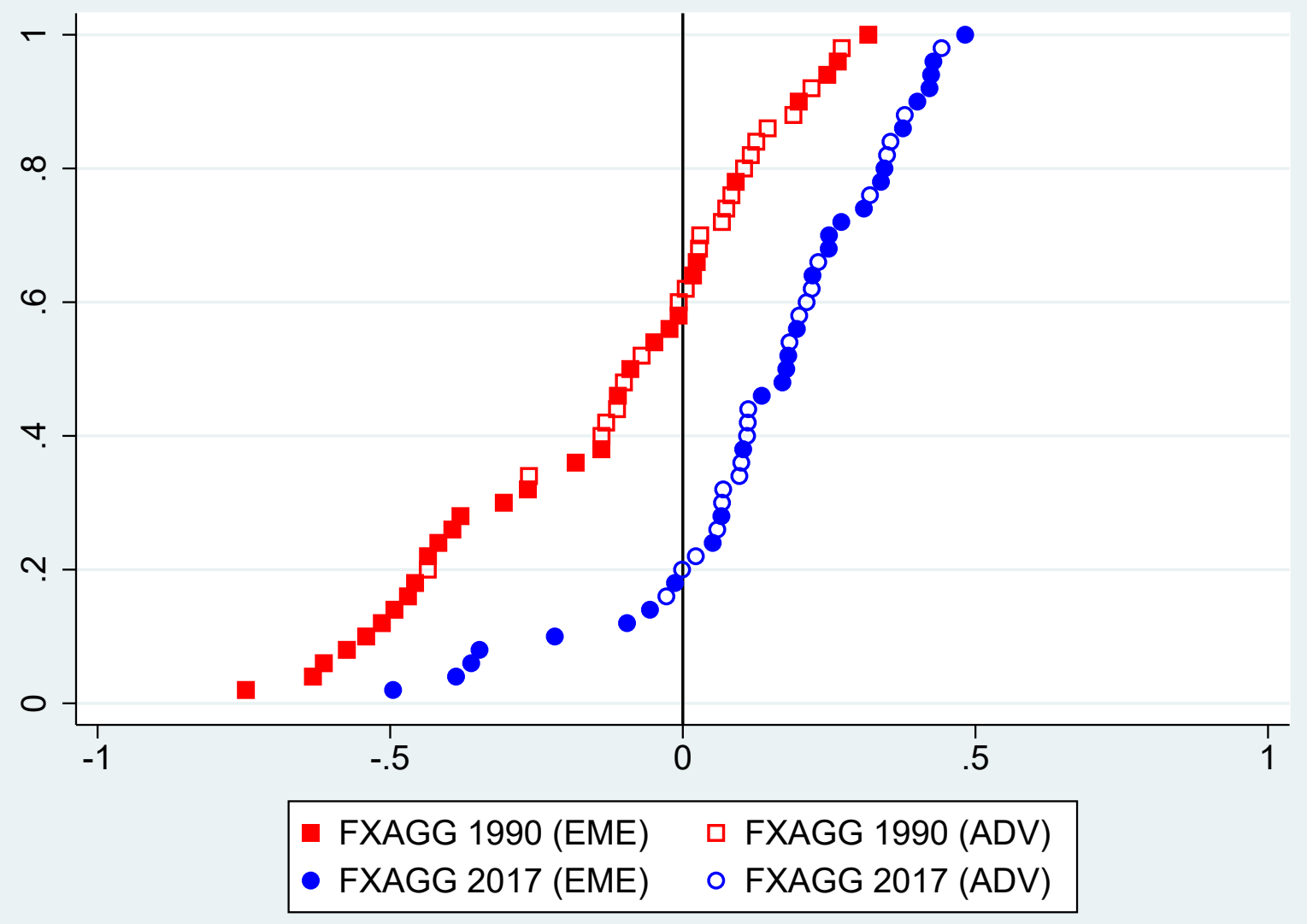

$(A-L) /(A+L)$

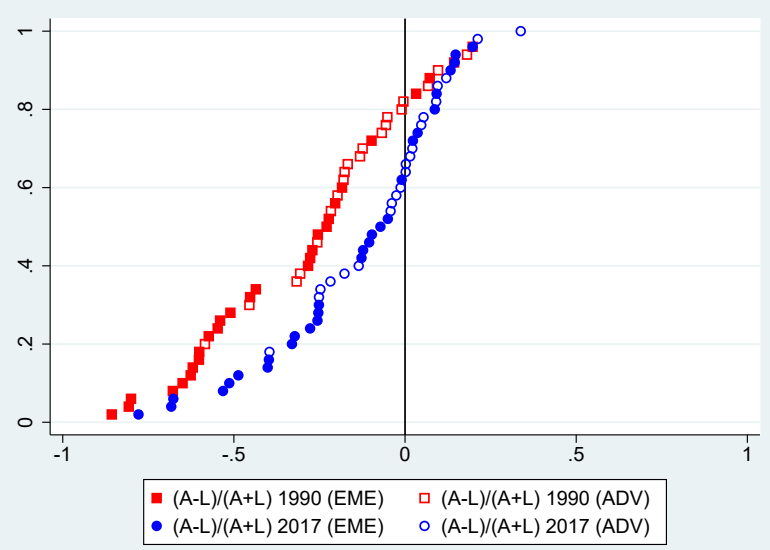

$F X_{O}^{A G G}$



Notes: $F X^{A G G}=\frac{(A-L)}{(A+L)}+F X_{o}^{A G G}$ as defined in main text. 
Figure 8: Long-term dynamics: $(A-L) /(A+L)$ decomposition
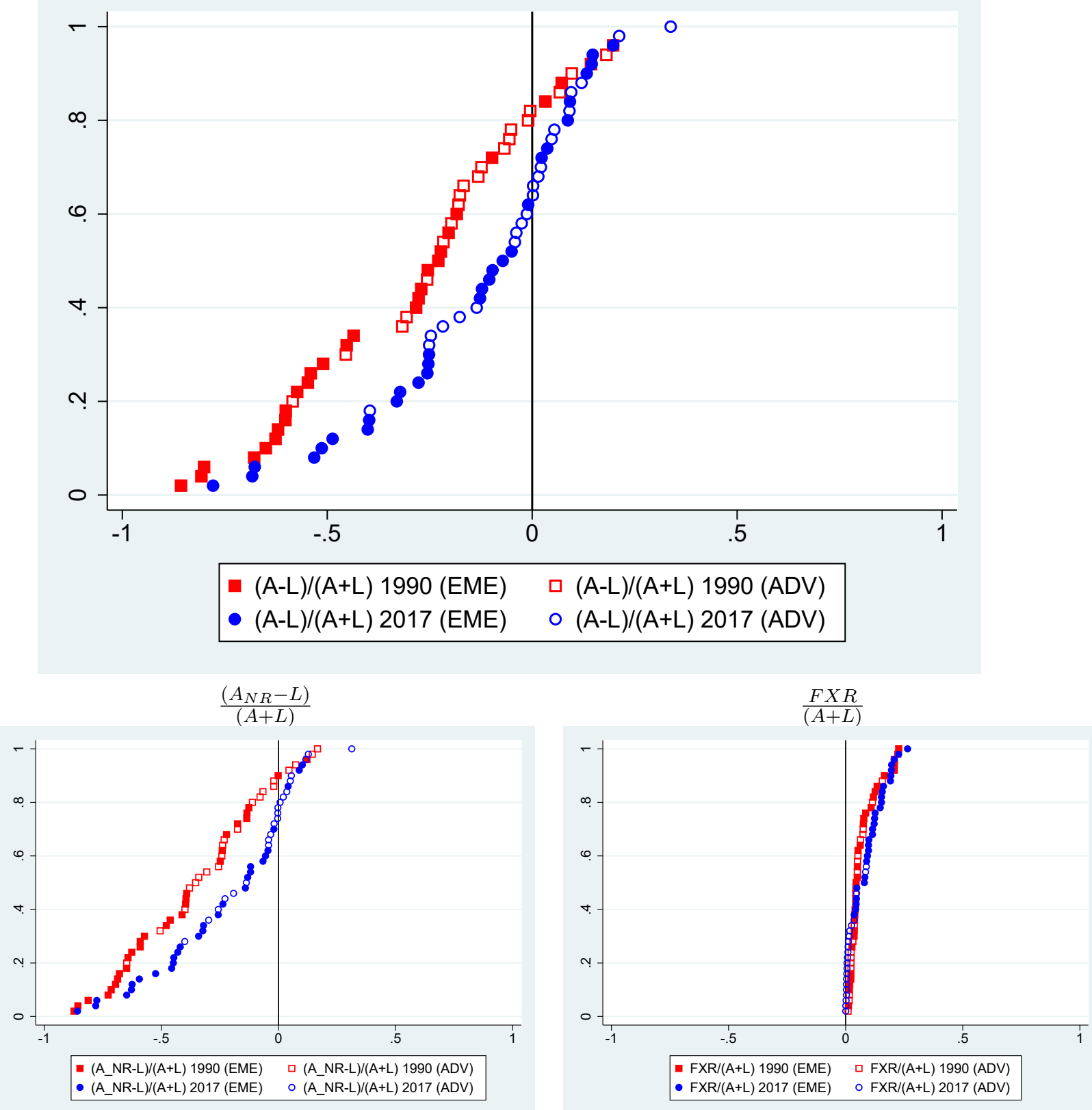

Notes: $\frac{(A-L)}{(A+L)}=\frac{\left(A_{N R}-L\right)}{(A+L)}+\frac{F X R}{(A+L)}$ as defined in main text. 
Figure 9: Long-term dynamics: $F X_{o}^{A G G}$ decomposition
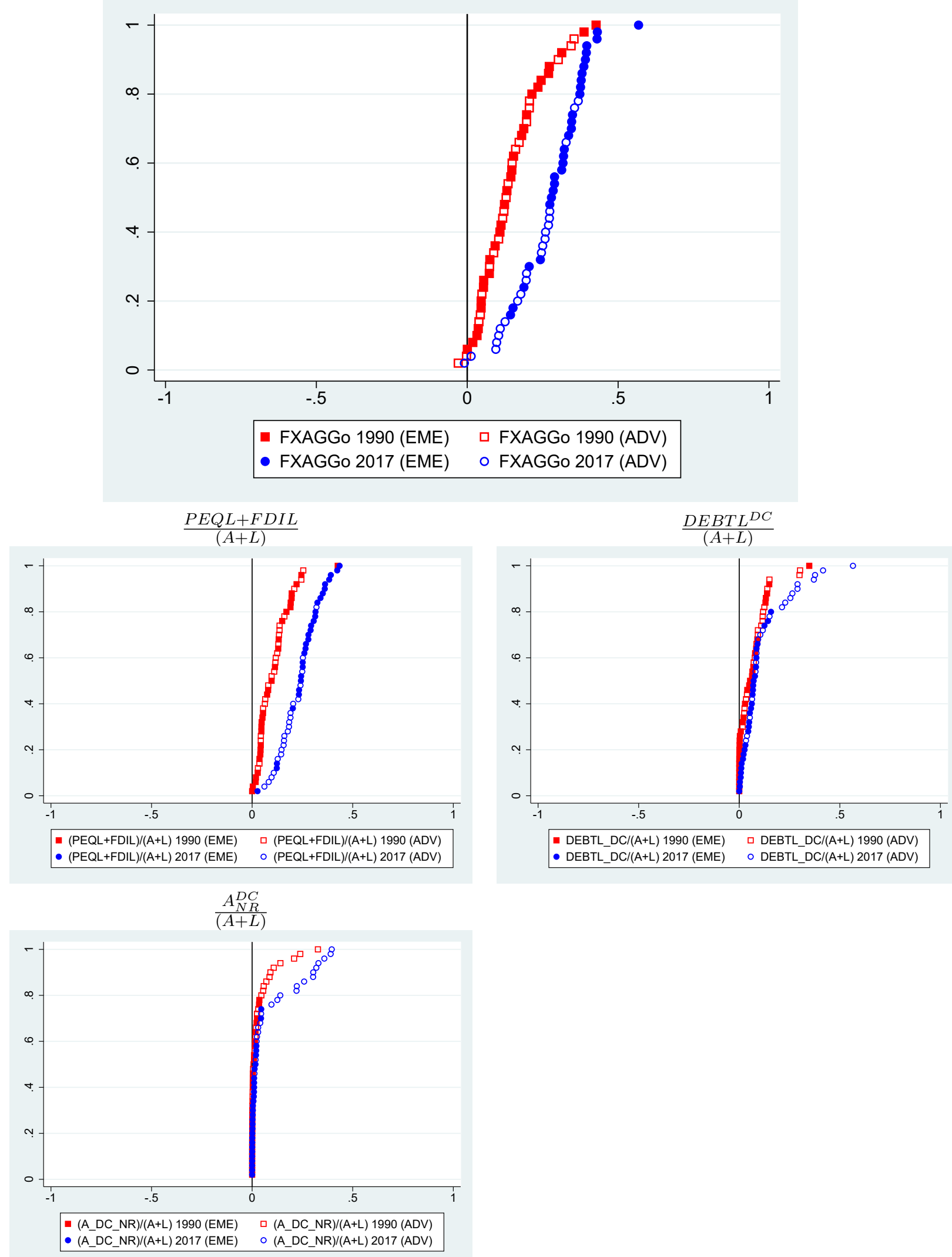

Notes: $F X_{o}^{A G G}=\frac{P E Q L+F D I L}{(A+L)}+\frac{D E B T L^{D C}}{(A+L)}-\frac{A_{N R}^{D C}}{(A+L)}$ as defined in main text. 
Figure 10: $F X^{A G G}$ long-term dynamics: 1997, 2007, 2012, 2017

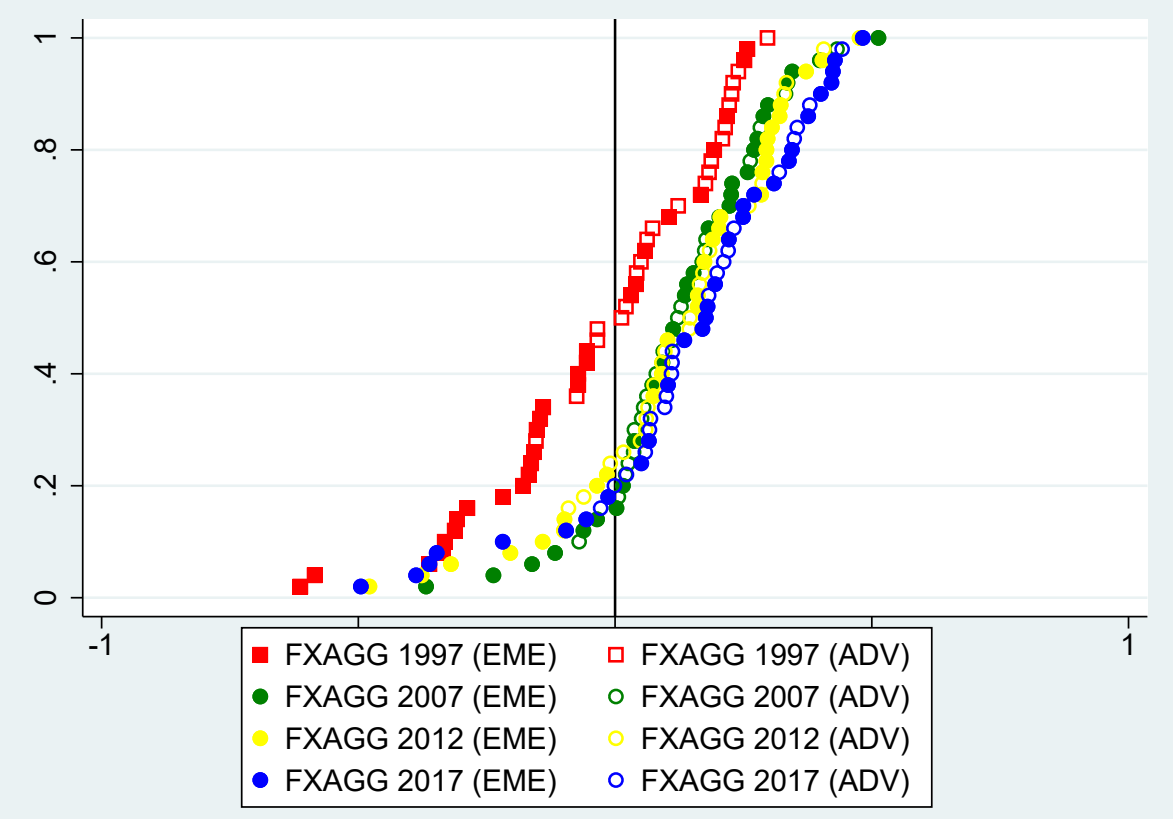

Notes: Cumulative distribution for net aggregate foreign-currency exposures defined as $F X_{i, t}^{A G G}=\omega_{A i, t}^{F} s_{i, t}^{A}-\omega_{L i, t}^{F} s_{i, t}^{L}$, where $s_{i, t}^{A}\left(s_{i, t}^{L}\right)$ is the share of total assets (liabilities) in the sum of total assets plus liabilities. $\omega_{A i, t}^{F}$ and $\omega_{L i, t}^{F}$ are the proportions of total assets and liabilities denominated in foreign currency, respectively. $F X_{i, t}^{A G G}$ is measured on the horizontal axis and ranges between -1 and 1 . The vertical axis measures the cumulative distribution, or the proportion of countries, below each $F X^{A G G}$ value in the horizontal axis. We include 50 countries. For Russia and Czech Republic, we use $F X_{i, t}^{A G G}$ for 1993. 
Figure 11: $F X^{A G G}$ dynamics pre- and post-crisis
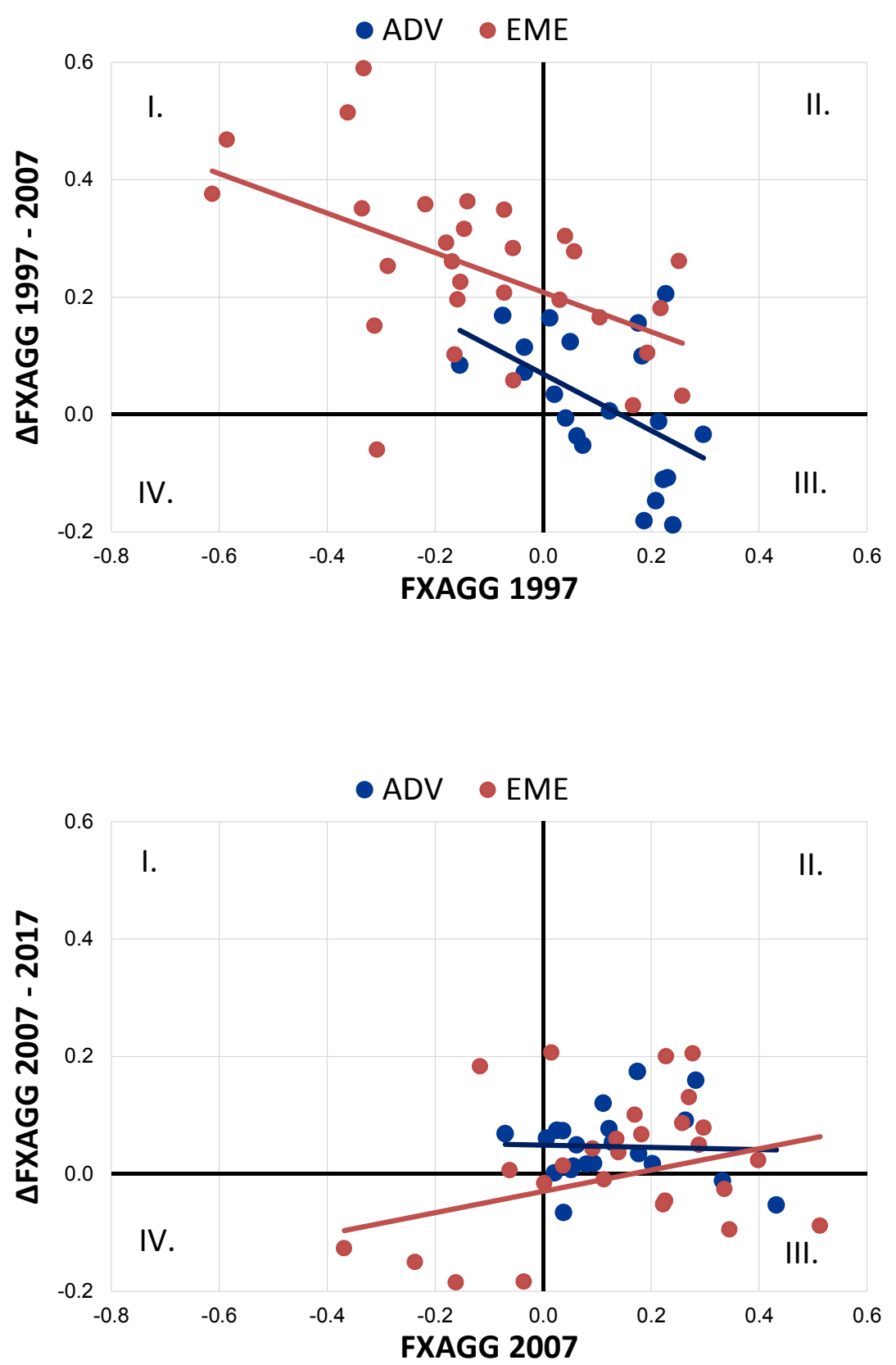

Notes: Net aggregate foreign-currency exposures defined as $F X_{i t}^{A G G}=\omega_{A i, t}^{F} s_{i, t}^{A}-\omega_{L i, t}^{F} s_{i, t}^{L}$, where $s_{i, t}^{A}\left(s_{i, t}^{L}\right)$ is the share of total assets (liabilities) in the sum of total assets plus liabilities. $\omega_{A i, t}^{F}$ and $\omega_{L i, t}^{F}$ are the proportions of total assets and liabilities denominated in foreign currency, respectively. $F X_{i, t}^{A G G}$ on the horizontal axis refers to 1997 (top panel) and 2007 (bottom panel). The vertical axis shows the change in $F X_{i, t}^{A G G}$ between 1997 and 2007 (top panel) and 2007 to 2017 (bottom panel). 
Table 1: Correlations of Exchange Rate Indices, 1990-2017

\begin{tabular}{llcccc}
\hline \hline & & $(A, L)$ & $(A, T)$ & $(L, T)$ & $(I, T)$ \\
\hline \multirow{2}{*}{ All Countries } & Mean & 0.854 & 0.453 & 0.398 & 0.107 \\
\multirow{3}{*}{ Advanced } & Median & 0.927 & 0.458 & 0.365 & 0.201 \\
\multirow{3}{*}{ Emerging and Developing } & Mean & 0.953 & 0.479 & 0.446 & 0.162 \\
& Median & 0.955 & 0.462 & 0.414 & 0.279 \\
& Mean & 0.750 & 0.426 & 0.346 & 0.046 \\
& Median & 0.778 & 0.448 & 0.354 & 0.109 \\
\hline \hline
\end{tabular}

Notes: The table shows the the means and medians of within-country correlations between the percentage change in exchange rate indices. Sample includes annual data over the period 1990-2017. $A$ and $L$, refer to asset and liability weighted indices, $T$ denotes trade-weighted index and $I$ is the financial exchange rate index. 
Table 2: Foreign Currency Exposure $\left(F X^{A G G}\right)$ and Subcomponents

\begin{tabular}{lcccc}
\hline \hline Variable & Mean & Median & $\mathrm{p} 25$ & $\mathrm{p} 75$ \\
\hline & All countries & & & \\
\hline$F X^{A G G}$ & 0.14 & 0.18 & 0.06 & 0.32 \\
$(A-L) /(A+L)$ & -0.13 & -0.06 & -0.26 & 0.05 \\
$F X_{o}^{A G G}$ & 0.27 & 0.28 & 0.20 & 0.36 \\
$\left(A_{N R}-L\right) /(A+L)$ & -0.21 & -0.13 & -0.42 & 0.00 \\
$F X R /(A+L)$ & 0.08 & 0.08 & 0.01 & 0.13 \\
$(P E Q L+F D I L) /(A+L)$ & 0.24 & 0.24 & 0.16 & 0.31 \\
$D E B T L^{D C} /(A+L)$ & 0.12 & 0.07 & 0.04 & 0.14 \\
$A_{N R}^{D C} /(A+L)$ & 0.08 & 0.02 & 0.00 & 0.10 \\
\hline \multicolumn{5}{c}{ Advanced } \\
$F X^{A G G}$ & 0.17 & 0.11 & 0.07 & 0.23 \\
$(A-L) /(A+L)$ & -0.03 & 0.00 & -0.14 & 0.05 \\
$F X_{o}^{A G G}$ & 0.20 & 0.20 & 0.11 & 0.27 \\
$\left(A_{N R}-L\right) /(A+L)$ & -0.04 & 0.00 & -0.14 & 0.04 \\
$F X R /(A+L)$ & 0.02 & 0.01 & 0.00 & 0.02 \\
$(P E Q L+F D I L) /(A+L)$ & 0.17 & 0.18 & 0.14 & 0.20 \\
$D E B T L^{D C} /(A+L)$ & 0.20 & 0.15 & 0.08 & 0.29 \\
$A_{N R}^{D C} /(A+L)$ & 0.18 & 0.14 & 0.03 & 0.30 \\
\hline & Emerging and Developing & & \\
\hline$F X^{A G G}$ & 0.12 & 0.18 & -0.01 & 0.34 \\
$(A-L) /(A+L)$ & -0.20 & -0.13 & -0.40 & 0.02 \\
$F X_{o}^{A G G}$ & 0.33 & 0.34 & 0.28 & 0.38 \\
$\left(A_{N R}-L\right) /(A+L)$ & -0.33 & -0.32 & -0.52 & -0.12 \\
$F X R /(A+L)$ & 0.13 & 0.12 & 0.09 & 0.16 \\
$(P E Q L+F D I L) /(A+L)$ & 0.28 & 0.28 & 0.24 & 0.34 \\
$D E B T L^{D C} /(A+L)$ & 0.05 & 0.05 & 0.02 & 0.08 \\
$A_{N R}^{D C} /(A+L)$ & 0.01 & 0.00 & 0.00 & 0.01 \\
\hline \hline
\end{tabular}

Notes: The table shows the mean, median, and the interquartile range of the foreign currency exposure indicator $\left(F X^{A G G}\right)$ and its main subcomponents for 2017. 
Table 3: $F X^{A G G}$ decomposition, correlations 1990-2017

\begin{tabular}{|c|c|c|c|c|c|c|c|c|c|c|c|c|c|c|c|c|}
\hline & & & \multicolumn{2}{|c|}{$F X^{A G G}$} & \multicolumn{2}{|c|}{$\frac{(A-L)}{(A+L)}$} & \multicolumn{2}{|c|}{$F X_{o}^{A G G}$} & \multicolumn{2}{|c|}{$\frac{\left(A_{N R}-L\right)}{(A+L)}$} & \multicolumn{2}{|c|}{$\frac{F X R}{(A+L)}$} & \multicolumn{2}{|c|}{$\frac{(P E Q L+F D I L)}{(A+L)}$} & \multicolumn{2}{|c|}{$\frac{D E B T L^{D C}}{(A+L)}$} \\
\hline \multicolumn{17}{|c|}{ All countries } \\
\hline \multirow{2}{*}{$\frac{(A-L)}{(A+L)}$} & mean & median & 0.67 & 0.83 & & & & & & & & & & & & \\
\hline & p25th & p75th & 0.50 & 0.95 & & & & & & & & & & & & \\
\hline \multirow{2}{*}{$F X_{o}^{A G G}$} & mean & median & 0.56 & 0.77 & -0.03 & 0.05 & & & & & & & & & & \\
\hline & p25th & p75th & 0.38 & 0.90 & -0.59 & 0.44 & & & & & & & & & & \\
\hline \multirow{2}{*}{$\frac{\left(A_{N R}-L\right)}{(A+L)}$} & mean & median & 0.55 & 0.70 & 0.90 & 0.97 & -0.09 & -0.08 & & & & & & & & \\
\hline & $\mathrm{p} 25$ th & p75th & 0.24 & 0.93 & 0.92 & 0.99 & -0.58 & 0.31 & & & & & & & & \\
\hline \multirow{2}{*}{$\frac{F X R}{(A+L)}$} & mean & median & 0.30 & 0.58 & 0.25 & 0.44 & 0.23 & 0.39 & -0.02 & -0.01 & & & & & & \\
\hline & $\mathrm{p} 25 \mathrm{th}$ & p75th & -0.31 & 0.85 & -0.31 & 0.78 & -0.17 & 0.66 & -0.52 & 0.49 & & & & & & \\
\hline \multirow{2}{*}{$\frac{(P E Q L+F D I L)}{(A+L)}$} & mean & median & 0.51 & 0.73 & 0.15 & 0.25 & 0.76 & 0.97 & 0.05 & 0.04 & 0.18 & 0.42 & & & & \\
\hline & p25th & p75th & 0.07 & 0.88 & -0.32 & 0.51 & 0.77 & 0.99 & -0.43 & 0.50 & -0.30 & 0.64 & & & & \\
\hline \multirow{2}{*}{$\frac{D E B T L^{D C}}{(A+L)}$} & mean & median & -0.04 & -0.02 & -0.11 & -0.07 & 0.16 & 0.18 & 0.00 & 0.03 & -0.17 & -0.13 & -0.04 & -0.06 & & \\
\hline & p25th & p75th & -0.64 & 0.53 & -0.63 & 0.34 & -0.25 & 0.74 & -0.34 & 0.38 & -0.79 & 0.25 & -0.56 & 0.46 & & \\
\hline \multirow{2}{*}{$\frac{A_{N R}^{D C}}{(A+L)}$} & mean & median & -0.02 & 0.08 & 0.09 & 0.06 & -0.08 & -0.08 & 0.23 & 0.35 & -0.33 & -0.42 & 0.01 & 0.14 & 0.36 & 0.50 \\
\hline & $\mathrm{p} 25$ th & p75th & -0.62 & 0.43 & -0.29 & 0.54 & -0.61 & 0.48 & -0.19 & 0.64 & -0.83 & 0.08 & -0.53 & 0.54 & -0.01 & 0.83 \\
\hline \multicolumn{17}{|c|}{ Advanced } \\
\hline \multirow{2}{*}{$\frac{(A-L)}{(A+L)}$} & mean & median & 0.47 & 0.68 & & & & & & & & & & & & \\
\hline & p25th & p75th & 0.08 & 0.92 & & & & & & & & & & & & \\
\hline \multirow{2}{*}{$F X_{o}^{A G G}$} & mean & median & 0.51 & 0.70 & -0.31 & -0.55 & & & & & & & & & & \\
\hline & $\mathrm{p} 25$ th & p75th & 0.34 & 0.86 & -0.75 & -0.06 & & & & & & & & & & \\
\hline & mean & median & 0.39 & 0.49 & 0.90 & 0.98 & -0.30 & -0.46 & & & & & & & & \\
\hline$\frac{\left(A_{N R}-L\right)}{(A+L)}$ & p25th & p75th & 0.12 & 0.92 & 0.92 & 1.00 & -0.58 & -0.09 & & & & & & & & \\
\hline & mean & median & -0.05 & -0.26 & -0.11 & -0.30 & 0.07 & 0.09 & -0.37 & -0.48 & & & & & & \\
\hline$\frac{F \times R}{(A+L)}$ & p25th & p75th & -0.45 & 0.58 & -0.67 & 0.43 & -0.36 & 0.64 & -0.79 & 0.05 & & & & & & \\
\hline & mean & median & 0.33 & 0.58 & 0.04 & 0.19 & 0.48 & 0.76 & -0.02 & -0.10 & -0.09 & -0.28 & & & & \\
\hline$\frac{(P E Q L+F D I L)}{(A+L)}$ & p25th & p75th & -0.05 & 0.77 & -0.47 & 0.42 & 0.18 & 0.93 & -0.43 & 0.36 & -0.64 & 0.57 & & & & \\
\hline & mean & median & -0.10 & -0.02 & -0.13 & -0.16 & 0.06 & 0.13 & 0.04 & 0.05 & -0.36 & -0.60 & -0.19 & -0.27 & & \\
\hline$\frac{D E B T L}{(A+L)}$ & $\mathrm{p} 25$ th & p75th & -0.70 & 0.52 & -0.55 & 0.34 & -0.35 & 0.55 & -0.30 & 0.38 & -0.85 & 0.14 & -0.61 & 0.07 & & \\
\hline & mean & median & -0.10 & -0.14 & 0.21 & 0.36 & -0.30 & -0.44 & 0.41 & 0.49 & -0.60 & -0.83 & -0.11 & -0.30 & 0.59 & 0.83 \\
\hline$\frac{A_{N R}^{N R}}{(A+L)}$ & p25th & p75th & -0.73 & 0.48 & -0.40 & 0.82 & -0.90 & -0.08 & 0.21 & 0.85 & -0.91 & -0.50 & -0.66 & 0.50 & 0.58 & 0.95 \\
\hline & & & & & & & ging an & Develop & & & & & & & & \\
\hline & mean & median & 0.81 & 0.90 & & & & & & & & & & & & \\
\hline$\frac{(A-L)}{(A+L)}$ & p25th & p75th & 0.75 & 0.96 & & & & & & & & & & & & \\
\hline & mean & median & 0.60 & 0.80 & 0.17 & 0.22 & & & & & & & & & & \\
\hline$F X_{o}^{A G G}$ & p25th & p75th & 0.45 & 0.90 & -0.04 & 0.49 & & & & & & & & & & \\
\hline & mean & median & 0.67 & 0.83 & 0.90 & 0.96 & 0.06 & 0.09 & & & & & & & & \\
\hline$\frac{\left(A_{N R-L)}\right.}{(A+L)}$ & p25th & p75th & 0.62 & 0.93 & 0.91 & 0.98 & -0.49 & 0.55 & & & & & & & & \\
\hline & mean & median & 0.55 & 0.72 & 0.51 & 0.66 & 0.35 & 0.47 & 0.23 & 0.37 & & & & & & \\
\hline$\frac{F A R}{(A+L)}$ & $\mathrm{p} 25 \mathrm{th}$ & p75th & 0.51 & 0.90 & 0.39 & 0.87 & -0.05 & 0.67 & -0.29 & 0.73 & & & & & & \\
\hline & mean & median & 0.63 & 0.81 & 0.22 & 0.26 & 0.96 & 0.99 & 0.09 & 0.06 & 0.38 & 0.51 & & & & \\
\hline$\frac{(P E Q L+F D I L)}{(A+L)}$ & $\mathrm{p} 25$ th & p75th & 0.53 & 0.91 & 0.07 & 0.63 & 0.97 & 1.00 & -0.26 & 0.58 & 0.23 & 0.69 & & & & \\
\hline & mean & median & 0.00 & -0.01 & -0.11 & -0.03 & 0.22 & 0.31 & -0.03 & 0.01 & -0.04 & -0.02 & 0.07 & 0.22 & & \\
\hline$\frac{D E B T L L}{(A+L)}$ & p25th & p75th & -0.63 & 0.61 & -0.63 & 0.27 & -0.09 & 0.76 & -0.53 & 0.35 & -0.59 & 0.46 & -0.47 & 0.65 & & \\
\hline & mean & median & 0.05 & 0.17 & 0.00 & -0.12 & 0.09 & 0.31 & 0.10 & 0.08 & -0.13 & -0.11 & 0.11 & 0.28 & 0.18 & 0.27 \\
\hline$\frac{A_{N R}^{L C K}}{(A+L)}$ & p25th & p75th & -0.46 & 0.42 & -0.28 & 0.34 & -0.46 & 0.57 & -0.28 & 0.50 & -0.50 & 0.26 & -0.41 & 0.57 & -0.23 & 0.53 \\
\hline
\end{tabular}

Notes: This table presents the mean, median, 25th and 75th percentile of the cross-country correlation coefficient between $F X^{A G G}$ and its sub-components. Correlation coefficients are computed based on the full time span in our data set: 1990-2017. 
Table 4: $F X^{A G G}$ determinants. All countries

\begin{tabular}{|c|c|c|c|c|c|c|c|c|}
\hline & $\begin{array}{c}F X^{A G G} \\
(1)\end{array}$ & $\begin{array}{c}\frac{(A-L)}{(A+L)} \\
(2)\end{array}$ & $\begin{array}{c}F X_{o}^{A G G} \\
(3)\end{array}$ & $\begin{array}{c}\frac{\left(A_{N R}-L\right)}{(A+L)} \\
(4)\end{array}$ & $\begin{array}{c}\frac{F X R}{(A+L)} \\
(5)\end{array}$ & $\begin{array}{c}\frac{(P E Q L+F D I L)}{(A+L)} \\
(6)\end{array}$ & $\begin{array}{c}\frac{D E B T L^{D C}}{(A+L)} \\
(7)\end{array}$ & $\begin{array}{c}\frac{A_{N R}^{D C}}{(A+L)} \\
(8)\end{array}$ \\
\hline Trade & $0.07^{* * *}$ & $0.07^{* * *}$ & 0.00 & $0.06^{* * *}$ & 0.00 & 0.01 & $-0.02^{* * *}$ & $-0.01^{* *}$ \\
\hline & $(0.02)$ & $(0.02)$ & $(0.01)$ & $(0.02)$ & $(0.01)$ & $(0.01)$ & $(0.01)$ & $(0.00)$ \\
\hline $\operatorname{vol}(G D P)$ & $\begin{array}{c}0.33^{* *} \\
(0.15)\end{array}$ & $\begin{array}{c}0.26 \\
(0.18)\end{array}$ & $\begin{array}{c}0.07 \\
(0.09)\end{array}$ & $\begin{array}{c}0.14 \\
(0.20)\end{array}$ & $\begin{array}{l}0.12 \\
(0.07)\end{array}$ & $\begin{array}{l}-0.03 \\
(0.08)\end{array}$ & $\begin{array}{l}-0.01 \\
(0.07)\end{array}$ & $\begin{array}{c}-0.11^{* * *} \\
(0.04)\end{array}$ \\
\hline $\operatorname{vol}(\pi)$ & $\begin{array}{c}0.01 \\
(0.01)\end{array}$ & $\begin{array}{c}0.00 \\
(0.01)\end{array}$ & $\begin{array}{c}0.01 \\
(0.00)\end{array}$ & $\begin{array}{l}-0.01 \\
(0.01)\end{array}$ & $\begin{array}{l}0.01^{*} \\
(0.00)\end{array}$ & $\begin{array}{c}0.01 \\
(0.00)\end{array}$ & $\begin{array}{l}-0.00 \\
(0.00)\end{array}$ & $\begin{array}{c}-0.00 \\
(0.00)\end{array}$ \\
\hline $\operatorname{vol}(I)$ & $\begin{array}{c}-0.08^{* *} \\
(0.04)\end{array}$ & $\begin{array}{l}-0.03 \\
(0.06)\end{array}$ & $\begin{array}{l}-0.06 \\
(0.04)\end{array}$ & $\begin{array}{l}-0.00 \\
(0.06)\end{array}$ & $\begin{array}{l}-0.03 \\
(0.02)\end{array}$ & $\begin{array}{l}-0.05 \\
(0.04)\end{array}$ & $\begin{array}{c}-0.02^{*} \\
(0.01)\end{array}$ & $\begin{array}{c}-0.01^{* *} \\
(0.01)\end{array}$ \\
\hline $\operatorname{corr}(G D P, I)$ & $\begin{array}{l}0.05^{*} \\
(0.03)\end{array}$ & $\begin{array}{l}0.07^{* *} \\
(0.03)\end{array}$ & $\begin{array}{l}-0.02 \\
(0.02)\end{array}$ & $\begin{array}{l}0.06^{* *} \\
(0.03)\end{array}$ & $\begin{array}{c}0.01 \\
(0.01)\end{array}$ & $\begin{array}{c}0.00 \\
(0.02)\end{array}$ & $\begin{array}{l}-0.01 \\
(0.02)\end{array}$ & $\begin{array}{l}0.01^{*} \\
(0.01)\end{array}$ \\
\hline KA open & $\begin{array}{c}0.00 \\
(0.02)\end{array}$ & $\begin{array}{c}0.02 \\
(0.02)\end{array}$ & $\begin{array}{c}-0.02^{* * *} \\
(0.01)\end{array}$ & $\begin{array}{c}0.03^{* *} \\
(0.02)\end{array}$ & $\begin{array}{l}-0.01^{*} \\
(0.01)\end{array}$ & $\begin{array}{c}-0.03 * * * \\
(0.01)\end{array}$ & $\begin{array}{c}0.01^{* * *} \\
(0.00)\end{array}$ & $\begin{array}{l}0.01^{* *} \\
(0.00)\end{array}$ \\
\hline Peg & $\begin{array}{c}0.02 \\
(0.03)\end{array}$ & $\begin{array}{c}0.05 \\
(0.03)\end{array}$ & $\begin{array}{l}-0.03 \\
(0.02)\end{array}$ & $\begin{array}{c}0.03 \\
(0.03)\end{array}$ & $\begin{array}{l}0.02^{* *} \\
(0.01)\end{array}$ & $\begin{array}{l}-0.03^{*} \\
(0.02)\end{array}$ & $\begin{array}{c}0.00 \\
(0.01)\end{array}$ & $\begin{array}{l}-0.00 \\
(0.01)\end{array}$ \\
\hline EMU & $\begin{array}{c}-0.20^{* * *} \\
(0.03)\end{array}$ & $\begin{array}{c}-0.12^{* * *} \\
(0.04)\end{array}$ & $\begin{array}{c}-0.09 * * * \\
(0.03)\end{array}$ & $\begin{array}{l}-0.05 \\
(0.03)\end{array}$ & $\begin{array}{c}-0.07^{* * *} \\
(0.01)\end{array}$ & $\begin{array}{c}-0.05^{* *} \\
(0.02)\end{array}$ & $\begin{array}{c}0.22^{* * *} \\
(0.03)\end{array}$ & $\begin{array}{c}0.26^{* * *} \\
(0.01)\end{array}$ \\
\hline Size & $\begin{array}{c}0.05^{* * *} \\
(0.01)\end{array}$ & $\begin{array}{c}0.04^{* * *} \\
(0.02)\end{array}$ & $\begin{array}{c}0.00 \\
(0.01)\end{array}$ & $\begin{array}{c}0.04^{* * *} \\
(0.01)\end{array}$ & $\begin{array}{c}0.00 \\
(0.00)\end{array}$ & $\begin{array}{l}-0.00 \\
(0.01)\end{array}$ & $\begin{array}{c}0.02^{* * *} \\
(0.00)\end{array}$ & $\begin{array}{c}0.01^{* * *} \\
(0.00)\end{array}$ \\
\hline GDPpc & $\begin{array}{c}0.10^{* * * *} \\
(0.02)\end{array}$ & $\begin{array}{c}0.11^{* * *} \\
(0.02)\end{array}$ & $\begin{array}{l}-0.01 \\
(0.01)\end{array}$ & $\begin{array}{c}0.14^{* * *} \\
(0.02)\end{array}$ & $\begin{array}{c}-0.03^{* * *} \\
(0.01)\end{array}$ & $\begin{array}{l}-0.01 \\
(0.01)\end{array}$ & $\begin{array}{l}0.01^{*} \\
(0.01)\end{array}$ & $\begin{array}{c}0.01^{* * *} \\
(0.00)\end{array}$ \\
\hline 2007 & $\begin{array}{l}0.05 \\
(0.04)\end{array}$ & $\begin{array}{l}-0.05 \\
(0.04)\end{array}$ & $\begin{array}{c}0.10^{* * *} \\
(0.02)\end{array}$ & $\begin{array}{l}-0.07^{*} \\
(0.04)\end{array}$ & $\begin{array}{c}0.02 \\
(0.01)\end{array}$ & $\begin{array}{c}0.09^{* * *} \\
(0.02)\end{array}$ & $\begin{array}{l}-0.01 \\
(0.01)\end{array}$ & $\begin{array}{c}-0.02^{* *} \\
(0.01)\end{array}$ \\
\hline 2017 & $\begin{array}{c}0.09 * * \\
(0.04)\end{array}$ & $\begin{array}{l}-0.01 \\
(0.04)\end{array}$ & $\begin{array}{c}0.11^{* * *} * \\
(0.02)\end{array}$ & $\begin{array}{l}-0.05 \\
(0.03)\end{array}$ & $\begin{array}{c}0.03^{* * *} \\
(0.01)\end{array}$ & $\begin{array}{c}0.08^{* * *} \\
(0.02)\end{array}$ & $\begin{array}{l}-0.01 \\
(0.01)\end{array}$ & $\begin{array}{c}-0.04^{* * *} \\
(0.01)\end{array}$ \\
\hline Constant & $\begin{array}{c}-1.82^{* * * *} \\
(0.31) \\
\end{array}$ & $\begin{array}{c}-2.04^{* * *} \\
(0.37) \\
\end{array}$ & $\begin{array}{c}0.23 \\
(0.19) \\
\end{array}$ & $\begin{array}{c}-2.29^{* * *} \\
(0.33) \\
\end{array}$ & $\begin{array}{l}0.25^{* *} \\
(0.10) \\
\end{array}$ & $\begin{array}{l}0.32^{*} \\
(0.17) \\
\end{array}$ & $\begin{array}{c}-0.39 * * * \\
(0.11) \\
\end{array}$ & $\begin{array}{c}-0.29^{* * *} \\
(0.07) \\
\end{array}$ \\
\hline $\begin{array}{l}\text { Obs. } \\
R^{2}\end{array}$ & $\begin{array}{l}150 \\
0.54\end{array}$ & $\begin{array}{l}150 \\
0.57\end{array}$ & $\begin{array}{l}150 \\
0.40\end{array}$ & $\begin{array}{l}150 \\
0.70\end{array}$ & $\begin{array}{l}150 \\
0.61\end{array}$ & $\begin{array}{l}150 \\
0.37\end{array}$ & $\begin{array}{l}150 \\
0.69\end{array}$ & $\begin{array}{l}150 \\
0.90\end{array}$ \\
\hline
\end{tabular}

Notes: Robust standard errors in parentheses. ${ }^{* * *},{ }^{* *}$, and ${ }^{*}$ denote, respectively $p<0.01, p<0.05$, and $p<0.1$. 
Table 5: $F X^{A G G}$ determinants. Advanced

\begin{tabular}{|c|c|c|c|c|c|c|c|c|}
\hline & $\begin{array}{c}F X^{A G G} \\
(1)\end{array}$ & $\begin{array}{c}\frac{(A-L)}{(A+L)} \\
(2)\end{array}$ & $\begin{array}{c}F X_{O}^{A G G} \\
(3)\end{array}$ & $\begin{array}{c}\frac{\left(A_{N R}-L\right)}{(A+L)} \\
(4)\end{array}$ & $\begin{array}{c}\frac{F X R}{(A+L)} \\
(5)\end{array}$ & $\begin{array}{c}\frac{(P E Q L+F D I L)}{(A+L)} \\
(6)\end{array}$ & $\begin{array}{c}\frac{D E B T L^{D C}}{(A+L)} \\
(7)\end{array}$ & $\begin{array}{c}\frac{A_{N R}^{D C}}{(A+L)} \\
(8)\end{array}$ \\
\hline \multirow[t]{2}{*}{ Trade } & $0.10^{*}$ & $0.13^{* *}$ & -0.04 & $0.16^{* * *}$ & $-0.03^{* *}$ & 0.06 & $-0.11^{* * *}$ & -0.02 \\
\hline & $(0.05)$ & $(0.06)$ & $(0.05)$ & $(0.06)$ & $(0.01)$ & $(0.04)$ & $(0.03)$ & $(0.03)$ \\
\hline \multirow[t]{2}{*}{$\operatorname{vol}(G D P)$} & -0.25 & $-0.85^{* *}$ & $0.60^{* *}$ & $-0.69^{* *}$ & -0.16 & 0.03 & $0.33^{*}$ & $-0.25^{*}$ \\
\hline & $(0.30)$ & $(0.37)$ & $(0.24)$ & $(0.32)$ & $(0.11)$ & $(0.15)$ & $(0.18)$ & $(0.14)$ \\
\hline \multirow[t]{2}{*}{$\operatorname{vol}(\pi)$} & 0.00 & -0.01 & $0.01^{* *}$ & -0.02 & $0.01 * * *$ & $0.01^{*}$ & 0.00 & 0.00 \\
\hline & $(0.01)$ & $(0.01)$ & $(0.01)$ & $(0.01)$ & $(0.00)$ & $(0.00)$ & $(0.00)$ & $(0.00)$ \\
\hline \multirow[t]{2}{*}{$\operatorname{vol}(I)$} & -0.23 & 0.04 & -0.27 & 0.04 & 0.00 & 0.02 & -0.32 & -0.04 \\
\hline & $(0.46)$ & $(0.54)$ & $(0.37)$ & $(0.51)$ & $(0.10)$ & $(0.30)$ & $(0.35)$ & $(0.20)$ \\
\hline \multirow[t]{2}{*}{$\operatorname{corr}(G D P, I)$} & -0.03 & 0.02 & -0.05 & 0.02 & -0.00 & 0.01 & $-0.04^{*}$ & 0.02 \\
\hline & $(0.03)$ & $(0.04)$ & $(0.03)$ & $(0.04)$ & $(0.01)$ & $(0.02)$ & $(0.02)$ & $(0.02)$ \\
\hline \multirow[t]{2}{*}{ KA open } & 0.00 & -0.01 & 0.01 & 0.00 & -0.01 & -0.01 & $0.05^{*}$ & 0.02 \\
\hline & $(0.03)$ & $(0.05)$ & $(0.05)$ & $(0.05)$ & $(0.01)$ & $(0.03)$ & $(0.03)$ & $(0.02)$ \\
\hline \multirow[t]{2}{*}{ Peg } & 0.00 & 0.01 & -0.00 & 0.00 & 0.01 & -0.02 & 0.02 & 0.00 \\
\hline & $(0.03)$ & $(0.04)$ & $(0.03)$ & $(0.04)$ & $(0.01)$ & $(0.02)$ & $(0.02)$ & $(0.02)$ \\
\hline \multirow[t]{2}{*}{ EMU } & $-0.15^{* * *}$ & -0.06 & $-0.09^{* *}$ & -0.03 & $-0.03^{* *}$ & -0.02 & $0.19^{* * *}$ & $0.26^{* * *}$ \\
\hline & $(0.04)$ & $(0.05)$ & $(0.04)$ & $(0.05)$ & $(0.01)$ & $(0.03)$ & $(0.03)$ & $(0.02)$ \\
\hline \multirow[t]{2}{*}{ Size } & $0.03^{* *}$ & 0.03 & -0.00 & $0.04^{* *}$ & $-0.01^{* *}$ & 0.00 & $0.02 *$ & $0.02^{* * *}$ \\
\hline & $(0.01)$ & $(0.02)$ & $(0.01)$ & $(0.02)$ & $(0.00)$ & $(0.01)$ & $(0.01)$ & $(0.01)$ \\
\hline \multirow[t]{2}{*}{ GDPpc } & $0.13^{* *}$ & $0.23 * *$ & $-0.10^{* *}$ & $0.24^{* * *}$ & -0.01 & -0.02 & $-0.07^{* *}$ & 0.00 \\
\hline & $(0.06)$ & $(0.09)$ & $(0.05)$ & $(0.09)$ & $(0.01)$ & $(0.03)$ & $(0.03)$ & $(0.03)$ \\
\hline \multirow[t]{2}{*}{2007} & 0.05 & 0.00 & 0.04 & -0.03 & 0.03 & 0.02 & 0.02 & -0.00 \\
\hline & $(0.08)$ & $(0.09)$ & $(0.05)$ & $(0.08)$ & $(0.03)$ & $(0.03)$ & $(0.04)$ & $(0.03)$ \\
\hline \multirow[t]{2}{*}{2017} & 0.03 & -0.11 & $0.14^{* * *}$ & $-0.11^{*}$ & -0.00 & 0.02 & $0.07^{* *}$ & $-0.05^{*}$ \\
\hline & $(0.05)$ & $(0.07)$ & $(0.05)$ & $(0.06)$ & $(0.01)$ & $(0.03)$ & $(0.03)$ & $(0.03)$ \\
\hline Constant & $\begin{array}{c}-1.78^{* * *} \\
(0.65)\end{array}$ & $\begin{array}{c}-2.91^{* * *} \\
(1.01)\end{array}$ & $\begin{array}{l}1.13^{*} \\
(0.60)\end{array}$ & $\begin{array}{c}-3.30^{* * *} \\
(0.97)\end{array}$ & $\begin{array}{c}0.39^{* * *} \\
(0.14)\end{array}$ & $\begin{array}{c}0.33 \\
(0.41)\end{array}$ & $\begin{array}{c}0.52 \\
(0.39)\end{array}$ & $\begin{array}{l}-0.28 \\
(0.30)\end{array}$ \\
\hline Obs. & 63 & 63 & 63 & 63 & 63 & 63 & 63 & 63 \\
\hline$R^{2}$ & 0.56 & 0.54 & 0.36 & 0.60 & 0.51 & 0.14 & 0.80 & 0.88 \\
\hline
\end{tabular}

Notes: Robust standard errors in parentheses. ${ }^{* * *},{ }^{* *}$, and $*$ denote, respectively $p<0.01, p<0.05$, and $p<0.1$. 
Table 6: $F X^{A G G}$ determinants. Emerging countries

\begin{tabular}{|c|c|c|c|c|c|c|c|c|}
\hline & $\begin{array}{c}F X^{A G G} \\
(1)\end{array}$ & $\begin{array}{c}\frac{(A-L)}{(A+L)} \\
(2)\end{array}$ & $\begin{array}{c}F X_{o}^{A G G} \\
(3)\end{array}$ & $\begin{array}{c}\frac{\left(A_{N R}-L\right)}{(A+L)} \\
(4)\end{array}$ & $\begin{array}{c}\frac{F X R}{(A+L)} \\
(5)\end{array}$ & $\begin{array}{c}\frac{(P E Q L+F D I L)}{(A+L)} \\
(6)\end{array}$ & $\begin{array}{c}\frac{D E B T L^{D C}}{(A+L)} \\
(7)\end{array}$ & $\begin{array}{c}\frac{A_{N R}^{D C}}{(A+L)} \\
(8)\end{array}$ \\
\hline Trade & 0.01 & 0.02 & -0.00 & 0.03 & -0.01 & -0.01 & 0.00 & -0.00 \\
\hline $\operatorname{vol}(G D P)$ & $\begin{array}{c}(0.02) \\
0.28 \\
(0.21)\end{array}$ & $\begin{array}{l}(0.02) \\
0.40^{*} \\
(0.21)\end{array}$ & $\begin{array}{c}(0.02) \\
-0.12 \\
(0.10)\end{array}$ & $\begin{array}{c}(0.02) \\
0.36 \\
(0.25)\end{array}$ & $\begin{array}{c}(0.01) \\
0.04 \\
(0.09)\end{array}$ & $\begin{array}{c}(0.02) \\
-0.10 \\
(0.10)\end{array}$ & $\begin{array}{c}(0.01) \\
0.01 \\
(0.06)\end{array}$ & $\begin{array}{c}(0.00) \\
0.03^{*} \\
(0.02)\end{array}$ \\
\hline $\operatorname{vol}(\pi)$ & $\begin{array}{l}-0.00 \\
(0.03)\end{array}$ & $\begin{array}{c}0.00 \\
(0.03)\end{array}$ & $\begin{array}{l}-0.00 \\
(0.01)\end{array}$ & $\begin{array}{l}-0.02 \\
(0.03)\end{array}$ & $\begin{array}{l}0.02^{*} \\
(0.01)\end{array}$ & $\begin{array}{l}-0.00 \\
(0.02)\end{array}$ & $\begin{array}{l}-0.01 \\
(0.01)\end{array}$ & $\begin{array}{c}-0.00^{* *} \\
(0.00)\end{array}$ \\
\hline $\operatorname{vol}(I)$ & $\begin{array}{c}-0.12^{* * *} \\
(0.04)\end{array}$ & $\begin{array}{l}-0.06 \\
(0.05)\end{array}$ & $\begin{array}{l}-0.06 \\
(0.04)\end{array}$ & $\begin{array}{l}-0.01 \\
(0.06)\end{array}$ & $\begin{array}{c}-0.05^{* *} \\
(0.02)\end{array}$ & $\begin{array}{l}-0.06 \\
(0.05)\end{array}$ & $\begin{array}{l}-0.00 \\
(0.02)\end{array}$ & $\begin{array}{l}-0.00 \\
(0.00)\end{array}$ \\
\hline $\operatorname{corr}(G D P, I)$ & $\begin{array}{c}0.12^{* * *} \\
(0.04)\end{array}$ & $\begin{array}{c}0.12^{\text {*** }} \\
(0.04)\end{array}$ & $\begin{array}{l}-0.00 \\
(0.02)\end{array}$ & $\begin{array}{l}0.10^{* *} \\
(0.04)\end{array}$ & $\begin{array}{c}0.02 \\
(0.01)\end{array}$ & $\begin{array}{l}-0.00 \\
(0.02)\end{array}$ & $\begin{array}{c}0.00 \\
(0.01)\end{array}$ & $\begin{array}{c}0.00 \\
(0.00)\end{array}$ \\
\hline KA open & $\begin{array}{c}0.01 \\
(0.02)\end{array}$ & $\begin{array}{c}0.03 \\
(0.02)\end{array}$ & $\begin{array}{c}-0.02^{* *} \\
(0.01)\end{array}$ & $\begin{array}{l}0.03^{*} \\
(0.02)\end{array}$ & $\begin{array}{l}-0.01 \\
(0.01)\end{array}$ & $\begin{array}{c}-0.02^{* *} \\
(0.01)\end{array}$ & $\begin{array}{c}0.00 \\
(0.00)\end{array}$ & $\begin{array}{l}0.00 \\
(0.00)\end{array}$ \\
\hline Peg & $\begin{array}{l}0.03 \\
(0.05)\end{array}$ & $\begin{array}{l}0.09^{* *} \\
(0.04)\end{array}$ & $\begin{array}{c}-0.07^{* *} \\
(0.03)\end{array}$ & $\begin{array}{c}0.07 \\
(0.04)\end{array}$ & $\begin{array}{l}0.03^{*} \\
(0.02)\end{array}$ & $\begin{array}{c}-0.06^{* *} \\
(0.03)\end{array}$ & $\begin{array}{l}-0.01 \\
(0.01)\end{array}$ & $\begin{array}{c}0.00 \\
(0.00)\end{array}$ \\
\hline Size & $\begin{array}{c}0.05^{* *} \\
(0.02)\end{array}$ & $\begin{array}{c}0.03 \\
(0.02)\end{array}$ & $\begin{array}{l}0.02^{*} \\
(0.01)\end{array}$ & $\begin{array}{c}0.02 \\
(0.02)\end{array}$ & $\begin{array}{l}0.01^{*} \\
(0.01)\end{array}$ & $\begin{array}{c}0.01 \\
(0.01)\end{array}$ & $\begin{array}{l}0.01^{* *} \\
(0.01)\end{array}$ & $\begin{array}{l}-0.00 \\
(0.00)\end{array}$ \\
\hline GDPpc & $\begin{array}{c}0.14^{* * *} \\
(0.03)\end{array}$ & $\begin{array}{c}0.12^{* * *} \\
(0.03)\end{array}$ & $\begin{array}{c}0.02 \\
(0.02)\end{array}$ & $\begin{array}{c}0.13^{* * *} \\
(0.03)\end{array}$ & $\begin{array}{l}-0.01 \\
(0.01)\end{array}$ & $\begin{array}{c}0.02 \\
(0.02)\end{array}$ & $\begin{array}{l}-0.00 \\
(0.01)\end{array}$ & $\begin{array}{c}0.00 \\
(0.00)\end{array}$ \\
\hline 2007 & $\begin{array}{c}0.03 \\
(0.05)\end{array}$ & $\begin{array}{r}-0.09^{*} \\
(0.05)\end{array}$ & $\begin{array}{c}0.12^{* * *} \\
(0.03)\end{array}$ & $\begin{array}{c}-0.10^{* *} \\
(0.05)\end{array}$ & $\begin{array}{c}0.01 \\
(0.02)\end{array}$ & $\begin{array}{c}0.12^{* * *} \\
(0.03)\end{array}$ & $\begin{array}{l}-0.00 \\
(0.01)\end{array}$ & $\begin{array}{l}-0.01 \\
(0.00)\end{array}$ \\
\hline 2017 & $\begin{array}{c}0.02 \\
(0.08)\end{array}$ & $\begin{array}{l}-0.07 \\
(0.07)\end{array}$ & $\begin{array}{c}0.09^{* *} \\
(0.04)\end{array}$ & $\begin{array}{l}-0.06 \\
(0.06)\end{array}$ & $\begin{array}{l}-0.00 \\
(0.02)\end{array}$ & $\begin{array}{l}0.08^{*} \\
(0.04)\end{array}$ & $\begin{array}{c}0.01 \\
(0.02)\end{array}$ & $\begin{array}{l}-0.00 \\
(0.00)\end{array}$ \\
\hline Constant & $\begin{array}{c}-2.12^{* * * *} \\
(0.50)\end{array}$ & $\begin{array}{c}-1.93^{* * *} \\
(0.55)\end{array}$ & $\begin{array}{l}-0.20 \\
(0.26)\end{array}$ & $\begin{array}{c}-1.93^{* * *} \\
(0.49)\end{array}$ & $\begin{array}{c}0.01 \\
(0.14)\end{array}$ & $\begin{array}{l}-0.03 \\
(0.28)\end{array}$ & $\begin{array}{c}-0.17^{*} \\
(0.10)\end{array}$ & $\begin{array}{l}-0.01 \\
(0.02)\end{array}$ \\
\hline $\begin{array}{l}\text { Obs. } \\
R^{2}\end{array}$ & $\begin{array}{c}87 \\
0.60\end{array}$ & $\begin{array}{c}87 \\
0.57\end{array}$ & $\begin{array}{c}87 \\
0.41\end{array}$ & $\begin{array}{c}87 \\
0.61\end{array}$ & $\begin{array}{c}87 \\
0.37\end{array}$ & $\begin{array}{c}87 \\
0.37\end{array}$ & $\begin{array}{c}87 \\
0.16\end{array}$ & $\begin{array}{c}87 \\
0.19\end{array}$ \\
\hline
\end{tabular}

Notes: Robust standard errors in parentheses. ${ }^{* * *},{ }^{* *}$, and ${ }^{*}$ denote, respectively $p<0.01, p<0.05$, and $p<0.1$. 
Table 7: Ten-year changes pre- and post-crisis vs. initial values. $F X^{A G G}$ and subcomponents.

\begin{tabular}{|c|c|c|c|c|c|c|c|c|}
\hline & $\begin{array}{c}F X^{A G G} \\
(1)\end{array}$ & $\begin{array}{c}\frac{(A-L)}{(A+L)} \\
(2)\end{array}$ & $\begin{array}{c}F X_{o}^{A G G} \\
(3)\end{array}$ & $\begin{array}{c}\frac{\left(A_{N R}-L\right)}{(A+L)} \\
(4)\end{array}$ & $\begin{array}{c}\frac{F X R}{(A+L)} \\
(5)\end{array}$ & $\begin{array}{c}\frac{(P E Q L+F D I L)}{(A+L)} \\
(6)\end{array}$ & $\begin{array}{c}\frac{D E B T L^{D C}}{(A+L)} \\
(7)\end{array}$ & $\begin{array}{c}\frac{A_{N R}^{D C}}{(A+L)} \\
(8)\end{array}$ \\
\hline \multicolumn{9}{|l|}{ A. Full sample } \\
\hline $1997-2007$ & & & & & & & & \\
\hline Bivariate & $-0.53^{* * *}$ & $-0.32^{* * *}$ & $-0.34^{* * *}$ & $-0.24^{* * *}$ & -0.08 & $-0.32 * *$ & -0.28 & 0.55 \\
\hline Risk controls & $-0.45^{* * *}$ & $-0.39^{* * *}$ & $-0.53^{* * *}$ & $-0.32^{* * *}$ & $-0.36^{*}$ & $-0.47^{* * *}$ & $-0.55^{* *}$ & 0.15 \\
\hline Full controls & $-0.51^{* * *}$ & $-0.45^{* * *}$ & $-0.63^{* * *}$ & $-0.55^{* * *}$ & $-0.68^{* * *}$ & $-0.54^{* * *}$ & -0.41 & 0.13 \\
\hline \multicolumn{9}{|l|}{$2007-2017$} \\
\hline Bivariate & 0.14 & 0.07 & $-0.22^{* * *}$ & 0.04 & $-0.28^{* * *}$ & $-0.27 * * *$ & 0.03 & -0.03 \\
\hline Risk controls & -0.03 & -0.05 & $-0.22^{* * *}$ & 0.02 & $-0.34^{* * *}$ & $-0.27 * * *$ & 0.03 & -0.09 \\
\hline Full controls & -0.05 & -0.09 & $-0.20^{* *}$ & -0.01 & $-0.27^{* * *}$ & $-0.28^{* * *}$ & 0.05 & -0.08 \\
\hline \multicolumn{9}{|c|}{ B. Advanced countries } \\
\hline $1997-2007$ & & & & & & & & \\
\hline Bivariate & $-0.48^{* *}$ & $-0.27^{* *}$ & $-0.48^{* *}$ & $-0.29^{* * *}$ & $-0.82^{* * *}$ & $-0.48^{* *}$ & $-0.69^{*}$ & -0.16 \\
\hline Risk controls & -0.35 & $-0.33^{* * *}$ & $-0.55^{* *}$ & $-0.39^{* * *}$ & $-0.64^{* * *}$ & $-0.51^{* * *}$ & -0.24 & -0.23 \\
\hline Full controls & $-0.76^{* *}$ & $-0.48^{* *}$ & -0.43 & $-0.52^{* *}$ & -0.36 & $-0.35^{*}$ & $-0.47^{*}$ & 0.13 \\
\hline \multicolumn{9}{|l|}{$2007-2017$} \\
\hline Bivariate & -0.02 & 0.03 & -0.17 & 0.01 & $-0.29^{* * *}$ & $-0.40^{*}$ & $0.13^{* *}$ & 0.01 \\
\hline Risk controls & 0.10 & 0.13 & -0.20 & 0.10 & -0.50 & -0.21 & 0.05 & -0.11 \\
\hline Full controls & -0.24 & -0.09 & -0.16 & -0.18 & -0.91 & -0.39 & -0.14 & -0.07 \\
\hline \multicolumn{9}{|c|}{ C. Emerging countries } \\
\hline $1997-2007$ & & & & & & & & \\
\hline Bivariate & $-0.34^{* * *}$ & $-0.28^{* * *}$ & $-0.47^{* * *}$ & $-0.28^{* *}$ & -0.50 & $-0.42^{* *}$ & $-0.71^{* * *}$ & -0.24 \\
\hline Risk controls & $-0.32^{* *}$ & $-0.30^{* *}$ & $-0.49^{* * *}$ & $-0.25^{* *}$ & -0.51 & $-0.48^{* *}$ & $-0.72^{* * *}$ & 0.02 \\
\hline Full controls & $-0.41^{* * *}$ & $-0.51^{* *}$ & $-0.62^{* * *}$ & $-0.67^{* * *}$ & $-0.73^{* * *}$ & $-0.51^{* * *}$ & $-0.60^{* * *}$ & 0.04 \\
\hline \multicolumn{9}{|l|}{$2007-2017$} \\
\hline Bivariate & 0.18 & 0.06 & $-0.29^{* * *}$ & 0.07 & $-0.42 * * *$ & $-0.29 * * *$ & -0.05 & $-0.42^{* *}$ \\
\hline Risk controls & -0.09 & -0.09 & $-0.27^{* * *}$ & 0.01 & $-0.44^{* * *}$ & $-0.28^{* * *}$ & -0.03 & $-0.47^{*}$ \\
\hline Full controls & -0.12 & -0.08 & $-0.23^{* *}$ & 0.07 & $-0.31^{* *}$ & -0.22 & -0.08 & -0.41 \\
\hline
\end{tabular}

Notes: Robust standard errors in parentheses. ${ }^{* * *},{ }^{* *}$, and ${ }^{*}$ denote, respectively $p<0.01, p<0.05$, and $p<0.1$. 


\section{Appendix A Data}

The approach followed for compiling this dataset consists of taking actual data (i.e. reported by statistical authorities) whenever available and extend its coverage by using estimation methods. More precisely, we splice actual data backwards using estimated currency weights for each component of the International Investment Position (IIP). ${ }^{1}$ This allows for filling the gaps in actual data and expand its coverage over the period 1990-2017. ${ }^{2}$ The estimation process builds on Lane and Shambaugh (2010) and Bénétrix et al. (2015), while offering a number of improvements with respect to their methodology. In particular, our dataset takes advantage of having access to superior data sources (including actual data), refines some of the estimation methods and incorporates a new dimension to foreign direct investment (FDI) by splitting it into the equity and debt components. The latter has gained relevance since the global financial crisis and represents a sizable share of FDI for some countries.

This data appendix is structured in four parts. Section A1 describes the different data sources and coverage of the actual data. Section A2 explains the specific approaches followed to generate the estimated data. Section A3 briefly describes the uses of the data and Section A4 provides a comparison between actual and estimated data.

\section{A.1 Actual Data}

One of the main improvements in this dataset consists in the incorporation of actual data on the currency composition of the IIP. These are obtained from a variety of sources: (i) a survey sent by the IMF to country authorities; (ii) the Coordinated Portfolio Investment Survey (CPIS); (iii) data that European Union (EU) countries report to the ECB and; (iv) data of banks' cross-border positions reported to the BIS and available in its Locational Banking Statistics (LBS). In what follows we describe each of the sources of actual data and the years of coverage in detail.

\section{A.1.1 IMF Survey to Authorities}

In order to collect actual data, the IMF Research Department in collaboration with the Statistics Department sent a survey to the authorities of the 52 countries which are part of the External Balance Assessment and/or the External Sector Report. ${ }^{3}$ Tables A.1 and A.2 include the survey template sent to authorities. The survey requested data from 1990 on the main components of the IIP broken down into the five SDR currencies (i.e. US dollar, euro, Japanese yen, Pound sterling and renminbi), domestic currency (when different from the five SDRs), and "other currencies" which bundle up all the other currencies not included in the previous two categories. Pre-1999 legacy currencies which are not the domestic currency of the country analyzed are included in the category of "other currencies."

The sample of countries includes emerging economies and advanced economies, which taken together, account for over 90 percent of World's GDP. Consistent with data submissions, the requested data was labeled to be treated as public unless country authorities objected to their

\footnotetext{
${ }^{1}$ We do not consider financial derivatives because the currency breakdown is largely unavailable due to methodological and data collection issues.

${ }^{2}$ Data for Russia start in 1993 due to lack of information. We report data for the Czech Republic since 1993 because that is the year in which the country was formed following the split of Czechoslovakia.

${ }^{3}$ The countries are: Argentina, Australia, Austria, Belgium, Brazil, Canada, Chile, China, Colombia, Czech Republic, Denmark, Egypt, Finland, France, Germany, Greece, Guatemala, Hong Kong SAR, Hungary, India, Indonesia, Ireland, Israel, Italy, Japan, Korea, Malaysia, Mexico, Morocco, Netherlands, New Zealand, Norway, Pakistan, Peru, Philippines, Poland, Portugal, Russia, Singapore, South Africa, Spain, Sri Lanka, Sweden, Switzerland, Thailand, Tunisia, Turkey, United Kingdom, United States and Uruguay.
} 
disclosure. $^{4}$

The response rate was 85 percent. ${ }^{5}$ However, not all country authorities were able to submit granular and complete data as described in the template. Partial submissions were encouraged as well. Figure A.1 describes the share of countries in the sample which reported currency composition at any level of disaggregation between 1990 and 2017. For recent years, around 52 percent of countries reported some data but as we go back in time the coverage is more limited. In particular, only one country submitted partial data covering the year 1990, while around 7 countries reported some information at the start of the 2000s and 27 countries in 2017.

In the construction of the final dataset, whenever available, we used actual data (unless the data were confidential). ${ }^{6}$

\section{A.1.2 CPIS}

The CPIS collects information on the stock of cross-border holdings of portfolio equity and portfolio debt securities for reporter countries vis-à-vis host countries. As of December 2017 a total of 82 countries reported core data to CPIS. Table 2 of CPIS includes the currency of denomination of portfolio equity and portfolio debt assets. The submission of information on the currency composition of portfolio equity and debt, included in Table 2, is an encouraged item which aims to further enhance the granularity of the CPIS data. ${ }^{7}$ For a number of countries in our dataset we used actual data on the currency composition of portfolio equity and portfolio debt assets sourced from CPIS Table 2. Note that whenever available, we used data from the survey and only used CPIS Table 2 data for the countries which did not provide the data breakdown to the survey (or the countries which classified the data as confidential). Table A.3 details the countries for which we used CPIS Table 2 data and the years of coverage.

\section{A.1.3 ECB Data}

The statistical requirements of the ECB in the field of external statistics are defined in Guideline ECB/2011/23 of 9 December 2011 (as amended). Euro Area countries are required to follow these guidelines when compiling their contributions to Euro Area external statistics, while the other European Union countries follow them on a voluntary basis.

To monitor developments in the international use of the euro (for instance in the annual "The International Role of the Euro" publications), the ECB Guideline includes the requirement to transmit on a quarterly basis national data on the currency denomination of portfolio debt asset and liability positions broken down into euro, US dollar and other currencies. These series are available for most EU countries since $2008 .^{8}$

\section{A.1.4 BIS Locational Banking Statistics}

This dataset includes cross-border positions of banks (aggregated at country-level) vis-à-vis bank and non-banks in counterpart countries. These data are presented at quarterly frequency starting from late 1970s for up to 36 reporters in the last part of the sample. In addition, the cross-border positions are broken down by the currency of denomination including US

\footnotetext{
${ }^{4}$ Any template containing confidential data was not used at all.

${ }^{5}$ This includes responses at any level of disaggregation and responses which included no actual data due to the lack of it.

${ }^{6}$ The only component of actual data which was not used was financial derivatives due to the lack of synthetic data and limited coverage.

${ }^{7}$ As of December 2017 a total of 59 countries reported to CPIS Table 2.

${ }^{8}$ Although these data are not always publicly available, they are incorporated in the dataset.
} 
dollar, euro, Japanese yen, Pound sterling and renminbi, as well as the domestic currency of the reporter country and other currencies not included in the previous list.

\section{A.2 Combining Estimated and Actual Data}

In this section we describe how we extend the coverage of actual data with estimated currency positions and the underlying methodologies for each item of the IIP.

\section{A.2.1 Foreign Assets}

The asset side of a country's external balance sheet contains five main items: portfolio equity, foreign direct investment (equity and debt), portfolio debt, other investment (largely bankrelated), and reserves. In order to obtain a time series of each item for each country we used estimation methods to complement the actual data. The estimation methods are summarized below and we also provide, for each item, a detailed table which describes the years for which actual data and estimation methods were used (see Table A.3).

\section{Portfolio Equity}

We report the currency composition of portfolio equity using actual data for the years and countries available in the IMF Survey and Table 2 of the IMF's CPIS. For countries with no data from these sources we follow an improved version of Lane and Shambaugh (2010). More precisely, we rely on the geography of cross-border positions as the best predictor for the currency of denomination of portfolio equity assets. To this end, we use the CPIS dataset which includes the geographical location of portfolio equity asset holdings for 82 reporting countries and 220 host countries since 2001. The approach relies on two main assumptions. First, we assume that equity issued by a country is denominated in the currency of that country. That is, US stocks are denominated in US dollars, Japanese stocks in Japanese yen and so on. Second, we remove holdings issued in offshore financial centers, as in Lane and Milesi-Ferretti (2008). ${ }^{9}$ By doing this, we implicitly assume that the securities issued in offshore centers follow the global currency distribution.

For the country pairs which are missing from the CPIS dataset or the coverage is limited to a maximum of three years, we follow a gravity-based model of bilateral equity holdings as in Lane and Shambaugh (2010). ${ }^{10}$ We assume that currency-related equity exposures are correlated with the geographical pattern in portfolio equity holdings and run the following regression model:

$$
\log \left(1+E Q_{i j t}\right)=\psi_{j}+\theta_{t}+\beta Z_{i j t}+\gamma X_{i t}+\epsilon_{i j t},
$$

where $E Q_{i j t}$ are portfolio equity assets from country $i$ to country $j$ in period $t, \psi_{j}$ represents host country fixed effects, $\theta_{t}$ are year fixed effects and $Z_{i j t}$ is a vector of bilateral variables including trade, distance, colonial relationship dummies, regional dummies, and measures of relative GDP such as a dummy for both countries belonging to the same income level. We do not include source country fixed effects, since our goal is to estimate missing source country data, but we add source country characteristics in $X_{i t}$ such as latitude, landlocked status, population, capital controls, GDP per capita and gross stocks of cross-border financial positions. This regression has considerable explanatory power $\left(R^{2}\right.$ values in the region of 0.75$)$ and coefficients on the independent variables yield expected signs and magnitudes. A summary

\footnotetext{
${ }^{9}$ We follow Lane and Milesi-Ferretti (2008) and primarily use the IMF Background Paper (2000), as our guide to labeling countries as offshore centers. Removing offshore financial centers is common practice as they tend to have a close to balanced net foreign asset positions.

${ }^{10}$ See also Lane and Milesi-Ferretti (2008), Portes and Rey (2005) and Martin and Rey (2004) for theoretical and empirical support for this approach.
} 
of the regression estimates and details on the data sources are available on Table A.5. ${ }^{11}$ We then use these predicted values as an estimate of the currency of denomination of portfolio equity holdings for the countries which are missing from the CPIS dataset. There is a group of countries composed by China, Guatemala, Morocco, Peru, Sri Lanka and Tunisia for which we do not have information on the currency mix from any source and gravity weights are therefore used for 1990-2017. For weights before 1998 we follow Lane and Shambaugh (2010), who use a trial survey for CPIS which took place in 1997 and included a set of 29 reporting countries. ${ }^{12}$ For the countries for which CPIS data are available for 1997, we use the 1997 weights for the years 1990-1997. For those countries not covered in CPIS in 1997 we use synthetic currency weights from the gravity model and apply those weights for 1990-1997. For the years between 1998 and 2001 we apply the CPIS 2001 weights. ${ }^{13}$ Table A.3 shows the years for which actual data and estimated data were used for portfolio equity assets.

\section{Foreign Direct Investment}

We distinguish between the equity and debt components of FDI and estimate their currency mix separately. This is an improvement with respect to Bénétrix et al (2015) which treats FDI as equity only. The share of equity in Foreign Direct Investment is obtained from the IMF's International Financial Statistics (IFS). As for others IIP items, we start by using the actual currency composition data available from the sources described above.

For the equity component of FDI, we use actual currency weights available from the IMF Survey. We then use estimated data to fill gaps following the same approach implemented in portfolio equity. In particular, we assume that the equity component of FDI is denominated in the currency of the host country. From 1990 to 2008 we update Bénétrix et al. (2015) who used the UNCTAD database on stocks and flows of bilateral direct investment for assets and liabilities. ${ }^{14}$ From 2009 until 2017 we use data from the IMF Coordinated Direct Investment Survey (CDIS) which includes outward and inward stocks of direct investment for 108 and reporting countries, respectively. ${ }^{15}$ For the countries with limited or no coverage in the CDIS, we implement the same gravity approach used in portfolio equity to generate estimated data. These countries are Argentina, China, Egypt, Indonesia, Singapore, Tunisia and Uruguay and the regression results are reported in Table A.5. The bilateral FDI positions obtained using the CDIS dataset and the gravity approaches are subsequently chain-linked with the UNCTADbased positions available before 2009. These two parts together form the estimated data that are used to complement actual data.

For the debt component of FDI we use actual data from the IMF Survey, which revealed that the debt and equity components of FDI have very different currency distributions. Since FDI debt represents up to 40 percent of total FDI in some countries, we estimated it separately. Whenever available, we used actual data and and extended the coverage using portfolio debt assets (explained below) as a proxy for the synthetic series. Table A.3 shows the years for which actual data and estimated data were used to compile the currency composition of FDI assets.

\footnotetext{
${ }^{11}$ Further details of these regression outputs are available upon request.

${ }^{12}$ These countries were Argentina, Australia, Austria, Belgium, Bermuda, Canada, Chile, Denmark, Finland, France, Iceland, Indonesia, Ireland, Israel, Italy, Japan, Korea, Malaysia, the Netherlands, New Zealand, Norway, Portugal, Singapore, Spain, Sweden, Thailand, the United Kingdom, the United States, and Venezuela.

${ }^{13}$ Lane and Shambaugh (2010) explain that since the geographical pattern of portfolio investment is very persistent they apply the values of 1997 for the years 1990-1997.

${ }^{14}$ For a small subset of their 116 country sample, where bilateral FDI stock data were not available, Lane and Shambaugh (2010) used flow data from UNCTAD to proxy geographical patterns. Those country pairs are not included in our 50-country sample.

${ }^{15}$ This is the coverage for 2017.
} 


\section{Portfolio Debt}

For portfolio debt assets we expand the coverage of actual data from the IMF Survey, CPIS Table 2, ECB and a number of national sources using a multi-step approach as in Lane and Shambaugh (2010) and Bénétrix el al. (2015). As in the cases of portfolio and FDI equity, we use a gravity model to fill out the geographical information for missing country pairs. ${ }^{16}$ The approach to estimate the currency composition of portfolio debt assets is the result of combining the geography of portfolio debt asset positions with the currency of denomination of host countries' bonds issued in international markets. This currency distribution is applied to the bilateral positions of source countries. For instance, if country A (the source country) has positions in countries B, C and D (host countries), the currency of denomination of those positions will be determined by how much $\mathrm{B}, \mathrm{C}$ and $\mathrm{D}$ issue in each currency. Issuance data are sourced from the BIS International Debt Statistics database. Those bilateral positions broken down by currency are then added up for each source country. Importantly, the currency distribution of the host countries used is net of the positions in US dollars held by US residents, positions in euros held by Euro Area countries and in Japanese yen held by Japanese residents. To net these out, we use data from the US Treasury's Report on the US Portfolio Holdings of Foreign Securities, the ECB and the Bank of Japan, respectively. ${ }^{17}$

For instance, if host country B is a non Euro Area country and issues 50 percent of its international debt in US dollars and 50 percent in euros, and 80 percent of the US dollar debt is held by the US and 50 percent of the euro issuance is held by an Euro Area country, any other country with a position in country B will be attributed the residual distribution to that bilateral position, ie. 29 percent in US dollar and 71 in euros.

As a final step, these synthetic data are used to expand the time-series coverage of actual data.

\section{Other Investment}

Information from the survey on other investment assets is available for 13 countries for a number of years (see Table A.3 for details). We complement the survey results with data on aggregate and bilateral country-level cross-border bank positions gathered from the restricted Bank for International Settlements' (BIS) dataset on Locational Banking Statistics (LBS), which follow balance of payments accounting principles. The LBS data feature the currency composition of outstanding cross-border assets and liabilities of banking offices located in BIS reporting countries.

Thirty four of the countries included in our sample report LBS data over the period 1990 to 2017 , with some cross-country heterogeneity in terms of data availability. ${ }^{18}$ The LBS data include the currency breakdown for the five SDR currencies (i.e. US dollar, euro, Japanese yen, Pound sterling and renminbi) and domestic currency. ${ }^{19}$

\footnotetext{
${ }^{16}$ The regression results are reported in Table A.5.

${ }^{17}$ The reason for doing this is that the US, the Euro Area and Japan report information that combines geography of portfolio debt asset positions and currency. Thus, the relevant issuance distribution to be used to allocate a currency to bilateral assets positions should exclude them.

${ }^{18}$ The LBS reporting countries in our sample are Australia, Austria, Belgium, Brazil, Canada, Chile, China, Denmark, Finland, France, Germany, Greece, Hong Kong, India, Indonesia, Ireland, Italy, Japan, Korea, Malaysia, Mexico, Netherlands, Norway, Philippines, Portugal, Russia, Singapore, South Africa, Spain, Sweden, Switzerland, Turkey, United Kingdom and the United States. Data for the United States are complemented with statistics on the currency denomination of cross-border bank positions from the U.S. Banking Data as reported in the Treasury International Capital (TIC) System of the US Treasury.

${ }^{19}$ We focus on banks' total foreign assets and liabilities including portfolio items (mainly debt) as the data coverage is considerably higher than for loans and deposits. The currency composition of total assets is however
} 
For those reporter countries which report all required currency details consistently over time, the computation of the currency composition is straightforward as it is purely based on their reported data. In case of data gaps in reporter countries and to obtain information on non-reporters' foreign assets, we employ a "mirror data" approach: in particular, we derive the currency composition of the foreign assets of non-reporting countries by using the aggregate currency composition of the foreign liabilities of the banking systems of the reporting countries. $^{20}$

The use of mirror data is justified by the high importance of reporter countries: aggregate cross-border liabilities of reporter countries account for around 90\% of reporter countries' external assets. Moreover, the mirror data LBS weights are in line with reported LBS weights when both are available (US dollar weights for instance exhibit a correlation of about $90 \%$ between reported and mirror series). We further assume that the domestic currency share in assets of a non-reporter corresponds to the share of "other" currencies in aggregate reporters' liabilities vis-á-vis this non-reporter. ${ }^{21}$

The euro series pre-1999 in the LBS data consist of the sum of the legacy currencies of the euro area Member States. To derive the share of individual legacy currencies in the foreign assets of euro area Member States before 1999, we use the series reported for "domestic currency" and information on positions in other individual legacy currencies which we obtained from the BIS. For non-euro area countries, we assume that the currency distribution into legacy currencies follows the same patterns as the aggregate distribution derived from the assets of the euro area countries.

For those countries which report other investment assets in the survey, we observe a very high correlation (of around 90\%) between the survey-based and BIS-based sets of currency weights. To obtain the final weights, we create the final series, using a hierarchy of sources, with priority given to survey data, followed by BIS LBS reported data and BIS LBS derived data.

\section{Reserves}

Data on the currency composition of reserves from 1990 to 2012 are sourced from Bénétrix el al. (2015). The main source of reserve weights by currency in Bénétrix el al. (2015) is obtained from Eichengreen and Mathieson (2000), who estimate the determinants on currency composition of international reserves based on trade shares, financial flows, and currency pegs. Specifically, the authors estimate an empirical model where the shares of international reserves in each major currency are the dependent variables and the independent variables are the trade shares with the major currency countries, the share of debt denominated in these currencies, and the exchange rate regime with these countries. Bénétrix el al. (2015) take the coefficients from the estimated model by Eichengreen and Mathieson (2000) and use them to predict the share of reserves of each of the major currencies (the US dollar, the Deutsche Mark, the euro after 1999, the Swiss Franc, the Japanese yen and the Pound sterling). ${ }^{22}$

In order to update the data up to 2017 we construct a second dataset by obtaining or estimating the reserve weights from non-confidential sources and then combine them with the Bénétrix el al. (2015) dataset. Given that we have to splice the Bénétrix el al. (2015) dataset with our second dataset, it is important that there are some years of overlap between them.

a very good proxy for the overall "other investment" components, reflecting the predominant role of loans and deposits in total assets (around $80 \%$ on average since 1990). See also BIS $(2009,2019)$.

${ }^{20}$ This approach is akin to the IMF's method of deriving liabilities data for all economies (reporters and non-reporters) in the CPIS.

21 "Other" currencies excluding the five SDR currencies and the Swiss Franc.

${ }^{22}$ Bénétrix el al. (2015) complement this approach with reserves information from other sources detailed in their paper. 
In what follows we describe the method used to obtain reserves data from 2010 to $2017 .{ }^{23}$ At the end of this section we explain how we interpolate both datasets.

There is a group of countries for which actual data on currency composition of reserves can be obtained from Central Bank or Ministry of Finance publications. In what follows we list the countries and the source of data in parenthesis: Canada (Department of Finance Canada), Chile (Central Bank of Chile), Colombia (Banco de la República), Peru (Central Bank of Peru), Poland (National Bank of Poland), Sweden (Riskbank), Switzerland (Swiss National Bank), United Kingdom (Bank of England), USA (US Treasury), and Uruguay (Central Bank of Uruguay). ${ }^{24}$

For the other countries, actual data are not available from their Central Banks publications and we therefore we have to infer them from other sources. The IMF Currency Composition of Official Foreign Exchange Reserves (COFER) keeps track of the currency composition of reserves of its member countries. However, due to confidentiality reasons it only disseminates end-of-period data aggregated for three groups of countries: total, advanced economies, and emerging and developing economies. COFER also reports, for each country, the aggregate of the total SDR and non-SDR currency breakdown in reserves. ${ }^{25}$ Although COFER data for individual countries are strictly confidential, since 2016 a small group of countries report an optional SDR breakdown by currency in the reserves template, which is publicly available. ${ }^{26}$ These countries are: Australia, Belgium, Brazil, Finland, Germany, Ireland, Netherlands (only 2017), Norway, and Portugal. For these 9 countries we use the currency breakdown from the reserves template and fill the gaps for the period 2010-2015 taking into account that the currency composition weights do not change by a large proportion in the short-term. Therefore, we fill the gaps assuming a two-year moving average (average of 2016 and 2017 for 2015 and so on) subject to the total weight of currencies in the SDR basket.

For the following countries we only have the aggregate weight of SDR and non-SDR currencies: Argentina, Austria, France, Italy, Japan, Korea, Czech Republic, China, Egypt, Greece, Hungary, India (only for 2010), Indonesia, Israel, Malaysia, Mexico, Morocco, New Zealand, Philippines, Russia, Singapore, South Africa, Thailand, and Turkey. In addition, we have the SDR breakdown by country groups (advanced and emerging). Therefore, we infer the currency composition for these countries by using the currency weights for the group they belong to and re-weight them based on their own SDR/non-SDR composition. ${ }^{27}$ For the countries which belong to the Euro Area we use the combined weight of euro and US dollar of the "advanced economies" group as a proxy for the currency weight of the US dollar (given that the euro weight is zero). In addition, for the Czech Republic, Russia, and Norway we refine the estimation by using the share of euros in total foreign reserve holdings for 2010-2017 from the ECB publication "The International Role of the Euro" (June 2016 and June 2018).

Following this steps, we end up with two datasets: the first one is sourced from Bénétrix el al. (2015) from 1990 to 2012 and the second one, available from 2010 to 2017, is obtained as described above. We merge the Bénétrix el al. (2015) series with the ones from 2010-2017

\footnotetext{
${ }^{23}$ For a subset of countries data are available from 2008-2017: Belgium, Canada, France, Germany, Italy, Japan, Netherlands, and Korea.

${ }^{24}$ For the United Kingdom we use the combined currency shares of the Bank of England and the UK Government (which includes other foreign currency assets such as claims vis-á-vis residents); for the USA we use the combined currency share of the Open Market Account (SOMA) at the Board of Governors of the Federal Reserve System and the US Treasury Exchange Stabilization Fund (ESF); for Chile we use the combined currency share in the liquidity and the investment portfolio of the central bank. Finally, the Central Bank of Peru reports the US dollar share of reserves and in their Annual Report they highlight that the reserve assets denominated in currencies other than the US dollar are mostly denominated in euros.

${ }^{25}$ SDR currencies consist of US dollar, euro, Japanese yen, Pound sterling, and Chinese renminbi (since 2016).

${ }^{26}$ http://data.imf.org/?sk=E6A5F467-C14B-4AA8-9F6D-5A09EC4E62A4

${ }^{27}$ Unfortunately, the breakdown for advanced and emerging market and developing economies is not available for 2015 onward. Therefore, we assume the same group weights for 2015-2017.
} 
using an interpolation method. Since Bénétrix el al. (2015) is largely based on Eichengreen and Mathieson (2000), we assume that the estimated Bénétrix el al. (2015) weights are the best prediction for reserve weights as we go back in time. We linearly interpolate the weights in the dataset starting from the 5 years preceding the availability of data from the second dataset. For most countries this would be from 2005. For the countries from which the second dataset starts in 2008 the first period of interpolation would be 2003.

\section{A.2.2 Foreign Liabilities}

The liability side of a country's external balance sheet contains four main items: portfolio equity, foreign direct investment (equity and debt), portfolio debt, and other investment (largely bank-related). In order to obtain a time series of each item for each country we used a combination of actual data and estimation methods summarized below.

\section{Portfolio Equity}

Consistent with the treatment on the assets side, portfolio equity liabilities are assumed to be denominated in the currency of the host country. Therefore, the total size of equity liabilities is assumed to be denominated in domestic currency. As a result, there is no foreign-currency exposure from portfolio equity liabilities.

\section{Foreign Direct Investment}

As in the case of assets, we split equity from debt components. The share of equity in Foreign Direct Investment is obtained from the IMF's IFS. For the equity component, we assume that the liabilities are denominated in the currency of the host country. For the debt component we follow the same approach as in assets (ie. we use as synthetic data the currency composition of portfolio debt liabilities). Whenever available, we used actual data and extend the coverage by using the currency mix of portfolio debt liabilities (explained below). For the cases where actual data were not available, we take the latter. Table A.4 shows the years for which actual and estimated data were used.

\section{Portfolio Debt}

This item was obtained using a variety of sources. Actual data are sourced from the survey and the ECB, while synthetic data are obtained from the BIS international debt issuance statistics and from Arslanalp and Tsuda (2014). For most countries, the baseline synthetic data are obtained from the BIS International Debt Statistics. These data are compiled by the BIS from a security-by security database using information from commercial data providers (Gruic and Wooldridge, 2012). The dataset covers all debt securities issued by non-residents, i.e. for those cases in which primary market issuance is outside the issuer's country of residence. These data include a comprehensive breakdown by currency. However, for emerging markets this dataset tends to underestimate the overall share of domestic currency issuance, as the BIS does not report the currency composition of domestically issued debt securities and there is moreover no information of the proportion of domestically issued securities which is held by non-resident investors. Due to the importance to correct for this, for a sample of 19 emerging countries, we use the share of central government securities denominated in domestic currency held by foreigners from Arslanalp and Tsuda (2014) as a proxy for the share of portfolio debt liabilities in domestic currency and compute the foreign currency shares based on the BIS international issuance data. The countries covered in Arslanalp and Tsuda (2014) are: Argentina, Brazil, Chile, China, Colombia, Egypt, Hungary, India, Indonesia, Malaysia, Mexico, Peru, Philip- 
pines, Poland, Russia, South Africa, Thailand, Turkey and Uruguay. These data are available from 2004 to 2017 and were spliced backwards using BIS international issuance data. Note that in the early 2000s the share of portfolio debt liabilities in domestic currency for emerging economies was small but acquired a larger weight towards the end of the sample period.

As in the case of the other series, we used actual data whenever available and spliced them backwards with the synthetic series. Table A.4 summarizes the sources and years for which actual and estimated data were used. ${ }^{28}$

\section{Other Investment}

The assembly of other investment liability weights proceeds in the same way as for other investment assets, i.e. information from the survey is complemented with country-level BIS LBS data. Information from the survey on other investment liabilities is available for 14 countries for a number of years (see Table A.4 for details).

In LBS data, the coverage of liabilities is very much aligned with the one for assets (see Section 2.1.4). Hence, we are able to rely on reporter countries' data, complemented with "mirror data": in particular, we derive the currency composition of the foreign liabilities of nonreporting countries by using the aggregate currency composition of the foreign banking assets of the reporting countries. Again, the use of mirror data is justified by the high importance of reporter countries and the close correlation between reported and derived LBS weights. Following the approach for assets, we further assume that the domestic currency share in liabilities of a non-reporter corresponds to the share of "other" currencies in aggregate reporters' assets vis-à-vis this non-reporter. ${ }^{29}$ In the case of euro legacy currencies, we apply the same method as for assets. To derive the share of individual legacy currencies in the foreign assets of euro area Member States before 1999, we use the series reported for 'domestic currency' and information on positions in other individual legacy currencies which we obtained from the BIS. For non-euro area countries, we assume that the currency distribution into legacy currencies follows the same patterns as the aggregate distribution derived from the assets of the euro area countries.

To obtain the final other investment liability weights, we complement the survey data, using the same hierarchy of sources as for assets.

\section{A.3 Uses}

The dataset we construct and make publicly available contains asset, debt asset, liability, and debt liability weights. These are obtained combining the shares of each component of the IIP from the External Wealth of Nations dataset by Lane and Milesi-Ferretti (2007) with the corresponding currency weights which we calculate using the methods described in this section. Debt assets include portfolio debt, FDI debt, other investment and reserve assets, while debt liabilities include portfolio debt, FDI debt and other investment.

We provide the decomposition of each variable into domestic and foreign currency components. In addition, we report the breakdown into the five SDR currencies (US dollar, euro, Japanese yen, Pound sterling and renminbi) and an aggregate denoted by "other" which includes all the currencies other than the five SDRs. ${ }^{30}$ We report the share of each variable

\footnotetext{
${ }^{28}$ Note that in the case of Germany, survey data prior to 2012 only contain the breakdown between domestic and all foreign currencies. In order to make the most out of the actual data, we kept the euro weights from 1999 to 2012 and the Deutschmark weights from 1990 to 1998 and used BIS international issuance data to derive the weights for the foreign currencies.

29 "Other" currencies excluding the five SDR currencies and the Swiss Franc.

${ }^{30}$ Note that the sum of domestic currency and foreign currency weights is equal to 1 . In addition, the sum of the US dollar, euro, Japanese yen, Pound sterling, renminbi and "other" weights also equals 1. Euro legacy
} 
broken down by currency as well as in proportion of GDP. In addition, the dataset includes the main indicators used in the paper.

\section{A.4 Comparison Between Actual and Estimated Currency Weights}

The estimation of the currency breakdown of the different components of the IIP requires making a number of assumptions and in some cases the availability of data is limited. As emphasized in the main text as well as in this Appendix, whenever available we build our dataset based on actual data. However, it is a useful exercise to compare the currency weights obtained from actual and estimated data. This can naturally only be done for the years for which actual data are available keeping in mind that the estimated data are used for comparison purposes but are not part of the final dataset since the hierarchy of sources gives priority to actual data.

Figures A.2- A.9 display, for each year, the average cross-country differences between actual and estimated data for the different items of the IIP. ${ }^{31}$ Currencies are broken down into four categories: US dollar, euro, domestic currency and all other foreign currencies which is a broad category which bundles up the Japanese yen, the Pound sterling, the renminbi and other currencies. Focusing on the asset side first, a few observations are in order:

1. When the number of observations is small, the difference between actual and estimated data tends to be larger and so are the confidence interval bands.

2. In most of the items on the asset side, in particular for portfolio equity and FDI equity, we observe that US dollar weights are underestimated. Synthetic data relies on the geography of cross-border positions as the closest predictor of currency of denomination. However, given the dominance of the US dollar, it is likely that certain cross-border positions outside the US are issued in US dollars and these would not be captured by geography. Therefore, it is to be expected that dollar weights are underestimated.

3. For portfolio equity assets, the differences between euro weights in actual and estimated data are very small. By contrast, US dollar weights tend to be underestimated. To obtain the currency composition of portfolio equity assets based on the geography of cross-border positions it is assumed that equity is denominated in the currency of the host country. Therefore, there is no domestic-currency exposure from equity assets. Actual data reveals that the domestic currency exposure is negligible and there are very few observations with non-zero values, resulting in very small differences between actual and estimated data. The difference between actual and estimated data for all other foreign currencies is also very small. One source of discrepancy between actual and estimated data is concentrated in the observations for which a gravity type model is used to fill the data gaps. Interestingly, the differences are more marked in the group of emerging economies. In fact, the correlation between actual and estimated portfolio equity assets in US dollars and euros are 0.90 and 0.82 for advanced economies, respectively. By contrast, the correlation drops to 0.5 both for US dollar and euro weights, for emerging economies. ${ }^{32}$

4. In the case of FDI equity assets, we observe that US dollar weights are underestimated and that the differences between actual and estimated data are small for the euro weights.

\footnotetext{
currencies before 1999 are included in "other."

${ }^{31}$ Only those years with more than 2 observations (or number of countries) are plotted.

${ }^{32}$ The correlations are computed for the years and countries for which actual data are available since we do not have enough time series by country to compute the correlations for individual countries.
} 
In the estimation it is assumed that equity is denominated in the currency of the host country and this implies that there is no domestic-currency exposure from FDI equity assets. Actual data reveal that the domestic currency exposure in FDI equity is tiny. As in the case of portfolio equity assets, one source of discrepancy between actual and estimated data involves the countries for which a gravity model is used. Other sources of discrepancy are observed in countries which are financial centers and in countries where the presence of SPEs (special purpose entities) could alter the geography of currency compositions.

5. For FDI debt assets, the differences tend to be a larger than for the other items. In particular, euro currency weights are overestimated while US dollar weights are underestimated, especially in the latest part of the sample. The estimation of this item poses a real challenge since actual data reveal that this item is largely concentrated on dominant currencies.

6. When we analyze the currency breakdown for portfolio debt assets we observe that euro weights are overestimated, while US dollar weights are underestimated. In addition, the differences in dollar weights are larger at the beginning of the sample. The gap between actual and estimated data is, for the most part, consistent across countries.

7. In the case of other investment assets, US dollar weights are underestimated and confidence bands are relatively wide in the earlier sample period. Euro weights are overestimated in the first years of the sample, for which we have few observations. Note that the estimation of this item is largely based on banking, while other investment is a broader category. Although banking is the largest component of other investment, the lack of data on the remaining components could partly explain the differences between estimated and actual data. The correlation between actual and estimated data for US dollar and euro weights is 0.94 and 0.91 , respectively.

In what follows let us summarize the main features of the liabilities side of the IIP.

1. For FDI debt liabilities, estimates are, on average, close to actual data, especially after 2004. In the earlier years we observe that US dollar weights are overestimated while domestic currency weights are underestimated.

2. In the case of portfolio debt liabilities, US dollar weights are overestimated since 2009, and the difference has grown larger since 2010. Euro weights are also overestimated but the differences are relatively small. By contrast, domestic currency weights are underestimated in particular in emerging countries. Recall that the main source of data for the estimation of this item is the international issuance statistics from the BIS LBS. One source of discrepancy between actual and estimated data could be driven by the lack of information on domestically issued debt securities held by non-residents which could potentially be denominated in domestic currency. The BIS does not report the currency composition of domestically issued debt securities and there is no information on the proportion of domestically issued securities which is held by non-resident investors.

3. In the early 2000s, other investment liabilities are overestimated for euro weights while under-estimated for US dollar weights. As it is the case for other investment assets, the estimation of this item is largely based on banking, while other investment is a broader category. Therefore, the lack of data on the remaining components could partly explain the differences between estimated and actual data. The correlation between actual and estimated data for US dollar and euro weights is 0.87 and 0.88 , respectively. 
4. We do not show the comparison for FDI equity liabilities and portfolio equity liabilities since both are assumed to be in domestic currency. A comparison with actual data reveals that this is the case.

This analysis provides a perspective on how close actual and estimated data are. Although there is some heterogeneity, the main trends in the data seem to be captured by the estimates. However, given that there are some differences are present, this exercise highlights the importance to incorporate as much actual data as possible to build the dataset. 
Figure A.1: Share of countries reporting IIP currency composition statistics

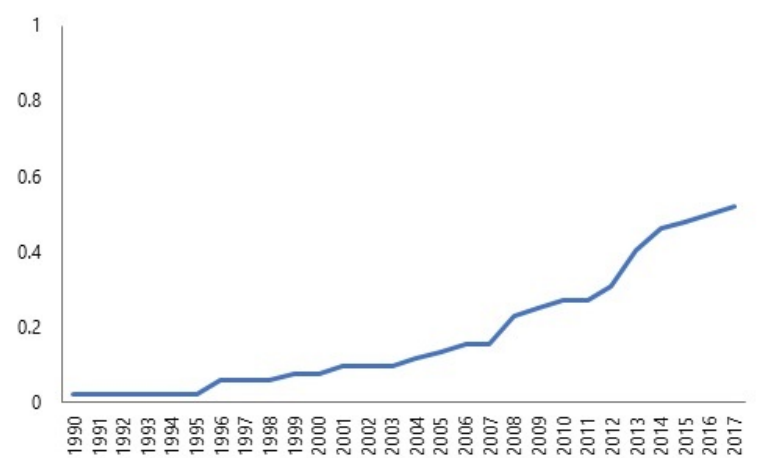

Sources: Authors' own elaboration based on survey responses.

Notes: This figure shows the share of countries reporting IIP currency composition statistics at any level of disaggregation for each year. 
Table A.1: Survey Template. Total Assets



Notes: The table shows the content of the survey template for total assets sent to authorities. $1 /$ denotes national currency exposures when different from US dollar, euro, Japanese yen, Pound sterling and renminbi. 2/ excludes US dollar, euro, Japanese yen, Pound sterling, renminbi and own currency. 
Table A.2: Survey Template. Total Liabilities



Notes: The table shows the content of the survey template for total liabilities sent to authorities. 1/ denotes national currency exposures when different from US dollar, euro, Japanese yen, Pound sterling and renminbi. 2/ excludes US dollar, euro, Japanese yen, Pound sterling, renminbi and own currency. 
Table A.3: Assets: Actual and Synthetic Data

\begin{tabular}{|c|c|c|c|c|c|c|c|c|c|c|}
\hline \multirow[t]{2}{*}{ Country } & \multicolumn{2}{|c|}{ FDI Equity Assets } & \multicolumn{2}{|c|}{ FDI Debt Assets } & \multicolumn{2}{|c|}{ Portfolio Equity Assets } & \multicolumn{2}{|c|}{ Portfolio Debt Assets } & \multicolumn{2}{|c|}{ Other Investment Assets } \\
\hline & Actual Data & Synthetic data & Actual Data & Synthetic data & Actual Data & Synthetic data & Actual Data & Synthetic data & Actual Data & Synthetic data \\
\hline Argentina & & $1990-2017$ & & $1990-2017$ & $2016-2017^{* *}$ & $1990-2015$ & 2016-2017** & $1990-2015$ & & $1990-2017^{* * * *}$ \\
\hline Australia & & $1990-2017$ & & $1990-2017$ & & $1990-2017$ & & $1990-2017$ & & $1990-2017^{* * *}$ \\
\hline Austria & & $1990-2017$ & & $1990-2017$ & $2001-2017^{* *}$ & $1990-2000$ & 2001-2017** & $1990-2000$ & & $1990-2017^{* * *}$ \\
\hline Belgium & 2013-2017 & $1990-2012$ & 2013-2017 & 1990-2012 & 2013-2017 & 1990-2012 & 2008-2017 & $1990-2007$ & 2013-2017 & $1990-2012^{* * *}$ \\
\hline Brazil & & $1990-2017$ & & $1990-2017$ & 2013-2017** & $1990-2012$ & 2013-2017** & $1990-2012$ & & $1990-2017^{* * *}$ \\
\hline Canada & & $1990-2017$ & & $1990-2017$ & 2015-2017, 2014** & $1990-2014$ & 2015-2017 & $1990-2014$ & $2015-2017$ & $1990-2014^{* * *}$ \\
\hline Chile & & $1990-2017$ & & 1990-2017 & $2002-2009^{* *}$ & $1990-2001$ & $2007-2009^{* *}$ & 1990-2006 & & $1990-2017^{* * *}$ \\
\hline China & & $1990-2017$ & & 1990-2017 & & 1990-2017 & & 1990-2017 & & $1990-2017^{* * *}$ \\
\hline Colombia & $1996-2017$ & $1990-1995$ & 2004-2017 & $1990-2003$ & $2001-2017^{* *}$ & $1990-2000$ & 2001-2017** & $1990-2000$ & 1996-2017 & 1990-1995 \\
\hline Czech Republic & 2013-2017 & 1993-2012 & $2013-2017$ & 1993-2012 & 2013-2017 & 1993-2012 & $2008-2017$ & $1993-2007$ & 2013-2017 & 1993-2012 \\
\hline Denmark & 2005-2017 & 1990-2004 & 2005-2017 & $1990-2004$ & 2005-2017, 2001-2004** & $1990-2004$ & 2005-2017 & 1990-2004 & $2005-2017$ & $1990-2004^{* * *}$ \\
\hline Egypt & & $1990-2017$ & & $1990-2017$ & $2005-2017^{* *}$ & $1990-2004$ & $2005-2017^{* *}$ & $1990-2004$ & & $1990-2017^{* * *}$ \\
\hline Finland & & $1990-2017$ & & $1990-2017$ & $2015-2017^{*}, 2013-2014^{* *}$ & $1990-2014$ & $2006-2017^{*}$ & $1990-2005$ & & $1990-2017^{* * *}$ \\
\hline France & 2008-2017 & $1990-2007$ & 2008-2017 & $1990-2007$ & 2008-2017, 2001-2007** & $1990-2007$ & 2008-2017 & $1990-2007$ & 2008-2017 & $1990-2007^{* * *}$ \\
\hline Germany & 2013-2017 & $1990-2012$ & 1997-2017 & 1990-1996 & $1990-2017$ & & 1990-2017 & & & $1990-2017^{* * *}$ \\
\hline Greece & & $1990-2017$ & & $1990-2017$ & 2004-2017, 2001-2003** & 1990-2003 & $2004-2016$ & 1990-2003, 2017 & & $1990-2017^{* * *}$ \\
\hline Guatemala & 2013-2017 & $1990-2012$ & & $1990-2017$ & & $1990-2017$ & 2013-2017 & 1990-2012 & 2013-2017 & 1990-2012 \\
\hline Hong Kong SAR & & $1990-2017$ & & $1990-2017$ & & & & $1990-2017$ & & $1990-2017^{* * *}$ \\
\hline Hungary & 2008-2017 & $1990-2007$ & 1999-2017 & 1990-1998 & 1999-2017 & 1990-1998 & 1999-2017 & 1990-1998 & 1999-2017 & 1990-1998 \\
\hline India & & $1990-2017$ & & $1990-2017$ & $2004-2017^{* *}$ & 1990-2003 & $2005-2017^{* *}$ & 1990-2004 & & $1990-2017^{* * *}$ \\
\hline Indonesia & & 1993-2017 & & $1990-2017$ & 2001-2017** & $1990-2000$ & 2001-2017** & $1990-2000$ & & $1990-2017^{* * *}$ \\
\hline Ireland & & $1990-2017$ & & $1990-2017$ & & $1990-2017$ & $2012-2017^{*}$ & $1990-2011$ & & $1990-2017^{* * *}$ \\
\hline Israel & & $1990-2017$ & & $1990-2017$ & $2001-2017^{* *}$ & $1990-2000$ & 2001-2017** & $1990-2000$ & & $1990-2017^{* * *}$ \\
\hline Italy & 2008-2017 & $1990-2007$ & 2008-2017 & $1990-2007$ & 2008-2017, 2001-2007** & $1990-2007$ & 2008-2017 & $1990-2007$ & 2008-2017 & 1990-2007* \\
\hline Japan & & $1990-2017$ & & 1990-2017 & 2004-2017, 2001-2003** & $1990-2003$ & 2004-2017 & $1990-2003$ & & $1990-2017^{* * *}$ \\
\hline Korea & 2008-2017 & $1990-2007$ & & $1990-2017$ & 2008-2017, 2001-2007** & $1990-2007$ & 2001-2017** & $1990-2000$ & 2008-2017 & $1990-2007^{* * *}$ \\
\hline Malaysia & & $1990-2017$ & & $1990-2017$ & $2001-2017^{* *}$ & $1990-2000$ & 2001-2017** & $1990-2000$ & & $1990-2017^{* * *}$ \\
\hline Mexico & & $1990-2017$ & & $1990-2017$ & $2003-2017^{* *}$ & $1990-2002$ & $2003-2017^{* *}$ & $1990-2002$ & & $1990-2017^{* * *}$ \\
\hline Morocco & & $1990-2017$ & & $1990-2017$ & & $1990-2017$ & & $1990-2017$ & & $1990-2017^{* * *}$ \\
\hline Netherlands & & $1990-2017$ & & $1990-2017$ & 2009-2017 & $1990-2008$ & 2009-2017 & $1990-2008$ & & $1990-2017 * * *$ \\
\hline New Zealand & & $1990-2017$ & & $1990-2017$ & & $1990-2017$ & & $1990-2017$ & & $1990-2017^{* * *}$ \\
\hline Norway & & $1990-2017$ & & $1990-2017$ & & $1990-2017$ & & $1990-2017$ & & $1990-2017^{* * *}$ \\
\hline Pakistan & & $1990-2017$ & & $1990-2017$ & $2002-2017^{* *}$ & $1990-2001$ & 2012-2017** & 1990-2011 & & $1990-2017^{* * *}$ \\
\hline Peru & & $1990-2017$ & & $1990-2017$ & $2015-2016^{* *}$ & 1990-2014, 2017 & $2015-2016^{* *}$ & 1990-2014, 2017 & & $1990-2017^{* * *}$ \\
\hline Philippines & & $1990-2017$ & & $1990-2017$ & $2007-2017^{* *}$ & $1990-2006$ & $2007-2017^{* *}$ & $1990-2006$ & & $1990-2017^{* * *}$ \\
\hline Poland & & $1990-2017$ & & 1990-2017 & 2001-2017** & $1990-2000$ & & $1990-2017$ & & $1990-2017^{* * *}$ \\
\hline Portugal & & $1990-2017$ & & 1990-2017 & 2001-2017** & $1990-2000$ & 2001-2017** & $1990-2000$ & & $1990-2017^{* * *}$ \\
\hline Russia & & 1993-2017 & & 1993-2017 & 2001-2017** & 1993-2000 & 2001-2017** & $1993-2000$ & & 1993-2017*** \\
\hline Singapor & & $1990-2017$ & & $1990-2017$ & & $1990-2017$ & & $1990-2017$ & & $1990-2017^{* * *}$ \\
\hline South Africa & & $1990-2017$ & & $1990-2017$ & $2012-2017^{* *}$ & $1990-2011$ & 2012-2017** & $1990-2011$ & & $1990-2017^{* * *}$ \\
\hline Spain & & $1990-2017$ & & $1990-2017$ & 2014-2017, 2001-2013** & $1990-2013$ & $2007-2017^{* *}$ & $1990-2006$ & & $1990-2017^{* * *}$ \\
\hline Sri Lanka & & $1990-2017$ & & 1990-2017 & & $1990-2017$ & & $1990-2017$ & & $1990-2017^{* * *}$ \\
\hline Sweden & & $1990-2017$ & & 1990-2017 & & 1990-2017 & 2003-2017** & 1990-2002 & & $1990-2017^{* * *}$ \\
\hline Switzerland & 2004-2017 & $1990-2003$ & 2004-2017 & 1990-2003 & 2004-2017, 2001-2003** & 1990-2003 & 2004-2017 & 1990-2003 & 2004-2017 & $1990-2003^{* * *}$ \\
\hline Thailand & 2006-2017 & $1990-2005$ & 2006-2017 & 1990-2005 & 2006-2017, 2004-2005** & 1990-2005 & 2007-2017 & $1990-2006$ & 2006-2017 & 1990-2005 \\
\hline Tunisia & & $1990-2017$ & & $1990-2017$ & & $1990-2017$ & & $1990-2017$ & & $1990-2017^{* * *}$ \\
\hline Turkey & 2014-2017 & $1990-2013$ & 2014-2017 & $1990-2013$ & 2014-2017, 2013** & $1990-2013$ & 2013-2017** & $1990-2012$ & 2014-2017 & $1990-2013^{* * *}$ \\
\hline United Kingdom & & $1990-2017$ & & 1990-2017 & & 1990-2017 & & $1990-2017$ & & $1990-2017^{* * *}$ \\
\hline United States & & $1990-2017$ & & 1990-2017 & & $1990-2017$ & 2003-2017** & 1990-2002 & & 1990-2017*** \\
\hline Uruguay & & $1990-2017$ & & $1990-2017$ & 2001-2016** & 1990-2000, 2017 & 2001-2016** & 1990-2000, 2017 & & $1990-2017^{* * *}$ \\
\hline
\end{tabular}

Notes: Actual data are from IMF survey unless otherwise indicated. ${ }^{*}$ denotes actual data from the ECB, ${ }^{* *}$ identifies actual data from CPIS T2 and ${ }^{* * *}$ indicates that the country is a BIS reporter. 
Table A.4: Liabilities: Actual and Synthetic Data

\begin{tabular}{|c|c|c|c|c|c|c|}
\hline \multirow[t]{2}{*}{ Country } & \multicolumn{2}{|c|}{ FDI Debt Liabilities } & \multicolumn{2}{|c|}{ Portfolio Debt Liabilities } & \multicolumn{2}{|c|}{ Other Investment Liabilities } \\
\hline & Actual Data & Synthetic data & Actual Data & Synthetic data & Actual Data & Synthetic data \\
\hline Argentina & & $1990-2017$ & & $1990-2017$ & & $1990-2017^{* * *}$ \\
\hline Australia & & $1990-2017$ & & $1990-2017$ & & $1990-2017^{* * *}$ \\
\hline Austria & & $1990-2017$ & $2006-2017^{*}$ & $1990-2005$ & & $1990-2017^{* * *}$ \\
\hline Belgium & $2013-2017$ & $1990-2012$ & 2013-2017 & $1990-2012$ & $2013-2017$ & $1990-2012^{* * *}$ \\
\hline Brazil & & $1990-2017$ & & $1990-2017$ & & $1990-2017^{* * *}$ \\
\hline Canada & & $1990-2017$ & $2015-2017$ & $1990-2014$ & $2015-2017$ & $1990-2014^{* * *}$ \\
\hline Chile & & $1990-2017$ & & $1990-2017$ & & $1990-2017^{* * *}$ \\
\hline China & & $1990-2017$ & & $1990-2017$ & & $1990-2017^{* * *}$ \\
\hline Colombia & $2000-2017$ & 1990-1999 & $1999-2017$ & $1990-1998$ & $2000-2017$ & 1990-1999 \\
\hline Czech Republic & $2013-2017$ & $1993-2012$ & $2013-2017$ & $1993-2012$ & $2013-2017$ & $1993-2012$ \\
\hline Denmark & $2005-2017$ & $1990-2004$ & $2005-2017$ & $1990-2004$ & $2005-2017$ & $1990-2004^{* * *}$ \\
\hline Egypt & & $1990-2017$ & & $1990-2017$ & & $1990-2017^{* * *}$ \\
\hline Finland & & $1990-2017$ & $2006-2017^{*}$ & $1990-2005$ & & $1990-2017^{* * *}$ \\
\hline France & $2008-2017$ & $1990-2007$ & 2008-2017 & $1990-2007$ & $2008-2017$ & $1990-2007^{* * *}$ \\
\hline Germany & $1997-2017$ & $1990-1996$ & $1990-2017$ & & & $1990-2017^{* * *}$ \\
\hline Greece & & $1990-2017$ & $2004-2017$ & $1990-2003$ & & $1990-2017^{* * *}$ \\
\hline Guatemala & $2013-2017$ & $1990-2012$ & $2013-2017$ & $1990-2012$ & $2013-2017$ & 1990-2012 \\
\hline Hong Kong SAR & & $1990-2017$ & & $1990-2017$ & & $1990-2017^{* * *}$ \\
\hline Hungary & $1999-2017$ & $1990-1998$ & $1999-2017$ & $1990-1998$ & $1999-2017$ & 1990-1998 \\
\hline India & & $1990-2017$ & & $1990-2017$ & & $1990-2017^{* * *}$ \\
\hline Indonesia & $2010-2017$ & $1990-2009$ & $2010-2017$ & $1990-2009$ & $2010-2017$ & $1990-2009^{* * *}$ \\
\hline Ireland & & $1990-2017$ & $2012-2017^{*}$ & $1990-2011$ & & $1990-2017^{* * *}$ \\
\hline Israel & & $1990-2017$ & & $1990-2017$ & & $1990-2017^{* * *}$ \\
\hline Italy & $2008-2017$ & $1990-2007$ & $2008-2017$ & $1990-2007$ & $2008-2017$ & $1990-2007^{* * *}$ \\
\hline Japan & & $1990-2017$ & $2014-2017$ & $1990-2013$ & & $1990-2017^{* * *}$ \\
\hline Korea & & $1990-2017$ & $2008-2017$ & $1990-2007$ & $2008-2017$ & $1990-2007^{* * *}$ \\
\hline Malaysia & & $1990-2017$ & & $1990-2017$ & & $1990-2017^{* * *}$ \\
\hline Mexico & & $1990-2017$ & & $1990-2017$ & & $1990-2017^{* * *}$ \\
\hline Morocco & & $1990-2017$ & & $1990-2017$ & & $1990-2017^{* * *}$ \\
\hline Netherlands & & $1990-2017$ & $2009-2017$ & $1990-2008$ & & $1990-2017^{* * *}$ \\
\hline New Zealand & & $1990-2017$ & & $1990-2017$ & & $1990-2017^{* * *}$ \\
\hline Norway & & $1990-2017$ & & $1990-2017$ & & $1990-2017^{* * *}$ \\
\hline Pakistan & & $1990-2017$ & & $1990-2017$ & & $1990-2017^{* * *}$ \\
\hline Peru & & $1990-2017$ & & $1990-2017$ & & $1990-2017^{* * *}$ \\
\hline Philippines & & $1990-2017$ & $2006-2017$ & $1990-2005$ & & $1990-2017^{* * *}$ \\
\hline Poland & & $1990-2017$ & & $1990-2017$ & & $1990-2017^{* * *}$ \\
\hline Portugal & & $1990-2017$ & & $1990-2017$ & & $1990-2017^{* * *}$ \\
\hline Russia & & $1993-2017$ & & $1993-2017$ & & $1993-2017^{* * *}$ \\
\hline Singapore & & $1990-2017$ & & $1990-2017$ & & $1990-2017^{* * *}$ \\
\hline South Africa & & $1990-2017$ & & $1990-2017$ & & $1990-2017^{* * *}$ \\
\hline Spain & & $1990-2017$ & & $1990-2017$ & & $1990-2017^{* * *}$ \\
\hline Sri Lanka & & $1990-2017$ & & $1990-2017$ & & $1990-2017^{* * *}$ \\
\hline Sweden & & $1990-2017$ & & $1990-2017$ & & $1990-2017^{* * *}$ \\
\hline Switzerland & $2004-2017$ & $1990-2003$ & $2004-2017$ & $1990-2003$ & $2004-2017$ & $1990-2003^{* * *}$ \\
\hline Thailand & $2006-2017$ & $1990-2005$ & $2006-2017$ & $1990-2005$ & $2006-2017$ & 1990-2005 \\
\hline Tunisia & & $1990-2017$ & & $1990-2017$ & & $1990-2017^{* * *}$ \\
\hline Turkey & $2014-2017$ & $1990-2013$ & $2014-2017$ & $1990-2013$ & 2014-2017 & $1990-2013^{* * *}$ \\
\hline United Kingdom & & $1990-2017$ & & $1990-2017$ & & $1990-2017^{* * *}$ \\
\hline United States & & $1990-2017$ & & $1990-2017$ & & $1990-2017^{* * *}$ \\
\hline Uruguay & & $1990-2017$ & & $1990-2017$ & & $1990-2017^{* * *}$ \\
\hline
\end{tabular}

Notes: Actual data are from IMF survey unless otherwise indicated. * denotes actual data from the ECB, ** identifies actual data from CPIS T2 and *** indicates that the country is a BIS reporter. Portfolio equity liabilities and FDI equity liabilities are assumed to be denominated in the currency of the host country and were therefore excluded from the table since all data are synthetic. 
Table A.5: Gravity models

\begin{tabular}{|c|c|c|c|}
\hline & $\begin{array}{l}(1) \\
\text { PEQA }\end{array}$ & $\begin{array}{l}(2) \\
\text { PDA }\end{array}$ & $\begin{array}{l}(3) \\
\text { FDI }\end{array}$ \\
\hline Trade $_{i j}$ & $\begin{array}{l}0.121^{* * *} \\
(0.00)\end{array}$ & $\begin{array}{l}0.102^{* * *} \\
(0.00)\end{array}$ & $\begin{array}{l}0.516^{* * *} \\
(0.01)\end{array}$ \\
\hline Distance $_{i j}$ & $\begin{array}{l}-0.492^{* * *} \\
(0.01)\end{array}$ & $\begin{array}{l}-0.490^{* * *} \\
(0.01)\end{array}$ & $\begin{array}{l}-0.550^{\text {*** }} \\
(0.02)\end{array}$ \\
\hline Both EMU & $\begin{array}{l}0.178^{* * *} \\
(0.04)\end{array}$ & $\begin{array}{l}1.437^{* * *} \\
(0.04)\end{array}$ & $\begin{array}{l}-0.045 \\
(0.06)\end{array}$ \\
\hline Both CEEC & $\begin{array}{l}0.753^{* * *} \\
(0.05)\end{array}$ & $\begin{array}{l}0.872^{\text {*** }} \\
(0.05)\end{array}$ & $\begin{array}{l}0.221^{* * *} \\
(0.08)\end{array}$ \\
\hline Both Same continent & $\begin{array}{l}-0.261^{* * *} \\
(0.02)\end{array}$ & $\begin{array}{l}0.204^{* * *} \\
(0.02)\end{array}$ & $\begin{array}{l}-0.274^{* * *} \\
(0.03)\end{array}$ \\
\hline Both South Asia & $\begin{array}{l}0.034 \\
(0.10)\end{array}$ & $\begin{array}{l}0.273^{* *} \\
(0.11)\end{array}$ & $\begin{array}{l}0.553^{* * *} \\
(0.09)\end{array}$ \\
\hline Both East Asia & $\begin{array}{l}-0.342^{* * *} \\
(0.03)\end{array}$ & $\begin{array}{l}-0.192^{* * *} \\
(0.03)\end{array}$ & $\begin{array}{l}0.468^{* * *} \\
(0.06)\end{array}$ \\
\hline Both Sub-Saharan Africa & $\begin{array}{l}0.512^{* * *} \\
(0.07)\end{array}$ & $\begin{array}{l}0.689^{* * *} \\
(0.09)\end{array}$ & $\begin{array}{l}-0.015 \\
(0.04)\end{array}$ \\
\hline Both Latin America & $\begin{array}{l}-0.280^{* * *} \\
(0.02)\end{array}$ & $\begin{array}{l}-0.465^{* * *} \\
(0.02)\end{array}$ & $\begin{array}{l}-0.022 \\
(0.05)\end{array}$ \\
\hline Both Middle East North Africa & $\begin{array}{l}0.177^{* *} \\
(0.07)\end{array}$ & $\begin{array}{l}0.171^{* *} \\
(0.08)\end{array}$ & $\begin{array}{c}-0.126 \\
(0.38)\end{array}$ \\
\hline Both high income & $\begin{array}{l}1.761^{* * *} \\
(0.01)\end{array}$ & $\begin{array}{l}1.636^{* * *} \\
(0.01)\end{array}$ & $\begin{array}{l}1.041^{* * *} \\
(0.02)\end{array}$ \\
\hline Both middle income & $\begin{array}{l}-0.416^{* * *} \\
(0.01)\end{array}$ & $\begin{array}{l}-0.577^{* * *} \\
(0.01)\end{array}$ & $\begin{array}{l}-0.520^{\text {*** }} \\
(0.02)\end{array}$ \\
\hline Both least developed & $\begin{array}{l}0.794 \\
(0.72)\end{array}$ & $\begin{array}{l}0.103^{*} \\
(0.06)\end{array}$ & $\begin{array}{l}0.273^{* * *} \\
(0.05)\end{array}$ \\
\hline Both low income & $\begin{array}{l}0.293^{* * *} \\
(0.03)\end{array}$ & $\begin{array}{l}0.445^{* * *} \\
(0.03)\end{array}$ & $\begin{array}{l}0.194^{* * *} \\
(0.03)\end{array}$ \\
\hline Same language & $\begin{array}{l}0.488^{* * *} \\
(0.02)\end{array}$ & $\begin{array}{l}0.224^{* * *} \\
(0.02)\end{array}$ & $\begin{array}{l}0.522^{* * *} \\
(0.04)\end{array}$ \\
\hline Same colonizer & $\begin{array}{l}0.268^{* * *} \\
(0.02)\end{array}$ & $\begin{array}{l}0.128^{* * *} \\
(0.02)\end{array}$ & $\begin{array}{l}0.340^{* * *} \\
(0.03)\end{array}$ \\
\hline Constant & $\begin{array}{l}1.771^{* *} \\
(0.79) \\
\end{array}$ & $\begin{array}{l}-3.563^{* * *} \\
(0.28)\end{array}$ & $\begin{array}{l}2.280^{* * *} \\
(0.69)\end{array}$ \\
\hline$R^{2}$ & 0.747 & 0.764 & 0.727 \\
\hline Observations & 96988 & 98228 & 44076 \\
\hline Country pairs & 7222 & 7222 & 6378 \\
\hline Period & 1997-2017 & 1997-2017 & 2009-2017 \\
\hline
\end{tabular}

Notes: The table shows a summary of the estimates of panel data models used to fill gaps in the geographical distribution of portfolio equity assets (PEQA), portfolio debt assets (PDA) and foreign direct investment (FDI). The sample covers all available years and countries from CPIS and CDIS data sets. Each model incorporates three dimensions: country source, country host and time. Robust standard errors are in parenthesis. All models include host country fixed effects and year fixed effects. In addition to the reported variables in the table all models also include source and host country dummy variables for EMU and CEEC (Central and Eastern European countries) memberships. Additional gravity variables include region (South Asia, East Asia, Sub-Saharan Africa, Latin America, Middle East and North Africa) and income (low, less developed middle and high income), available in Andrew Rose's webpage (http://faculty.haas.berkeley.edu/arose/RecRes.htm). Area, landlocked, latitude and longitude included for source and host countries' are from the Centre d'Etudes Prospectives et d'Informations Internationales (CEPII). The regressions include a measure of capital account openness sourced from Chinn and Ito (2006) and the overall portfolio investment from the External Wealth of Nations dataset. GDP per capita is included to capture different degrees of development, and is sourced from the World Bank World Development Indicators database. 
Figure A.2: Average Difference between Actual and Estimated Data: Portfolio Equity Assets
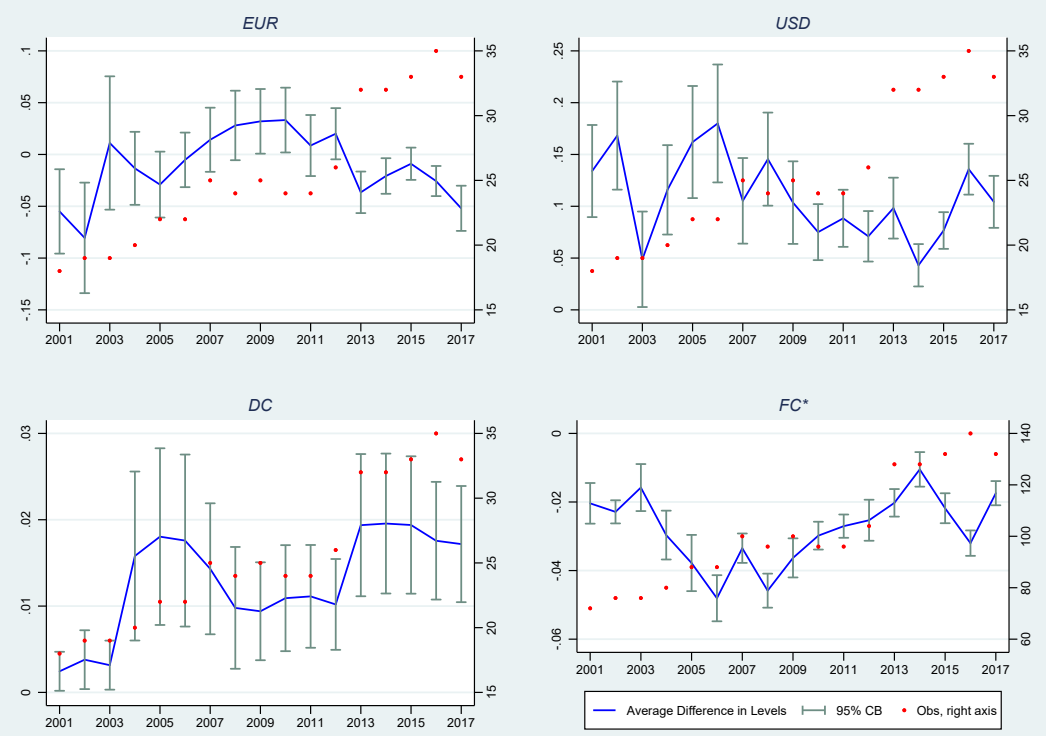

Notes: The graph shows the cross-country average difference between actual and estimated data (in blue), the 95 percent confidence bands (in teal) and the number of observations which represents the number of countries (red dot). FC* is a broad category used for the Japanese yen, the Pound sterling, the renminbi and other currencies. Only those years with more than 2 observations are plotted.

Figure A.3: Average Difference between Actual and Estimated Data: FDI Equity Assets
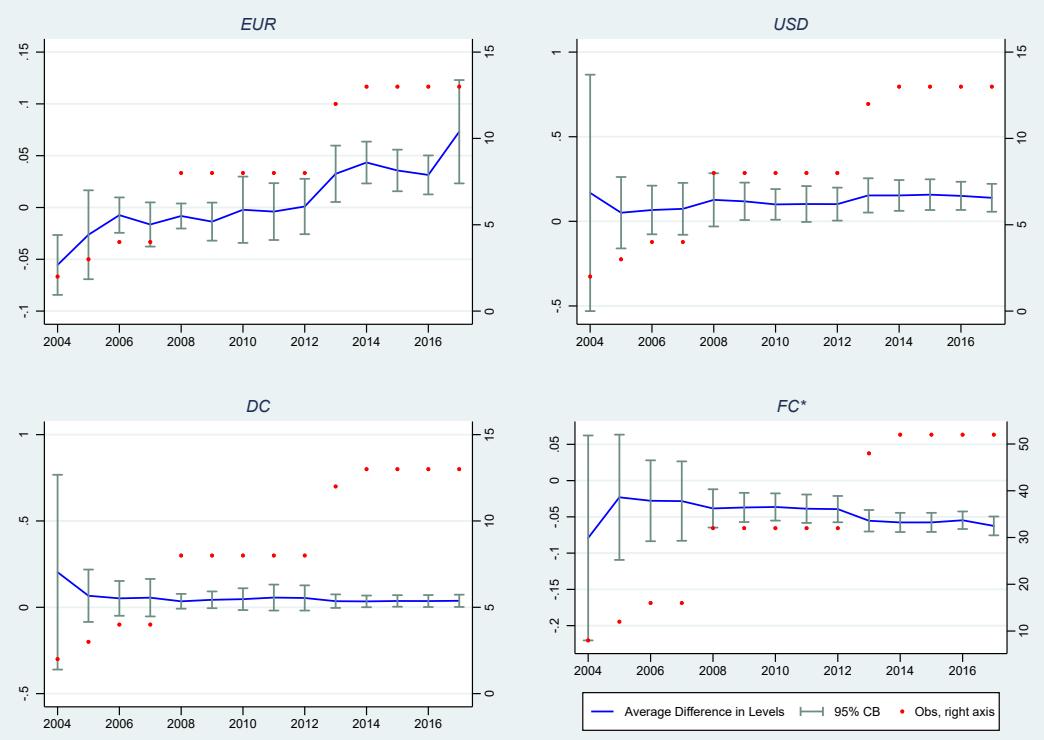

Notes: The graph shows the cross-country average difference between actual and estimated data (in blue), the 95 percent confidence bands (in teal) and the number of observations which represents the number of countries (red dot). FC* is a broad category used for the Japanese yen, the Pound sterling, the renminbi and other currencies. Only those years with more than 2 observations are plotted. 
Figure A.4: Average Difference between Actual and Estimated Data: FDI Debt Assets
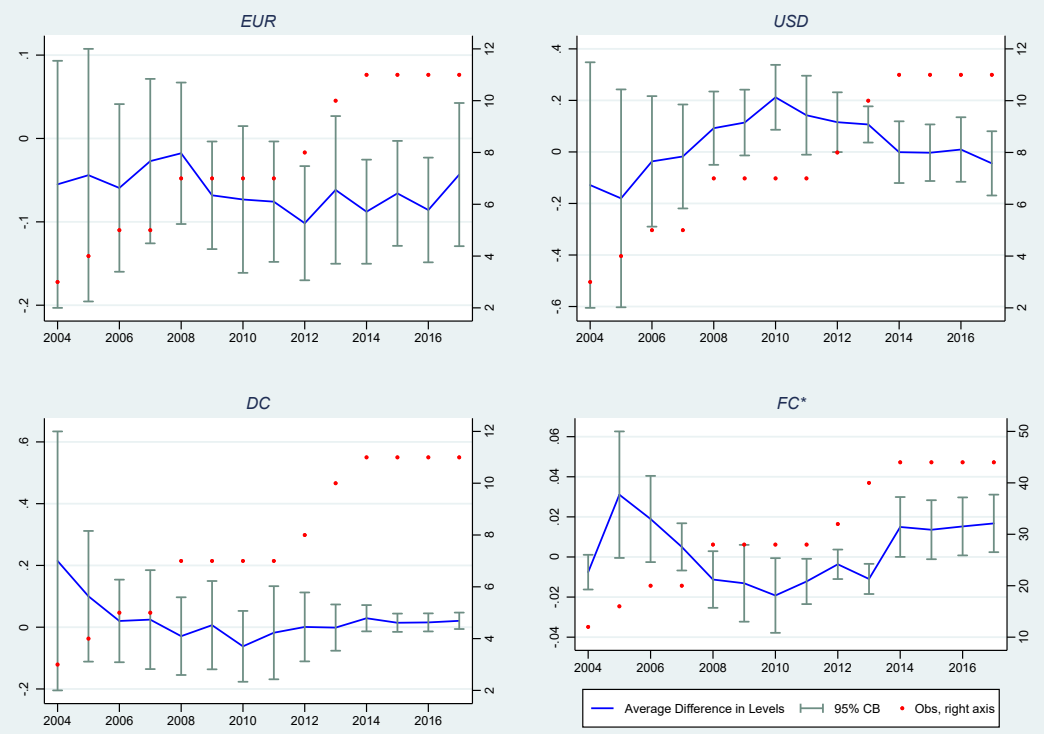

Notes: The graph shows the cross-country average difference between actual and estimated data (in blue), the 95 percent confidence bands (in teal) and the number of observations which represents the number of countries (red dot). FC* is a broad category used for the Japanese yen, the Pound sterling, the renminbi and other currencies. Only those years with more than 2 observations are plotted.

Figure A.5: Average Difference between Actual and Estimated Data: Portfolio Debt Assets


Notes: The graph shows the cross-country average difference between actual and estimated data (in blue), the 95 percent confidence bands (in teal) and the number of observations which represents the number of countries (red dot). FC* is a broad category used for the Japanese yen, the Pound sterling, the renminbi and other currencies. Only those years with more than 2 observations are plotted. 
Figure A.6: Average Difference between Actual and Estimated Data: Other Investment Assets
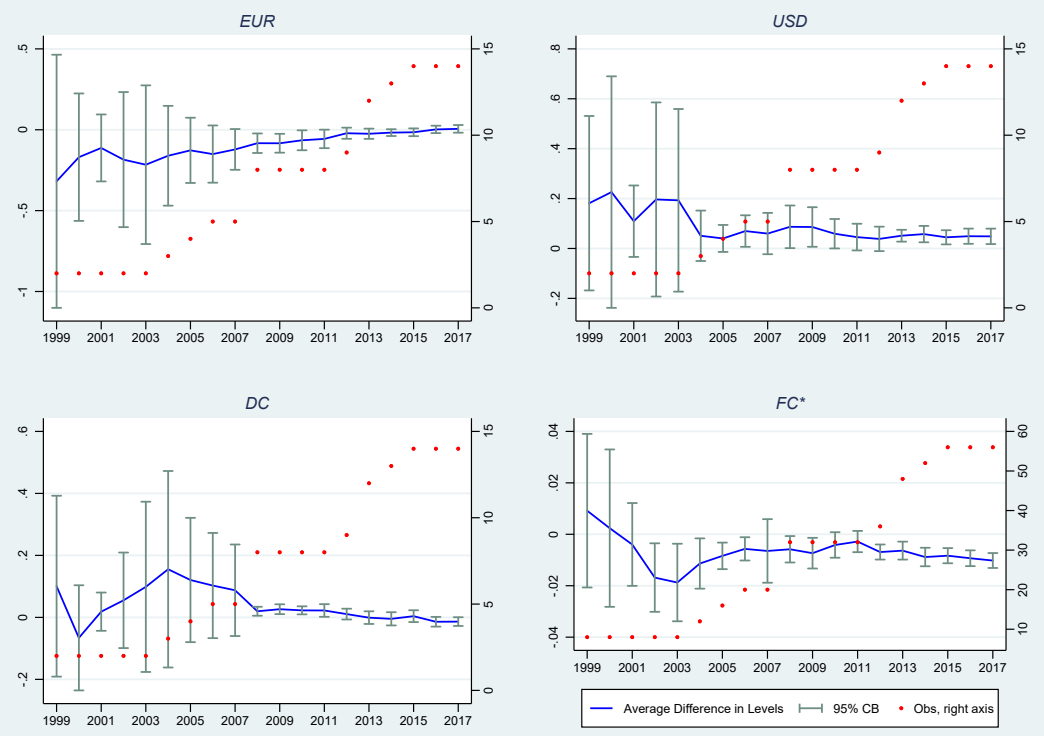

Notes: The graph shows the cross-country average difference between actual and estimated data (in blue), the 95 percent confidence bands (in teal) and the number of observations which represents the number of countries (red dot). FC* is a broad category used for the Japanese yen, the Pound sterling, the renminbi and other currencies. Only those years with more than 2 observations are plotted.

Figure A.7: Average Difference between Actual and Estimated Data: FDI Debt Liabilities
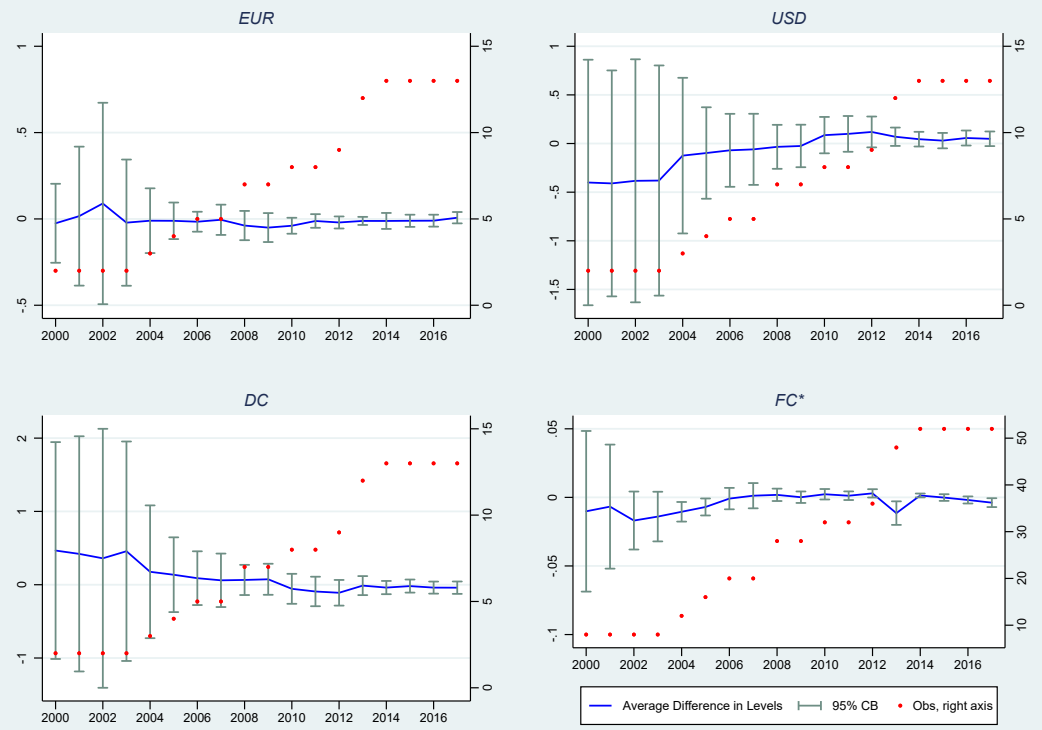

Notes: The graph shows the cross-country average difference between actual and estimated data (in blue), the 95 percent confidence bands (in teal) and the number of observations which represents the number of countries (red dot). FC* is a broad category used for the Japanese yen, the Pound sterling, the renminbi and other currencies. Only those years with more than 2 observations are plotted. 
Figure A.8: Average Difference between Actual and Estimated Data: Portfolio Debt Liabilities
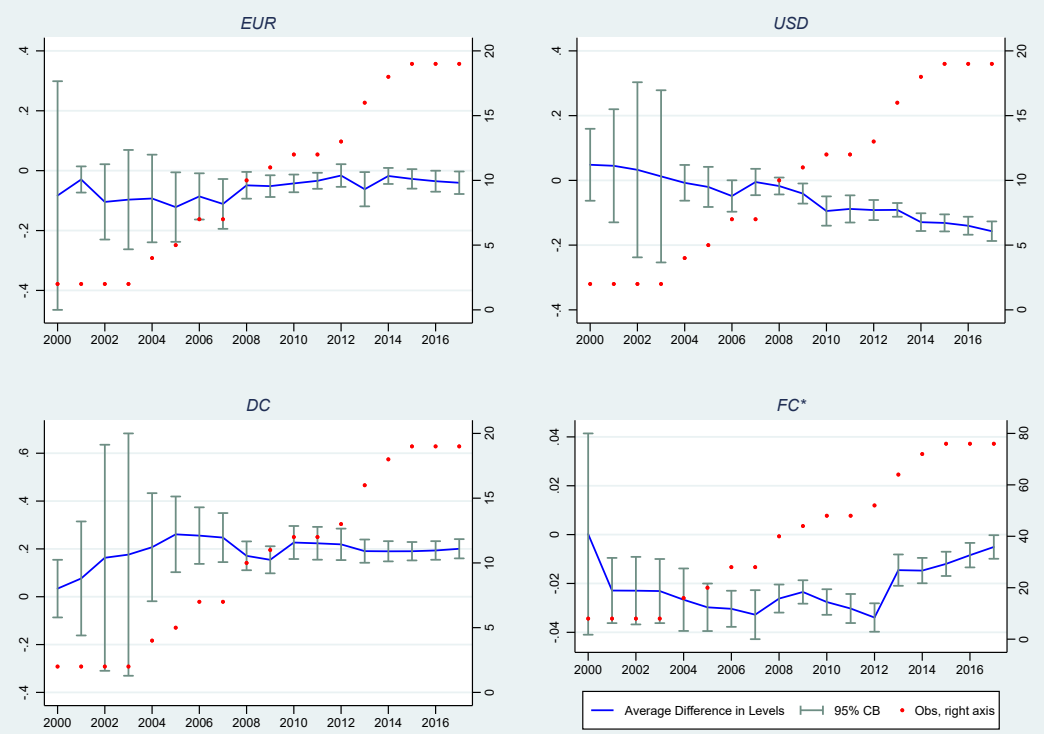

Notes: The graph shows the cross-country average difference between actual and estimated data (in blue), the 95 percent confidence bands (in teal) and the number of observations which represents the number of countries (red dot). FC* is a broad category used for the Japanese yen, the Pound sterling, the renminbi and other currencies. Only those years with more than 2 observations are plotted.

Figure A.9: Average Difference between Actual and Estimated Data: Other Investment Liabilities
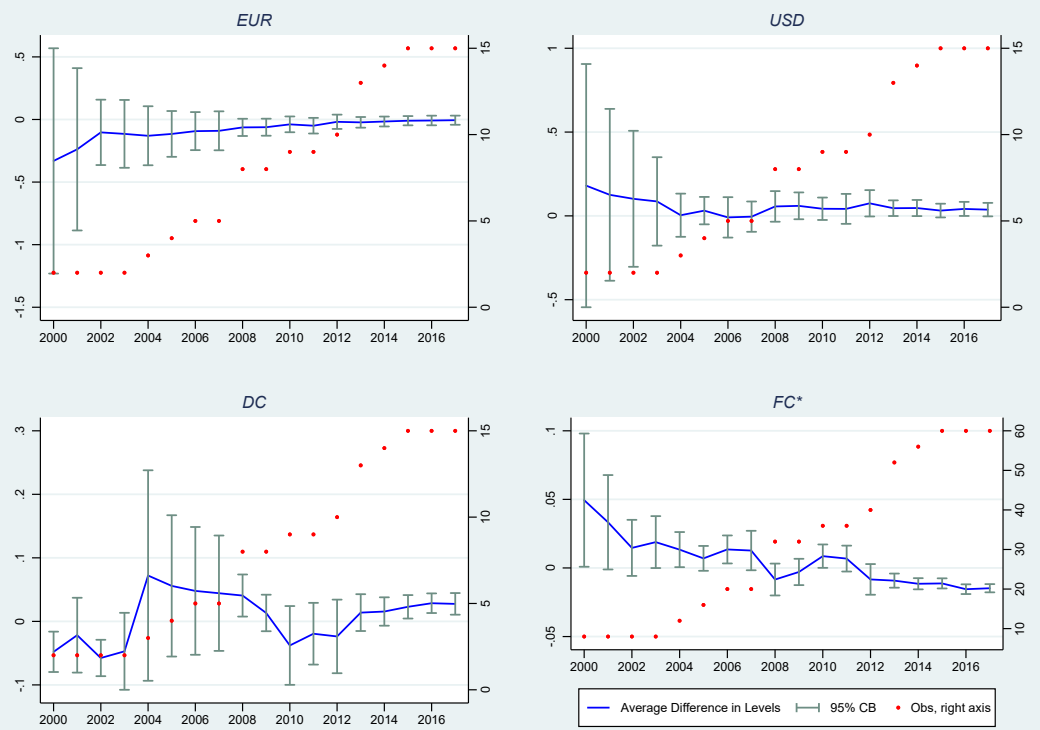

Notes: The graph shows the cross-country average difference between actual and estimated data (in blue), the 95 percent confidence bands (in teal) and the number of observations which represents the number of countries (red dot). FC* is a broad category used for the Japanese yen, the Pound sterling, the renminbi and other currencies. Only those years with more than 2 observations are plotted. 


\section{References}

[1] Arslanalp S. and T. Tsuda (2014), "Tracking Global Demand for Emerging Market Sovereign Debt," IMF Working paper No 14/39.

[2] Bank of International Settlements (2009), Guide to the International Financial Statistics.

[3] Bank of Internatioanl Settlements (2019), Reporting Guidelines for the BIS International Banking Statistics.

[4] Bénétrix, A., P. R. Lane and J. C. Shambaugh (2015), "International Currency Exposures, Valuation Effects and the Global Financial Crisis, Journal of International Economics 96, 98-109.

[5] Chinn, M.D. and H. Ito (2006), "What Matters for Financial Development? Capital Controls, Institutions and Interactions," Journal of Development Economics 81, 163-192

[6] Eichengreen, B. and D. Mathieson (2000), "The Currency Composition of Foreign Exchange Reserves: Retrospect and Prospect," IMF Working Paper No. 00/131.

[7] European Central Bank (2016), The International Role of the Euro, Interim Report, European Central Bank.

[8] European Central Bank (2018), The International Role of the Euro, European Central Bank.

[9] Gruic, B. and P. Wooldridge (2012), "Enhancements to the BIS debt securities statistics," BIS Quarterly Review, Bank for International Settlements, December.

[10] International Monetary Fund (2000), "Offshore Financial Centers," IMF Background Paper.

[11] Lane, P.R. and G.M. Milesi-Ferretti (2007) "The External Wealth of Nations Mark II," Journal of International Economics 73, 223-250.

[12] Lane, P.R. and G.M. Milesi-Ferretti (2008), "International Investment Patterns," Review of Economics and Statistics 90(3), 538-549.

[13] Lane, P. R., and J. C. Shambaugh (2010), "Financial Exchange Rates and International Currency Exposures," American Economic Review, 100 (1), 518-40.

[14] Martin, P. and H. Rey (2004), "Financial Super-Markets: Size Matters for Asset Trade," Journal of International Economics 64, 335-361.

[15] Portes, R. and H. Rey (2005), "The Determinants of Cross-Border Equity Flows," Journal of International Economics 65, 269-296. 